Article

\title{
Syntheses and Functional Properties of Phthalocyanines
}

\section{Keiichi Sakamoto $^{1,2, *}$ and Eiko Ohno-Okumura ${ }^{2,3, \#}$}

1 Department of Sustainable Engineering, College of Industrial Technology, Nihon University, 1-2-1 Izumi-cho, Narashino-shi, Chiba-ken 275-8575 Japan

2 Department of Applied Molecular Chemistry, College of Industrial Technology, Nihon University, 12-1 Izumi-cho, Narashino-shi, Chiba-ken 275-8575 Japan; E-Mail: eiko.okumura@tokyokasei.co.jp

3 Research Institute of Chemical Science, Technology and Education, 8-37-1-104 Narashinodai, Funabashi-shi Chiba-ken 274-0063 Japan

\# Current address: Tokyo Chemical Industry Co. Ltd., 4-10-2 Nihombashi-honcho, Chuo-ku, Tokyo 103-0023 Japan.

* Author to whom correspondence should be addressed; E-Mail: sakamoto.keiichi@nihon-u.ac.jp; Tel. +81-474742572; Fax: +81-474742579.

Received: 27 June 2009; in revised form: 19 August 2009 / Accepted: 24 August 2009 / Published: 28 August 2009

\begin{abstract}
Metal phthalocyanine tetrasulfonic acids, metal phthalocyanine octacarboxylic acids, metal octakis(hexyloxymethyl)phthalocyanines, and metal anthraquinocyanines have been synthesized. Then, zinc bis(1,4-didecylbenzo)-bis(3,4-pyrido)porphyrazines, the cyclotetramerization products of a 1:1 mixture of 3,6-didecylphthalonitrile and 3,4dicyanopyridine, were synthesized. Futher, subphthalocyanine and its derivatives, with substituents such as thiobutyl and thiophenyl moieties were synthesized. Electrochemical measurements were performed on the abovementioned phthalocyanine derivatives and analogues in order to examine their electron transfer abilities and electrochemical reaction mechanisms in an organic solvent. Moreover, 1,4,8,11,15,18,22,25-octakis(thiophenylmethyl)phthalocyanes were synthesized. The Q-bands of the latter compounds appeared in the near-infrared region. Furthermore, non-colored transparent films in the visible region can be produced.
\end{abstract}


Keywords: phtalocyanine; subphthalocyanine; electrochemistry; near infrared absorption

\section{Introduction}

Phthalocyanine derivatives, which have a similar structure to porphyrin, have been utilized in important functional materials in many fields. Their useful properties are attributed to their efficient electron transfer abilities. The central cavity of phthalocyanines is known to be capable of accomodating 63 different elemental ions, including hydrogens (metal-free phthalocyanine, $\mathrm{H}_{2}-\mathrm{PC}$ ). A phthalocyanine containing one or two metal ions is called a metal phthalocyanine (M-PC). In the last decade, as a result of their high electron transfer abilities, M-PCs have been utilized in many fields such as molecular electronics, optelectronics, photonics, etc [1-6] (Figure 1). The functions of M-PCs are almost universally based on electron transfer reactions because of the $18 \pi$ electron conjugated ring system found in their molecular structure.

Figure 1. Typical function of phthalocyanine derivatives.

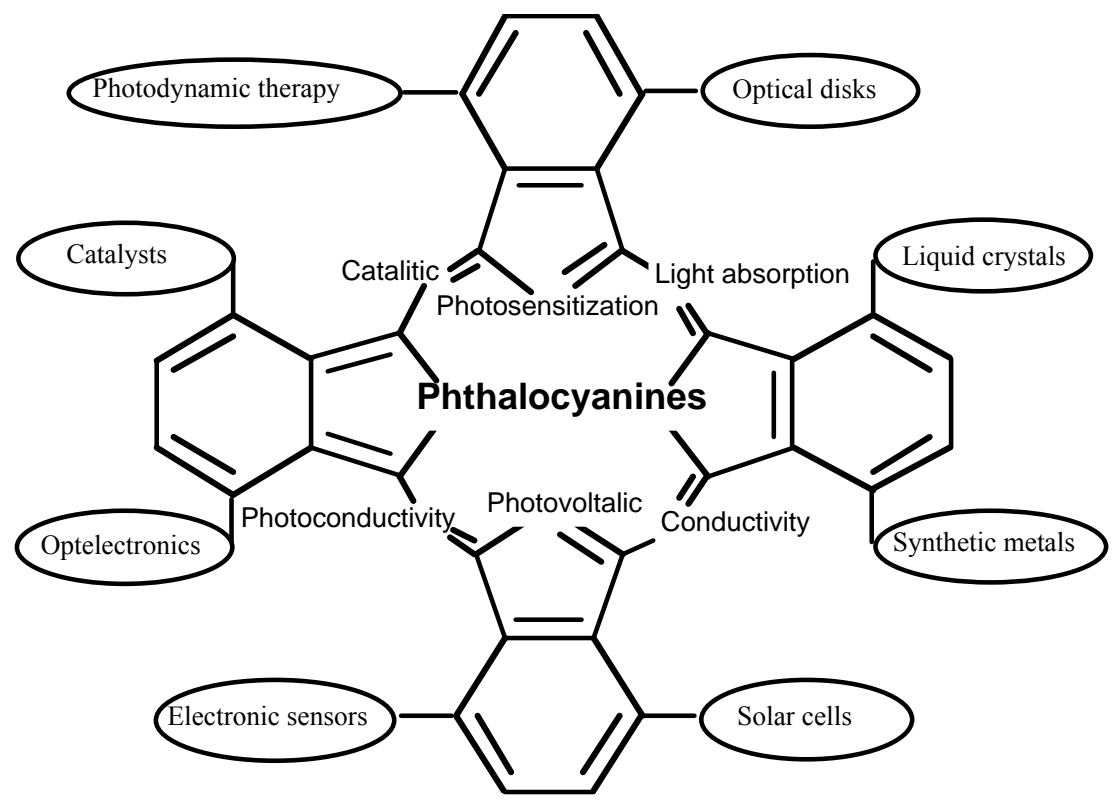

Further, particular derivatives are known to have potential as second-generation photosensitisers for photodynamic therapy (PDT) of cancer [7] because they show strong absorption of the far-red light between the wavelengths of 600 and $850 \mathrm{~nm}$, which has greater tissue penetration properties [8], and satisfactory photosensitization of singlet oxygen [9].

For some applications, the lower solubility of unsubstituted M-PCs can present problems, but low solubility in common organic solvents can be overcome by the introduction of appropriate substituents onto the ring system. In this context M-PC analogues containing a pyridine (Py) ring in place of one or more of the benzenoid rings are particularly interesting compounds because quaternization of the pyridine nitrogen is expected to confer solubility in aqueous media.

Tetrapyridoporphyrazine M-PC analogues in which all four benzenoid rings are replaced by pyridinoid rings were first synthesized by Linstead and his co-workers in 1937 [10]. They obtained an 
insoluble product from the self-condensation of 3,4-dicyanopyridine which was presumably a mixture of 'positional isomers' or regioisomers. Subsequently, Yokote and Shibamiya reported the synthesis and dying properties of some unsubstituted benzopyridopyridoporphyrazines [11,12] and the ring system attracted the attention of other groups, resulting in a substantial increase in the number of known derivatives [13,14]. Yokote and Shibamiya also reported the synthesis of unsubstituted benzopyridoporphyrazines containing a mixture of benzenoid and pyridinoid rings by cross cyclotetramerization of phthalic anhydride and pyridine carboxylic anhydride [15].

For many applications the absorption maxima of M-PCs are best if moved near the infrared region. The strongest absorption of M-PCs in the visible region, the so-called Q band, can be attributed to the allowed highest occupied molecular orbital (HOMO) - lowest unoccupied molecular orbital (LUMO) $\left(\pi-\pi^{*}\right)$ transition. The Q-band of M-PCs can be moved by bathochromic effects through extension of the $\pi$ conjugation system such as seen in naphthalocyanines and anthracyanines, but yields of naphthalocyanines and anthracyanines are however usually low. To solve the problem, novel M-PCs having non-peripheral $S$-aryl substituents have been synthesized. These novel M-PCs will show a high strain structure and no liquid crystal properties.

The authors reported a charge transfer thin film exhibiting organic electroluminescent (EL) properties that was made from an organic varnish including an aniline oligomer as a charge transfer material. $\mathrm{Cu}-\mathrm{PC}$ is used as a standard charge transfer material in the field of organic EL; it is coated on a surface as a thin film using a suitable dry process such as a vacuum method because of its low solubility. There is a need for $\mathrm{Cu}$-PCs having high heat and light resistance for use in wet processes such as spin-coating, spraying, and ink-jet methods because of the demand in large EL display manufacture. $\mathrm{Cu}-\mathrm{PCs}$ presents the disadvantage of lower transmittance in the visible region because of their strong absorption maxima $\mathrm{Q}$ bands.

In the present paper, we describe the synthesis and electrochemical characteristics of some soluble M-PC derivatives and analogues which are expected to be useful as sensitizers for PDT, in photovoltaic cells and laser printing systems. Syntheses of soluble M-PCs [16], including phthalocyanine-4,4',4', 4','-tetrasulfonic acids 1 having sulfonic acid groups, phthalocyanine2,3,9,10,16,17,23,24-octacarboxylic acids 2, 2,3,9,10,16,17,23,24-octakis-(hexoxymethyl)phthalocyanines 3 and a novel M-PC derivative, anthraquinocyanine (4), which has four 9,10-anthraquinone units in the molecule, have been reported $[16,17]$. The authors have measured cyclic voltammograms (CVs) and performed chronocoulometric analyses of 1-4 in order to estimate their electron transfer properties and the corresponding mechanisms.

Next, we have reported the preparation and characterization of zinc alkybenzopyridoporphyrazines 5, which were synthesized by reaction of 3,6-didecylphthalonitrile [17,19] and 3,4-dicyanopyridine (or 2,3-dicyanopyridine) [18] in mole ratios of 4:0, 3:1, 1:1, 1:3 and 0:4, respectively. These compounds showed liquid crystal behavior, but incorporation of zinc into the macrocycle inhibited mesophase formation. The 1:1 mole ratio cross cyclotetramerization product has been separated, as the corresponding zinc derivative, with particular attention given to the isolation of the five possible isomers of the zinc bis(1,4-didecylbenzo)-bis(3,4-pyrido)porphyrazine (5c). Then zinc bis(1,4didecylbenzo)-bis(2,3-pyrido)porphyrazine (5f) was also synthesized. The compounds $\mathbf{5 c}$ and $\mathbf{5 f}$ exhibit solubility in organic solvents and are expected to have a higher tumor affinity than water soluble M-PCs such as the tetrasulfophthalocyanines. Amphiphilic phthalocyanine derivatives are 
considered the best compounds for a new generation of photosensitizers for PDT [19] and quaternization of the Py nitrogen in zinc bis(1,4-didecylbenzo)bis(3,4-pyrido)porphyrazine is expected to confer solubility in an aqueous media [15], and lead to good bioavailability and in vivo distribution, thus the quaternization of $\mathbf{5 c}$ and $\mathbf{5 f}$ would provide amphiphilic M-PCs.

In general, M-PCs have four isoindole units and a central metal. A class of M-PC-related compounds, the subphthalocyanine (SubPC) derivatives 6, are the lowest homologues, consisting of three isoindole units and a central boron. Unsubstituted M-PC derivatives are known to have poor solubility in common organic solvents, whereas SubPC derivatives have excellent solubility since these phenomena are attributed to their non-planar crystal structures [7,22,23].

The SubPC derivatives have previously only been used as reagents for ring enlargement reactions leading to unsymmetric M-PCs. Now, another application of SubPC has been recently reported $[24,25]$. In order to develop new applications of SubPC, we synthesized SubPC and six of its derivatives: tris-(tert-butyl)subphtalocyaine (tert-butylSubPC; 6b), dodecylfluorosubphthalocyanine $\left(\mathrm{SubPCF}_{12} ; \mathbf{6 c}\right)$, hexakis(S-butyl)hexafluoro-subphthalocyanine ( $\left.\operatorname{SubPC}(S \text {-butyl) })_{6} \mathrm{~F}_{6} ; 6 \mathbf{6 d}\right)$, hexakis $(S$ phenyl)-hexa-fluorosubphthalocyanine $\left(\operatorname{SubPC}(S \text {-phenyl })_{6} \mathrm{~F}_{6} ; \quad 6 e\right)$, dodecylkis(S-butyl)subphthalocyanine (SubPC(S-butyl) $\left.)_{12} ; \mathbf{6 f}\right)$ and dodecylkis(S-phenyl)subphthalocyanine (SubPC(S-phenyl) $\left.{ }_{12} ; \mathbf{6 g}\right)$.

Then, to develop new charge transfer materials, we attempted the synthesis of the 1,4,8,11,15,18,22,25-octakis(thiophenyl)phthalocyanines 15, novel non-peripheral S-aryl substituted M-PCs with linking through sulfur atom electron-donating groups which show near-infrared absorption, high strain structures, no liquid crystal properties and no isomers.

\section{Results and Discussion}

\subsection{Synthesis of phthalocyanines}

Compounds 1 were synthesized from 4-sulfophthalic acid, a metal halide, urea and 1,8diazabicyclo-[5,4,0]undec-7-ene (DBU) as a catalyst (Scheme 1) [16,26,27].

Scheme 1. Synthetic pathway to compounds 1.

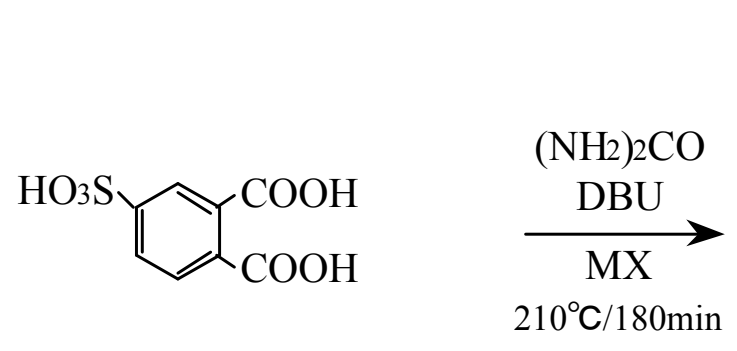

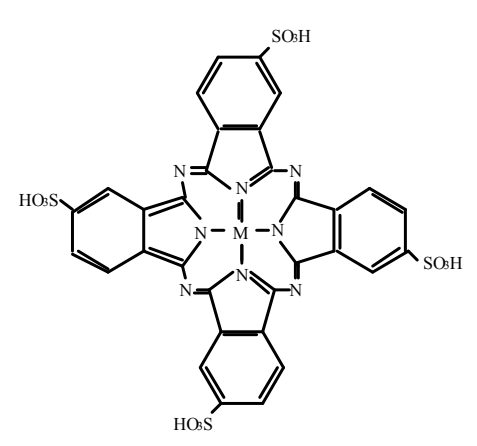

1

The position of the absorption peaks in their infrared (IR) and ultraviolet-visible (UV-Vis) spectra, and elemental analytical data of $\mathbf{1}$ were all in agreement with the proposed structures and literature data $[19,24]$. 
Compounds 2 were synthesized from benzene-1,2,4,5-tetracarboxylic dianhydride (pyromellitic dianhydride), a metal halide and urea under the reaction conditions used for the monomer preparation (Scheme 2) [16,26,27]. The IR spectrum of cobalt octasubstituted phthalocyanine synthesized from pyromellitic dianhydride gave a characteristic imide group pattern in the region from $1,600-1,800 \mathrm{~cm}^{-1}$. The imide functional groups in the synthesized metal octasubstituted phthalocyanine were changed to carboxylic acida by hydrolysis with potassium hydroxide $(\mathrm{KOH})$. The position of the absorption peaks in the IR and UV-Vis spectra and elemental analysis data of 2 are in agreement with the proposed structure and literature data $[28,29]$.

Scheme 2. Synthetic pathway to compounds 2.

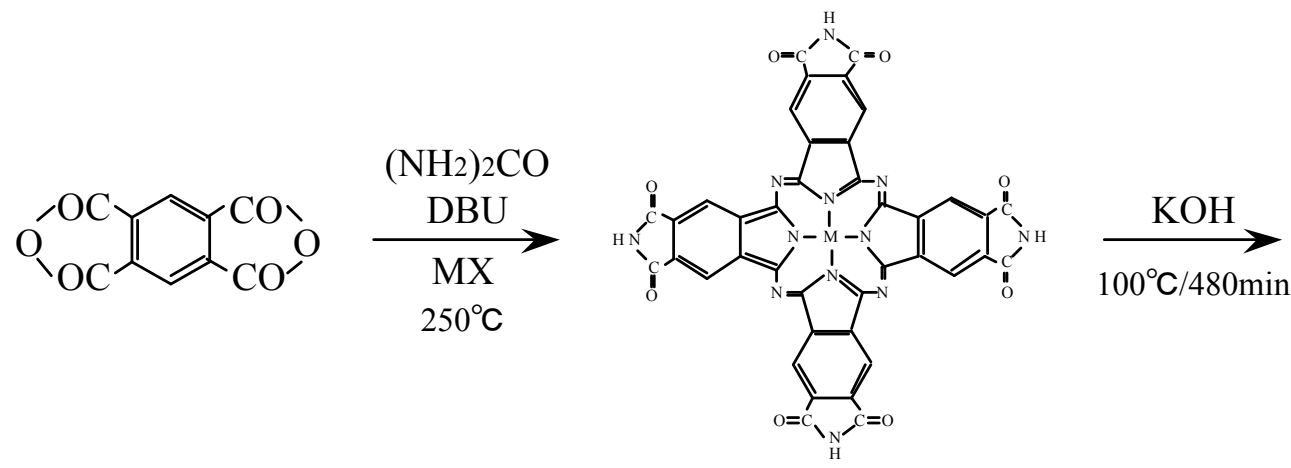

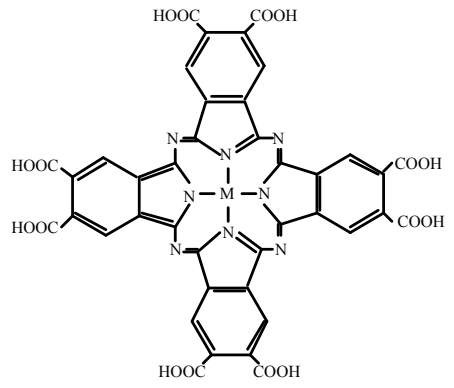

2

Compounds 3 were synthesized from a metal halide and 1,2-dicyano-4,5-bis(hexoxymethyl)benzene (10) which was synthesized in turn from o-xylene via 1,2-dibromo-4,5-dimethylbenzene (7), 1,2-dibromo-4,5-bis(bromomethylbenzene) (8) and 1,2-dibromo-4,5-bis(hexoxymethyl)benzene (9) (Scheme 3) [16,25,27].

Scheme 3. Synthetic pathway to compounds 3.

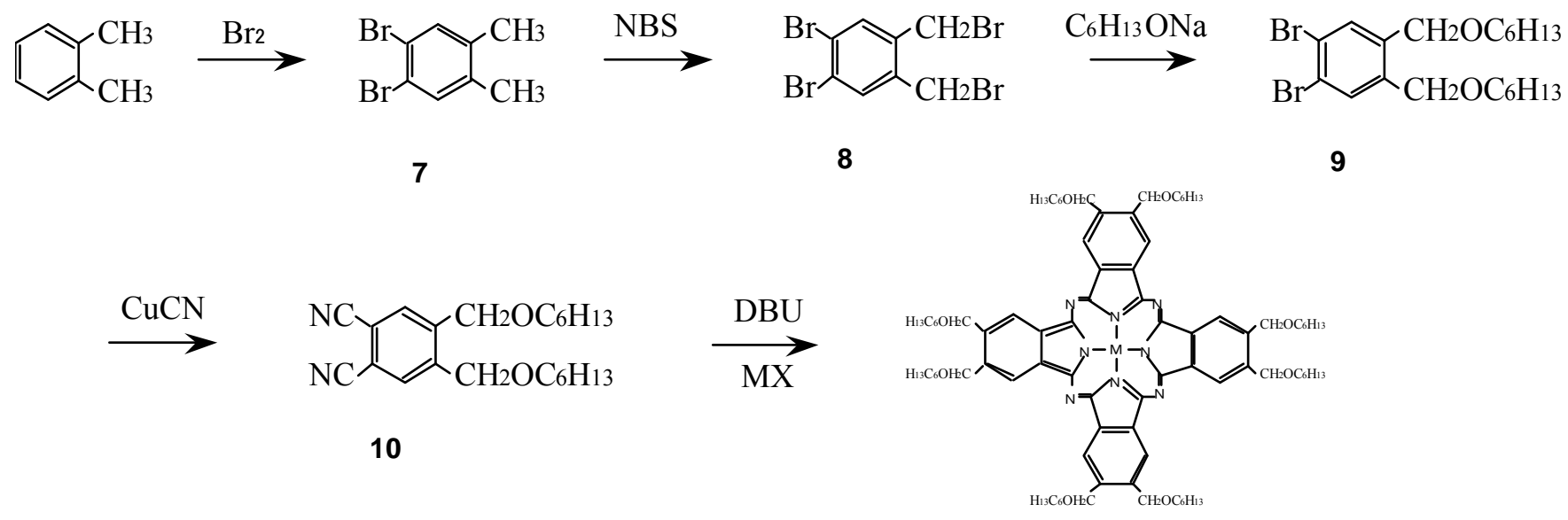

3

Compounds 4 are a new type of phthalocyanine derivative which was synthesized from 9,10anthraquinone-2,3-dicarboxylic acid (13), which in turn was prepared from $o$-xylene and phthalic anhydride via $o$-(3,4-dimethybenzoyl)benzoic acid (11), 2,3-dimethyl-9,10-anthraquinone (12), and 
metal halide with urea (Scheme 4) [17]. The intermediates 11 - 13 of $\mathbf{4}$ have been analyzed by ${ }^{1} \mathrm{H}-$ NMR and IR spectra, and elemental analysis and the analytical data were in good agreement with the proposed structures.

Scheme 4. Synthetic pathway to compounds 4 .

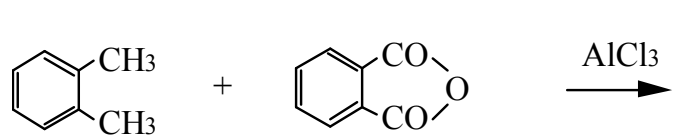

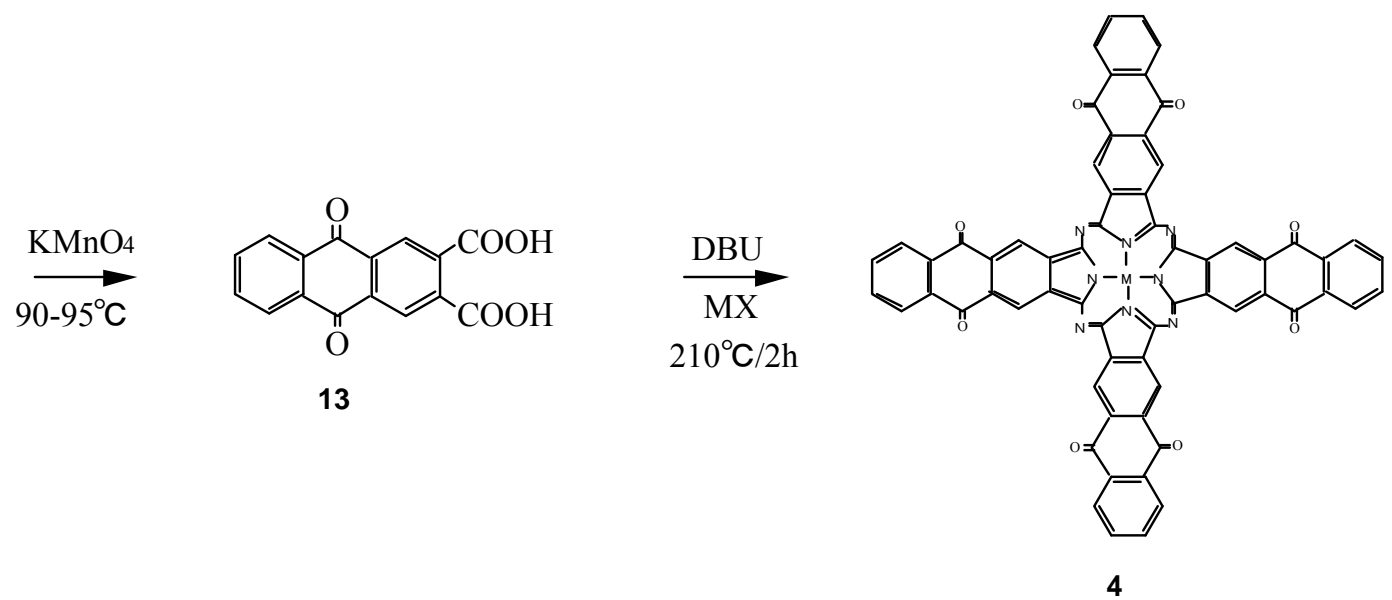

13

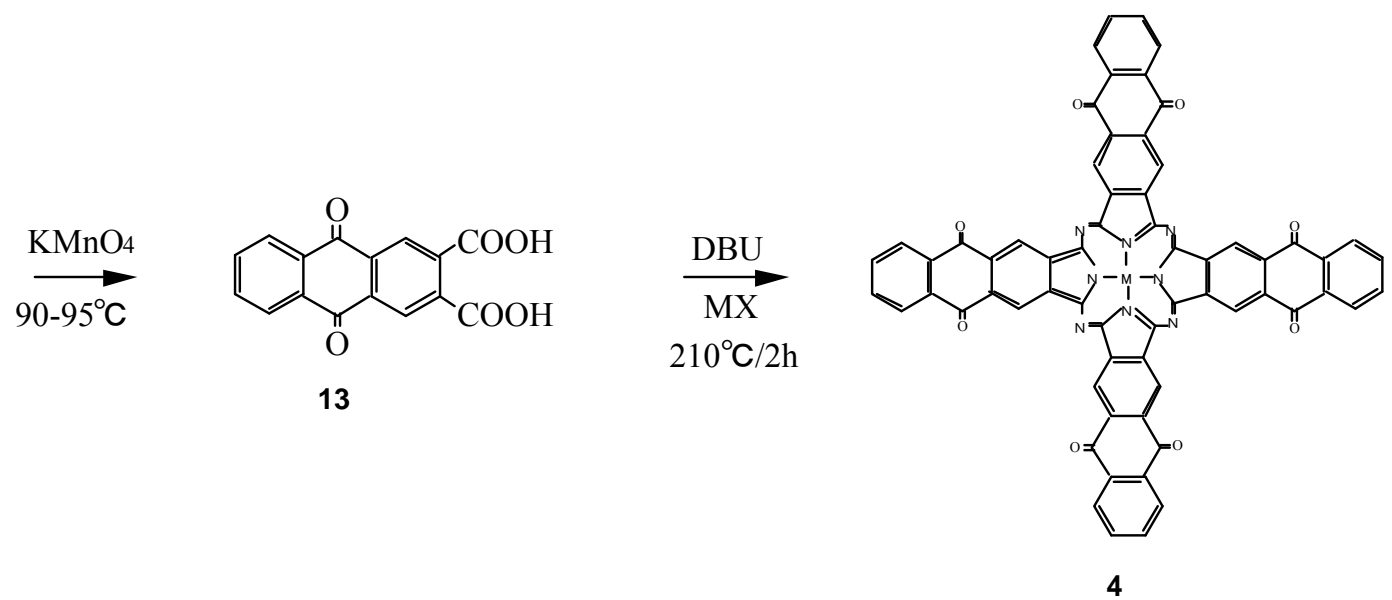<smiles>Cc1ccc(C(=O)c2ccccc2C(=O)O)cc1C</smiles>

11

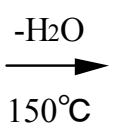

$150^{\circ} \mathrm{C}$<smiles>Cc1cc2c(cc1C)C(=O)c1ccccc1C2=O</smiles>

12

The IR spectra of $\mathbf{4}$ are similar to those of M-PC derivatives which have heterocyclic rings in the molecule and possess characteristic absorption bands. The formation of $\mathbf{4}$ was confirmed by the appearance of a pyrrole peak and the product's IR spectrum and the electron absorption band appearing at $680 \mathrm{~nm}$ were consistent with the formation of the anthraquinocyanine ring. Yields of 4-M $(\mathrm{M}=$ cobalt, iron and zinc) were largely independent of the kind of central metal used.

The Pariser-Parr-Pople (PPP) self consistent field molecular orbital (MO) method with configuration interaction was employed to calculate the properties of the metal phthalocyanine derivatives synthesized in this work. The PPP-MO calculation was carried out with the programmed software written by Tokita and his co-workers [31].

The calculated electron absorption spectra are shown in Table 1 . The $\Delta \lambda_{\text {obs.calc. }}$ shows the difference between the observed absorption peak $\lambda_{\max }$ value in the $\mathrm{Q}$ band which could be attributed to the allowed $\pi-\pi^{*}$ transition, and the calculated one. The value of $\Delta \lambda_{\text {obs.calc. }}$ is in the range of $18-21 \mathrm{~nm}$. The difference in value between the observed and calculated absorption peaks is attributable to the lack of estimation of the central metal in the software. 
Table 1. The calculated absorption spectra from PPP molecular orbital method.

\begin{tabular}{cccccccc}
\hline Compound & \multicolumn{6}{c}{ Calculated absorption spectra $/ \mathbf{n m}$} & $\Delta \boldsymbol{\lambda}$ obs.-calcs. in Q band / $\mathbf{~ m}$ \\
\hline $\mathbf{1}$ & 328 & 345 & 394 & 414 & 702 & 809 & 18 \\
$\mathbf{3}$ & 324 & 430 & 385 & 412 & 686 & 802 & 21 \\
$\mathbf{4}$ & 322 & 347 & 395 & 414 & 708 & 803 & 20 \\
\hline
\end{tabular}

It is confirmed from the PPP-MO calculation that the eight alkoxyalkyl groups in metal octakis(hexoxymethyl)phthalocyanines act as electron-donating substituents, while the eight carbonyl groups in $\mathbf{1 1}$ act as electron-withdrawing substituents. Though the PPP-MO method is unable to estimate the effect of the central metal, it is considered that since $\mathbf{3}$ and $\mathbf{4}$ were synthesized by this method, the difference between the observed value and the calculated one was within $20 \mathrm{~nm}$, even in the case of $\mathbf{1}$ and $\mathbf{2}$. These substituents produce a red shift of the absorption peak in comparison with unsubstituted M-PC.

Cobalt-1, 2, 3 and 4 have the strongest absorption peaks, around the $680 \mathrm{~nm}$ region. These strongest absorption peaks are assigned to the $\mathrm{Q}$ band, which could be attributed to the allowed $\pi-\pi^{*}$ transition [26,32]. The $\mathrm{Q}$ band absorption of soluble metal phthalocyanine derivatives synthesized in this work was shifted by $50-80 \mathrm{~nm}$ to a longer wavelength in comparison with unsubstituted metal phthalocyanines which appeared around $600 \mathrm{~nm}$. The shift of absorption maxima depends upon the change in electron distribution in the phthalocyanine macrocycle by substituents (Table 2).

Table 2. Absorption maximum of $\mathrm{Q}$ band in UV-Vis spectrum of cobalt phthalocyanine derivatives.

\begin{tabular}{cc}
\hline Compound & $\lambda$ max in Q band / nm \\
\hline $\mathbf{1}$ & 649 \\
$\mathbf{2}$ & 684 \\
$\mathbf{3}$ & 665 \\
$\mathbf{4}$ & 688 \\
\hline
\end{tabular}

Compounds 5 were synthesized by a multi step process. One raw material, 3,6didecylphthalonitrile, was synthesized from thiophene in three steps via 2,5-didecylthiophene and 2,5didecylthiophene-1,1-dioxide. The other raw material, 3,4-pyridine carbodinitrile, was synthesized from cinchomeronic acid in three steps (Scheme 5) [33]. Compound 5f was synthesized from 2,5didecylthiophene-1,1-dioxide and 2,3-pyridinecarbodinitrile, which prepared from quinolinic acid [34].

The intermediates of 5 were analyzed by IR, ${ }^{1} \mathrm{H}-\mathrm{NMR}$, mass (MS) spectrometry and elemental analysis. The analytical data for all compounds were in good agreement with the proposed structures. Compounds 5 displayed strong absorption peaks around $680 \mathrm{~nm}$ for the Q band [18,20,33-36]. The Q band absorption of 5 shifted by $50-80 \mathrm{~nm}$ to a longer wavelength in comparison with unsubstituted phthalocyanines (Table 3). 
Scheme 5. Synthetic pathway to compounds 5.

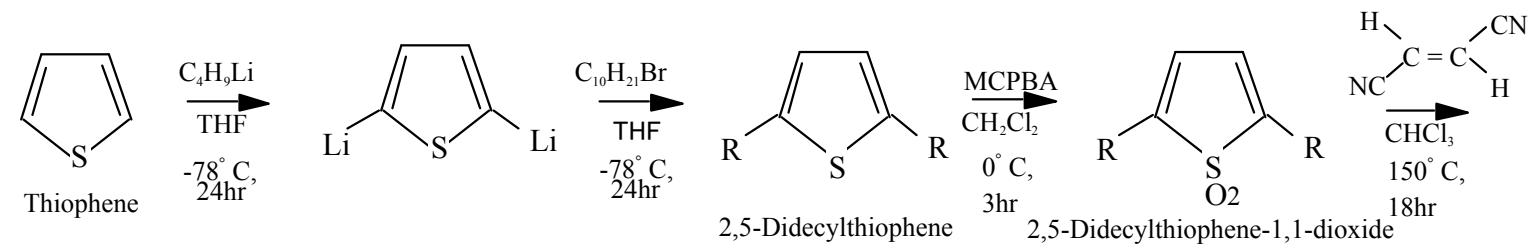<smiles>[R]c1ccc([R])c(C#N)c1C#N</smiles>

3,6-Didecylphthalonitrile

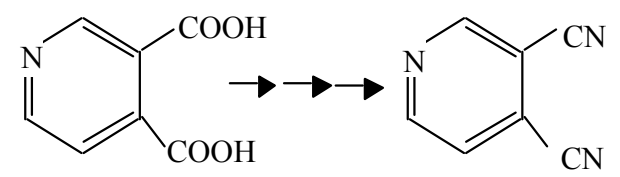
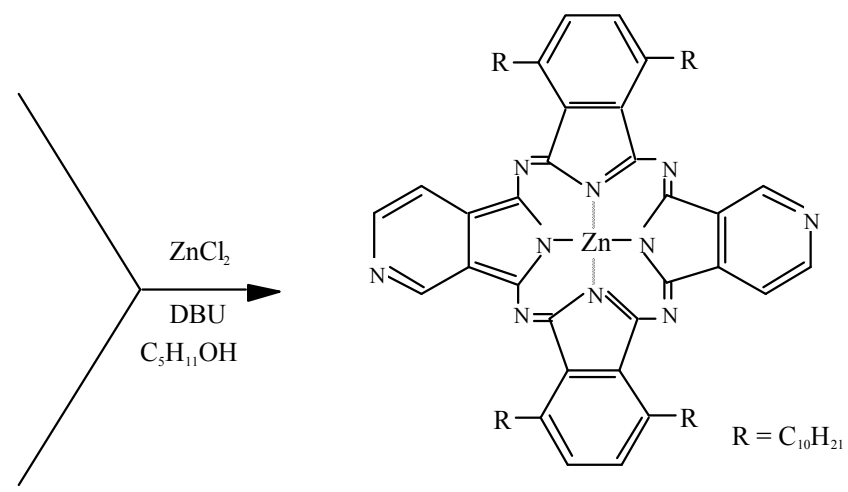

A typical product of bis(1,4-didecylbenzo)bis(3,4pyrido)porphyrazine (5)

(5a) ; Zinc tetra-3,4-pyridoporphyrazine,

(5b); zinc 1,4-didecylbenzo-tris(3,4-pyrido)porphyrazine,

(5c); zinc bis(1,4-didecylbenzo)-bis(3,4-pyrido)porphyrazine,

(5d) ; zinc tris(1,4-didecylbenzo)-3,4-pyridoporphyrazine,

(5e); zinc octadecylphthalocyanine.

Compound 5c, synthesized from a 1:1 mol ratio of raw materials, has five regioisomers (Figure 2). It has two non-peripheral substituted benzenoid and pyridinoid rings, located at different positions. In the molecule the pyridinoid rings can be adjacent or opposite to each other. In the case of adjacent pyridinoid rings, three types of isomer exist, depending on the orientation of the ring. Meanwhile, two types of isomers exist in the case of opposite pyridinoid rings. We attempted to separate the regioisomers of the compound 5c using thin layer chromatography (TLC) (Merck silica gel 60F 254 on aluminum sheet, eluent: toluene - Py, 7:3). Four green- to blue-colored fractions presenting different ${ }^{1} \mathrm{H}-\mathrm{NMR}, \mathrm{UV}-\mathrm{Vis}$ and fluorescent spectra were obtained in 26.1, 17.4, 17.4 and 39.1\% yield, respectively, and can be attributed to four of five possible regioisomers of the $5 \mathbf{c}$. These fractions were numbered from 1, 2, 3 and 4, according to the $\mathrm{R}_{\mathrm{f}}$ values $(0.95,0.91,0.75$ and 0.65 , respectively). Each fraction was recovered by scraping the absorbent from the TLC plate, extracting with Py, filtering and removing the solvent.

Table 3. The Q band maxima of compounds 5 after purification by TLC.

\begin{tabular}{cccc}
\hline Compound & \multicolumn{3}{c}{ Q band $\lambda$ max toluene $/ \mathbf{n m}$} \\
\hline $\mathbf{5 a}$ & $675^{*}$ & $664^{*}$ & $603^{*}$ \\
$\mathbf{5 b}$ & 686 & 635 & 617 \\
$\mathbf{5 c}$ & 686 & 636 & 717 \\
$\mathbf{5 d}$ & 686 & 635 & 617 \\
$\mathbf{5 e}$ & 703 & 634 & \\
\hline \multicolumn{4}{c}{} \\
\end{tabular}


Figure 2. Regioisomers of metal bis(1,4-didecylbenzo)-bis(3,4-pyrido)porphyrazine 5c.

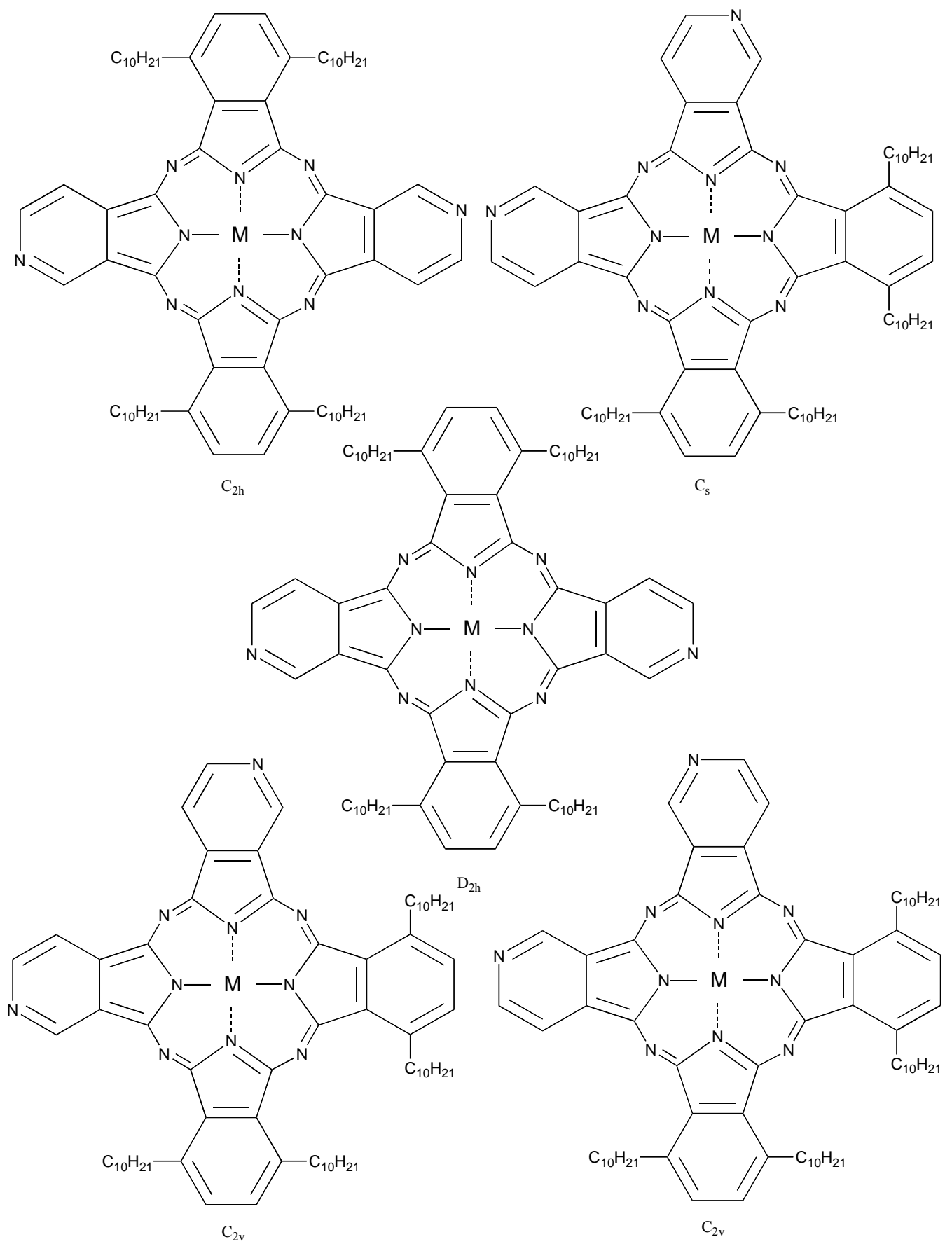

The regioisomers of the 5c were estimated by ${ }^{1} \mathrm{H}-\mathrm{NMR}$, UV-Vis $\mathrm{Q}$ band absorption and MO calculations. The MO calculations of the isomers were performed using the ZINDO/S semi-empirical CI configurations available in the HyperChem 5.1Pro software package in order to obtain their theoretical Q band absorptions.

Compounds 5c and 5f were next further reacted with quaternizing agents (AX) such as monochloroacetic acid (MCAA), diethyl sulfate (DES) and dimethyl sulfate (DMS) in $N, N$ dimethylformamide (DMF) as solvent at $140{ }^{\circ} \mathrm{C}$ (Scheme 6). 
Scheme 6. Quaternization reactions of compounds $\mathbf{5 c}$ and $\mathbf{5 f}$ with quaternizing agents (AX).

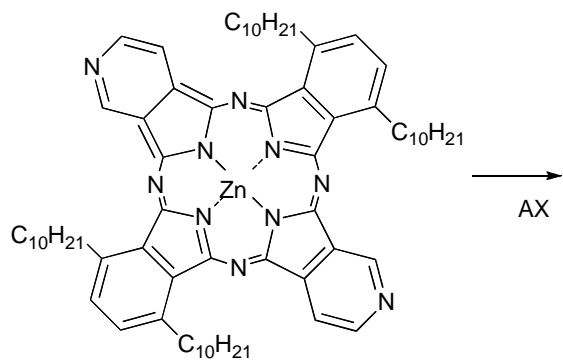

(5c)

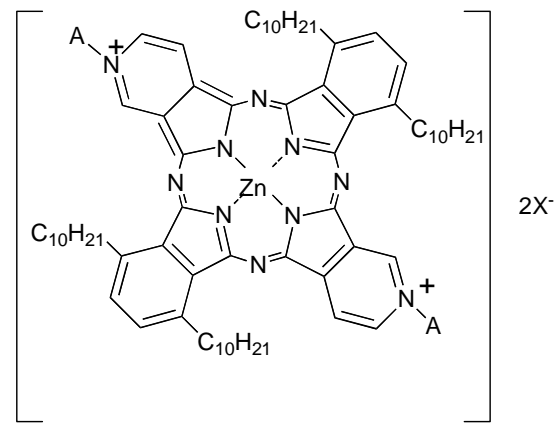

$2 x^{-}$

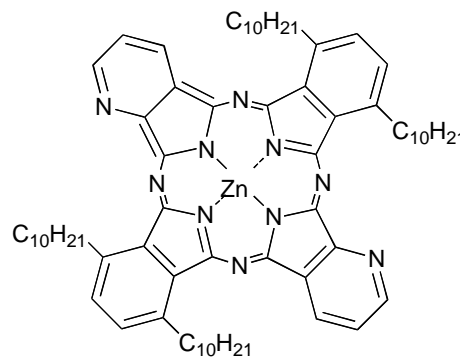

(5f)

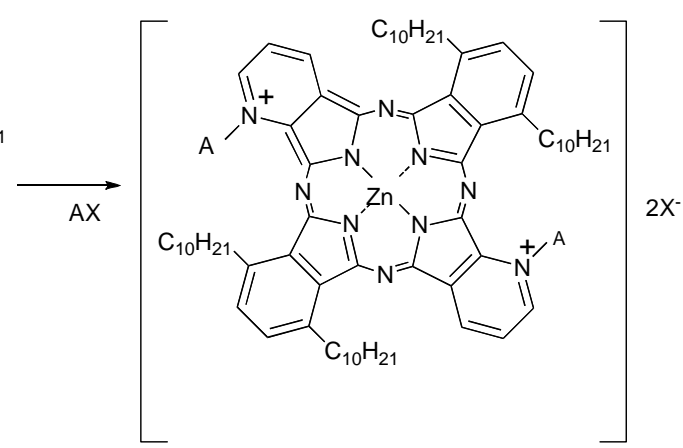

Yields of products of $5 c$ using MCAA, DES and DMS as quaternizing agents were $23 \%, 17 \%$ and $28 \%$, respectively. The corresponding yields of products with the same reagents when $\mathbf{5 f}$ was the substrate were $24 \%, 21 \%$ and $25 \%$, respectively. After reaction with the quaternizing agents, the products of $\mathbf{5 c}$ and $\mathbf{5 f}$ were identified through spectroscopic techniques such as ${ }^{1} \mathrm{H}-\mathrm{NMR}$, IR and UVVis spectrometry. When the quaternizing agent was MCAA or DMS, it is confirmed that $\mathrm{N}-\mathrm{CH}_{2} \mathrm{COOH}$ or $\mathrm{N}-\mathrm{CH}_{3}$ bonds were obtained on the pyridinoid rings, while when DES was used, we noted that quaternization was not achieved but rather sulfonation occurred. The shapes of the UV-Vis spectra in Py solution changed after quaternatization, and it is thought that interactions between the molecules are complicated when DES and DMS were used as quaternizing agents, since the quaternized products easily aggregate in aqueous media. After reaction with quaternizing agents, all compounds became water soluble, and acquired amphiphilic properties (Table 4).

Table 4. Solubilities of 5c and quaternized compounds with MCAA, DES and DMS.

\begin{tabular}{cllll}
\hline Compound & Toluene & Chloroform & Pyridine & Water \\
\hline 5c & Soluble & Soluble & Soluble & Insoluble \\
With MCAA & Soluble & Soluble & Soluble & Soluble \\
With DES & Soluble & Soluble & Soluble & Soluble \\
With DMS & Soluble & Soluble & Soluble & Soluble \\
\hline
\end{tabular}

Compounds 5c and $\mathbf{5 f}$ are readily soluble in Py, with their strongest absorption appearing at $687 \mathrm{~nm}$ ( $\log \varepsilon_{\max }$ 4.81). The Q band absorption of the compound quaternized with DMS showed a peak at 739 $\mathrm{nm}$, shifted by $56 \mathrm{~nm}$ to longer wavelength in comparison with compounds reacted with MCAA and 
DES. After reacting with MCAA, DES and DMS, all compounds are very soluble in water, and they show strongest absorptions in the Q band at 715, 731 and $747 \mathrm{~nm}$, respectively (Figure 3).

Figure 3. UV-Vis spectra of 5c quaternized with MCAA, DES and DMS. The UV-Vis spectra of each quaternized compound was measured in pyridine solution or water.
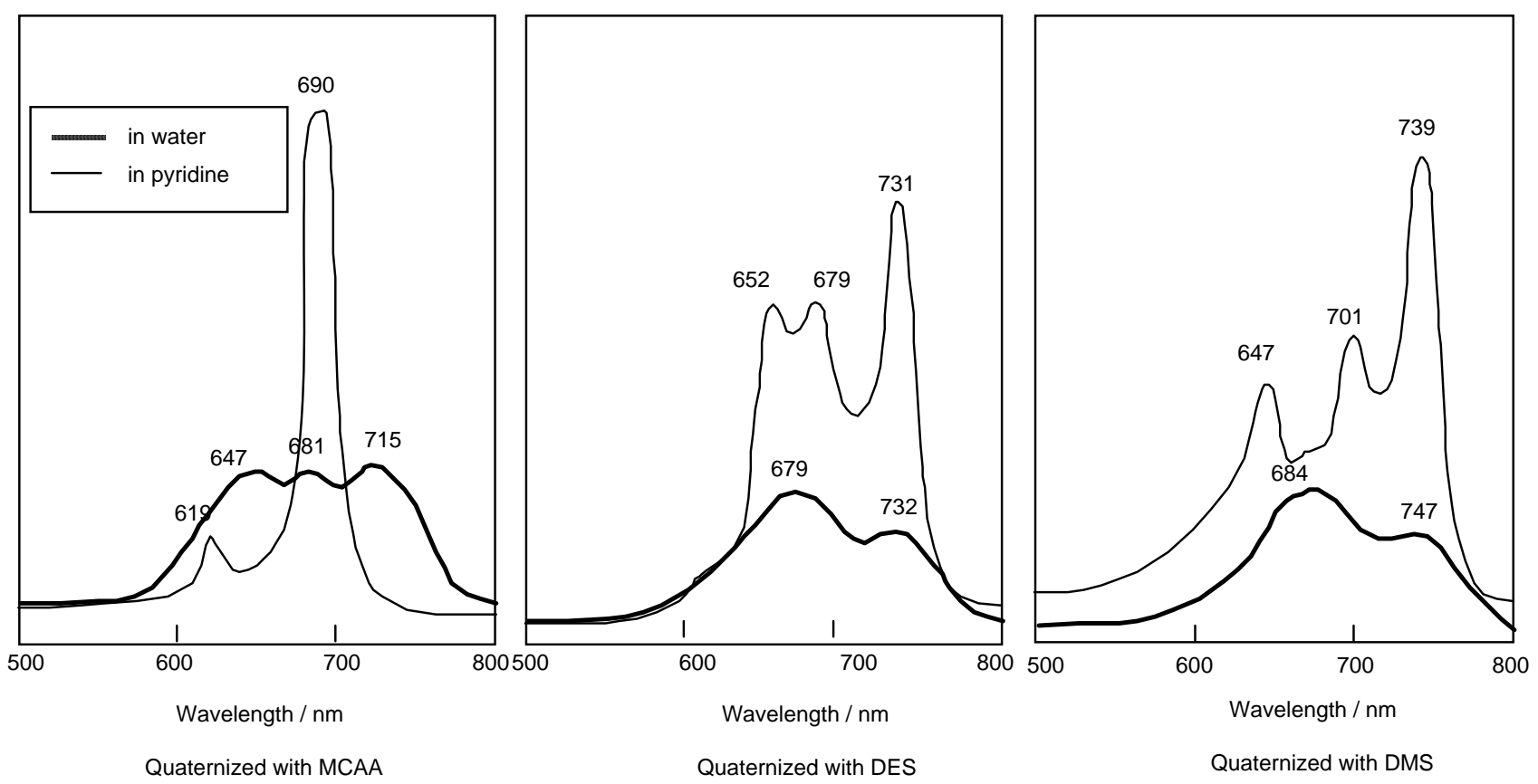

The separated regioisomers of 5c were also quaternized with DMS. Yields of products were 11\%, $9 \%, 15 \%$ and $11 \%$ for fractions 1, 2, 3 and 4, respectively. Quaternized regioisomers were also identified using spectroscopic techniques such as ${ }^{1} \mathrm{H}-\mathrm{NMR}$, IR, UV-Vis and fluorescence spectra. A comparison of the UV-Vis spectra before and after the quaternization of the regioisomers with DMS, showed that the Q band absorptions of quaternized regioisomers were split into two or more bands. After quaternization, the $\mathrm{Q}$ band absorptions were also moved to longer wavelengths (Figure 4).

In general, fluorescence spectra appear as the mirror images of excitation spectra. Excitation spectra show the same absorption band profiles. Fluorescence spectra show longer wavelengths than absorption and excitation spectra. For the quaternized products, except for fractions 1 and 4 , the fluorescence spectra showed longer wavelengths than their corresponding absorption spectra.

In fractions 1 and 4, a degree of overlap between absorption and fluorescence spectra was observed. These phenomena result from fluorescence re-absorption or re-emission. Accordingly, the fluorescence spectra of fractions 1 and 4 showed shorter wavelength than the longest wavelength of the absorption bands.

Compound 6a was synthesized from 1,2-dicyanobenzene. Compound 6c was synthesized from 1,2dicyano-3,4,5,6-tetrafluorobenzene (Scheme 7) [36]. Compounds 6d-g were synthesized from the precursors 1,2-dicyano-3,6-bis(thiobutyl)-4,5-difluorobenzene (14a), 1,2-dicyano-3,4,5,6-tetrakis(thiobutyl)benzene (14b), 1,2-dicyano-3,6-bis(thiophenyl)-4,5-difluorobenzene (14c) and 1,2-dicyano3,4,5,6-tetrakis(thiophenyl)benzene (14d), respectively. 
Figure 4. UV-Vis spectra of each regioisomer in 5c quaternized with DMS. The UV-Vis spectra of each quaternized compound was measured in Py solution.
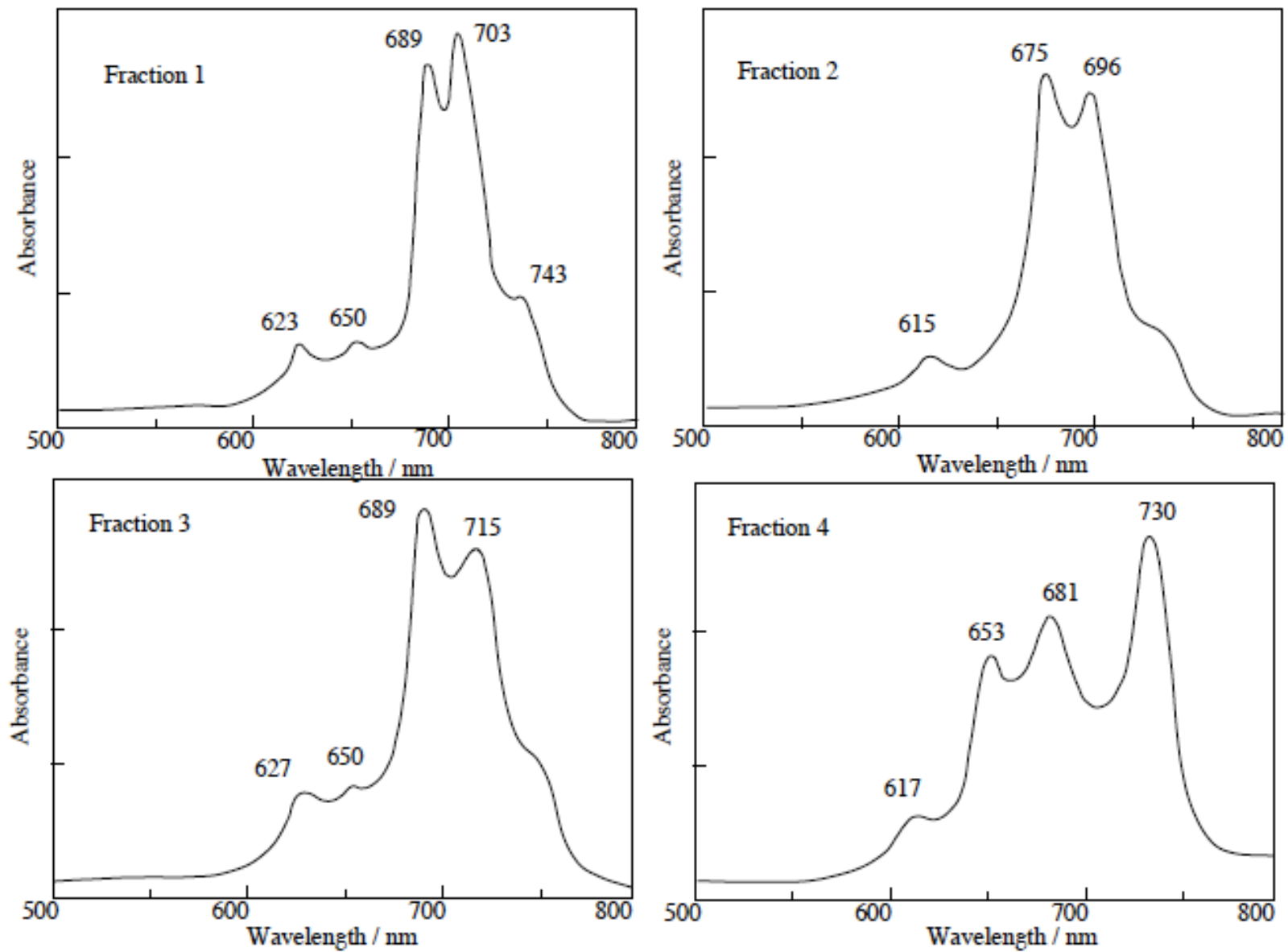

Scheme 7. Synthetic pathway to compounds 6.

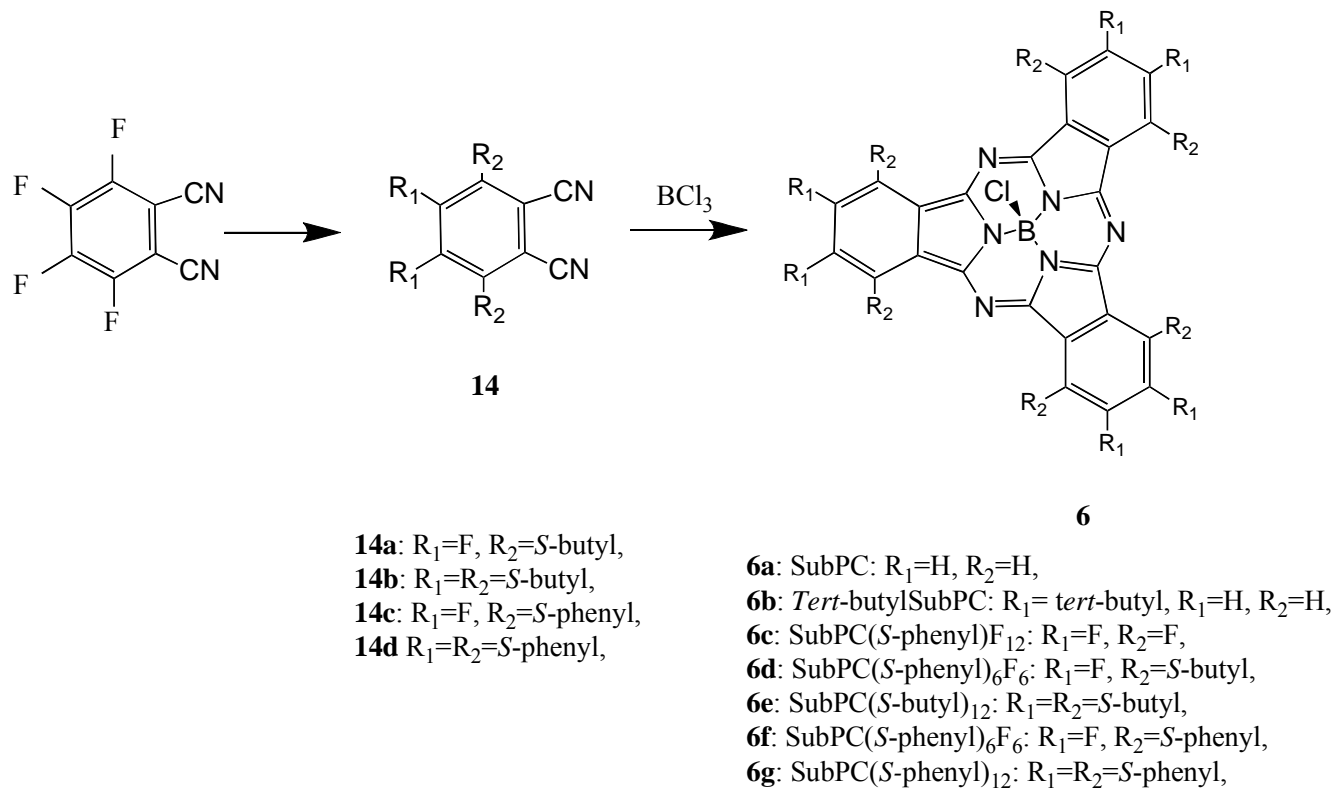

Compounds 6d-g were synthesized from the precursors 1,2-dicyano-3,6-bis(thiobutyl)-4,5-difluorobenzene (14a), 1,2-dicyano-3,4,5,6-tetrakis(thiobutyl)benzene (14b), 1,2-dicyano-3,6-bis(thiophenyl)- 
4,5-difluorobenzene (14c) and 1,2-dicyano-3,4,5,6-tetrakis(thiophenyl)benzene (14d), respectively. The precursors of the SubPC derivatives were analyzed and the analytical data were in good agreement with the proposed structures.

The target SubPC and derivatives were analyzed by UV-Vis, IR and ${ }^{1} \mathrm{H}-\mathrm{NMR}$ spectroscopy and the analytical data were in good agreement with the proposed structures. Absorption bands in the IR spectra of SubPC and its derivatives are assigned as follows: peaks around 1,600 $\mathrm{cm}^{-1}$ are aromatic ring absorptions; those in the 1,200-1,050 $\mathrm{cm}^{-1}$ region are mainly absorption from out-of-plane bending of $\mathrm{CH}$ and $\mathrm{NH}$ in pyrrole rings, in which cyclotrimerization is found. These absorption bands in the IR spectrum are characteristic peaks of M-PCs.

The absorption maxima of SubPC and its derivatives appeared around $560-630 \mathrm{~nm}$ in benzene solution. The Q band absorption of SubPC and its derivatives is shifted by around $100 \mathrm{~nm}$ to a shorter wavelength in comparison with normal metal phthalocyanine derivatives, in which they appear around $650 \mathrm{~nm}$. The shift of absorption maxima depends upon the change in electron distribution and the size of the macrocycle. Absorption maxima of SubPC derivatives shifted to longer wavelength with increasing molecular weight. The synthesized SubPC and its derivatives were sufficiently soluble in some organic solvents such as dichloromethane, chloroform, acetone and DMF.

Scheme 8. Synthetic pathway to compounds 15.

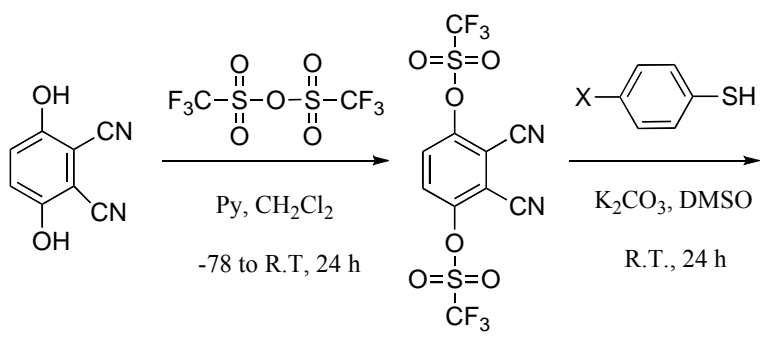

16

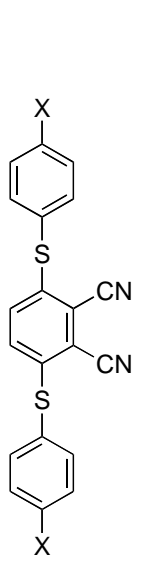

17

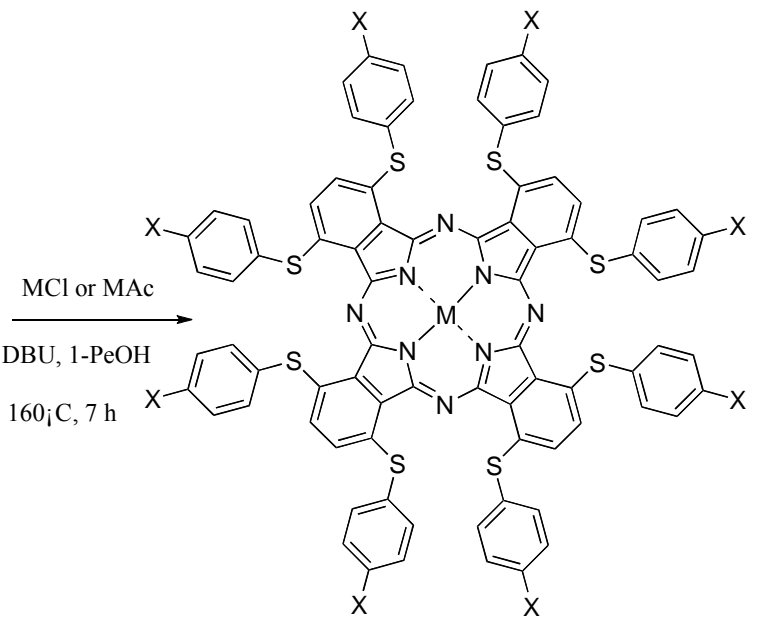

15

17a: $X=\mathrm{CH}_{3}$
17b: $X=\mathrm{OCH}_{3}$
17c: $X=t$-butyl 15a: $\mathrm{X}=\mathrm{CH}_{3}$ 15b: $\mathrm{X}=\mathrm{OCH}_{3}$ 15c: $X=t$-butyl $\mathrm{M}=\mathrm{Cu}, \mathrm{Co}, \mathrm{Ni}, \mathrm{Zn}, \mathrm{Pb}$

The 1,4,8,11,15,18,22,25-octakis(thiophenyl)phthalocyanine compounds $\mathbf{1 5}$ were synthesized in three steps via the intermediates phthalonitrile-3,6-ditriflate (16) and 3,6-bis(thiophenyl)phthalonitriles (17). Intermediate 16 was synthesized from 2,3-dicyanohydroquinon and trifluoromethanesulfonic anhydride for $24 \mathrm{~h}$ in accordance with a description from the literature [37]. Intermediates 17 were synthesized, respectively, from 1 and thiophenols such as $p$-toluenethiol, 4-methoxybenzenethiol and tert-butylthiophenol at room temperature for $24 \mathrm{~h}$ to obtain 3,6-bis(thiophenylmethyl)phthalonitrile (17a), 3,6-bis(thiophenylmethoxy)phthalonitrile (17b) and 3,6-bis(thiophenyl tert-butyl)phthalonitrile 
(17c). Intermediates 16 and 17 were analyzed using IR and ${ }^{1} \mathrm{H}-\mathrm{NMR}$ spectroscopy, and elemental analysis. Their analytical data showed good agreement with the proposed structures (Scheme 8).

1,4,8,11,15,18,22,25-octakis(Thiophenylmethyl)phthalocyanines (15a), 1,4,8,11,15,18,22,25-octakis(thiophenylmethoxy)phthalocyanines (15b) and 1,4,8,11,15,18,22,25-octakis(thiophenyl tertbutyl)phthalocyanines (15c) were synthesized, respectively, from the corresponding intermediates 17a, 17b, and 17c and metal salt in 1-pentanol in the presence of DBU as catalyst for $7 \mathrm{~h}$ (Scheme 1) [38]. As metal salts, chloride or acetate of copper, cobalt, nickel, zinc, and lead were chosen [39]. Metalfree compounds 15 were obtained directly by refluxing 17 in 1-pentanol. The products were isolated using column chromatography on silica gel with toluene as eluent. The most readily apparent feature of the compounds $\mathbf{1 5}$ is their solubility in various solvents. The target compounds $\mathbf{1 5}$ were analyzed using elemental analysis and MS spectroscopy. The analytical data showed good agreement with the proposed structures.

\subsection{Electrochemical Properties}

Cyclic voltammetry $(\mathrm{CV})$ is often used in electrochemistry studies. It consists of the cyclic potential of a stationary electrode immersed in a quiescent solution and measuring the resulting current. The excitation signal is a linear potential scan with a triangular waveform. This triangular potential excitation signal sweeps the potential of the working electrode. The triangle returns at the same speed and permits the display of a complete voltammogram. Therefore, if a molecular is reduced in the forward scan, it will be reoxidized on the reverse scan. The current response shows the upper half, cathodic (reduction) and the lower half, an anodic (oxidation) peak.

Figure 5 shows CVs and their first differential curves for compounds 1, 2, 3 and 4, respectively. The reduction and oxidation potentials of cobalt-1, 2, $\mathbf{3}$ and $\mathbf{4}$ are summarized in Table 5 . The reported potentials are the midpoint potential of anodic and cathodic peaks for each couple, Emid, and the peak potential for the irreversible step.

The CV of cobalt-1 showed two cathodic peaks at -0.63 and $-1.00 \mathrm{~V}$ vs. silver (Ag)/ silver chloride $(\mathrm{AgCl})$ saturated sodium chloride, and four anodic peaks at $0.89,0.67,-0.60$ and $-0.90 \mathrm{~V}$ vs. $\mathrm{Ag} / \mathrm{AgCl}$. The peaks of cobalt-1 are attributed to a five reduction stage. The first reversible reduction potential at $-0.62 \mathrm{~V}$ vs. $\mathrm{Ag} / \mathrm{AgCl}$ and the first oxidation potential of cobalt-1 appeared at $0.67 \mathrm{~V} \mathrm{vs} . \mathrm{Ag} / \mathrm{AgCl}$.

In the case of cobalt-2, three cathodic peaks and six anodic peaks appeared. The peaks were sorted into three reversible reduction couples at $-0.24,-0.66$ and $-1.39 \mathrm{~V}$ vs. $\mathrm{Ag} / \mathrm{AgCl}$, and three irreversible oxidation waves at $0.67,0.87$ and $1.06 \mathrm{~V}$ vs. $\mathrm{Ag} / \mathrm{AgCl}$. The reduction and oxidation of metal phthalocyanine derivatives are due to the interaction between the phthalocyanine ring and the central metal $[40,41]$. The reduction and oxidation potential of cobalt phthalocyanine derivatives reported by Rollmann [42] and Orihashi [43] showed more negative values than in the case of cobalt-1 and 2. Carboxylic and sulfonic groups are electron-withdrawing groups so they are expected to reduce the electron charge in the phthalocyanine ring. The change in the redox potential is due to the kind and number of substituents. 
Figure 5. Cyclic voltammograms and their first differential curves of covalt phthalocyanine derivatives in dimethylsulfoxide (DMSO) with $0.1 \mathrm{~mol} \cdot \mathrm{L}^{-1}$ tetrabutylammonium perchlorate (TBAP), scan rate: $50 \mathrm{mV} \cdot \mathrm{s}^{-1}$; a): First differential curve of upper half of cyclic voltammogram; b): Cyclic voltammogram; c): First differential curve of lower half of cyclic voltammmogram; (1) Cobalt phthalocyanine tetrasulfonic acid; (2) Cobalt phthalocyanine octacarboxylic acid; (3) Cobalt octakis(hexoxymethyl)phthalocyanine; (4) Cobalt anthraquinocyanine.
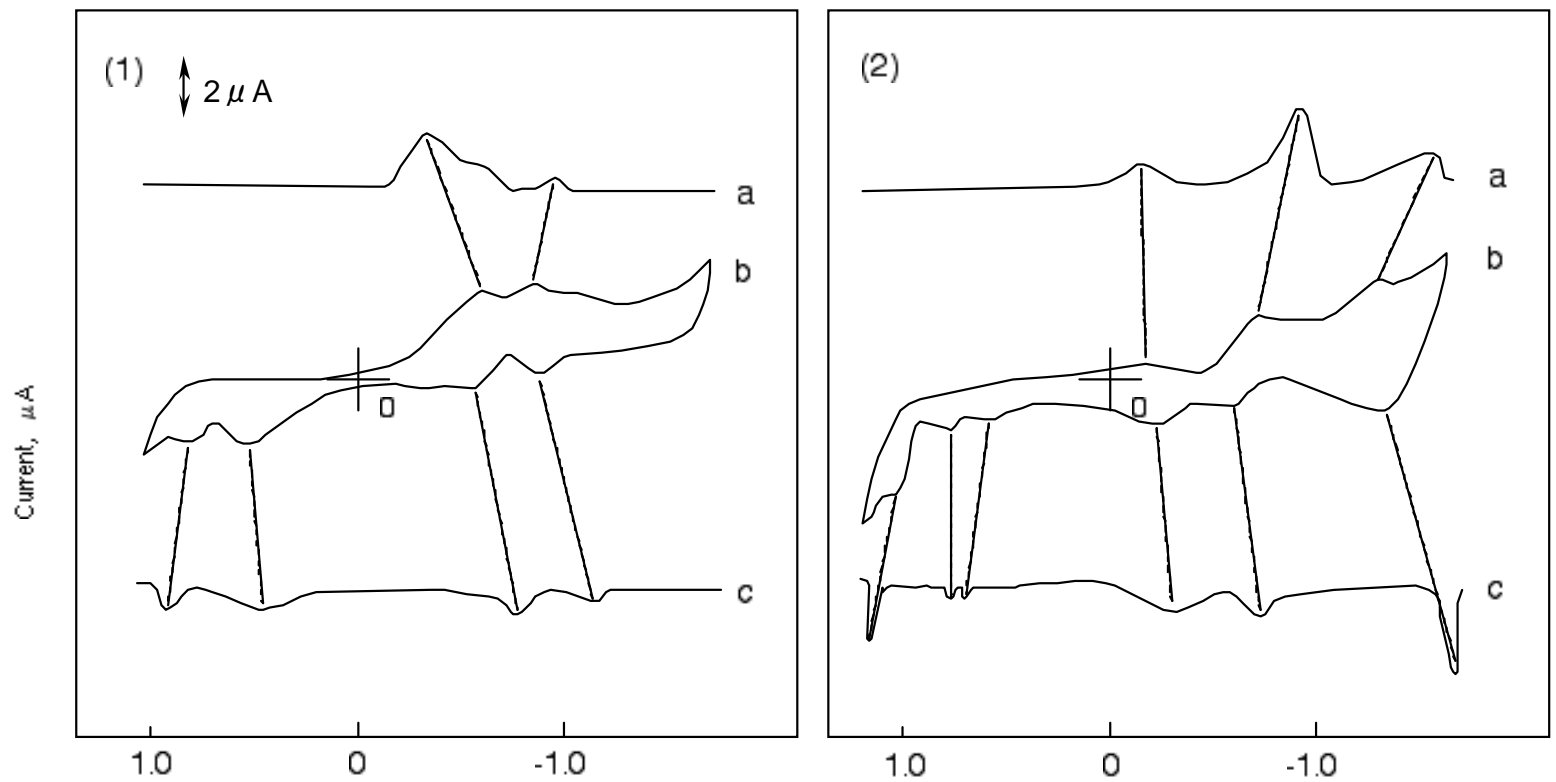

Potential, V vs. $\mathrm{Ag} / \mathrm{AgCl}$

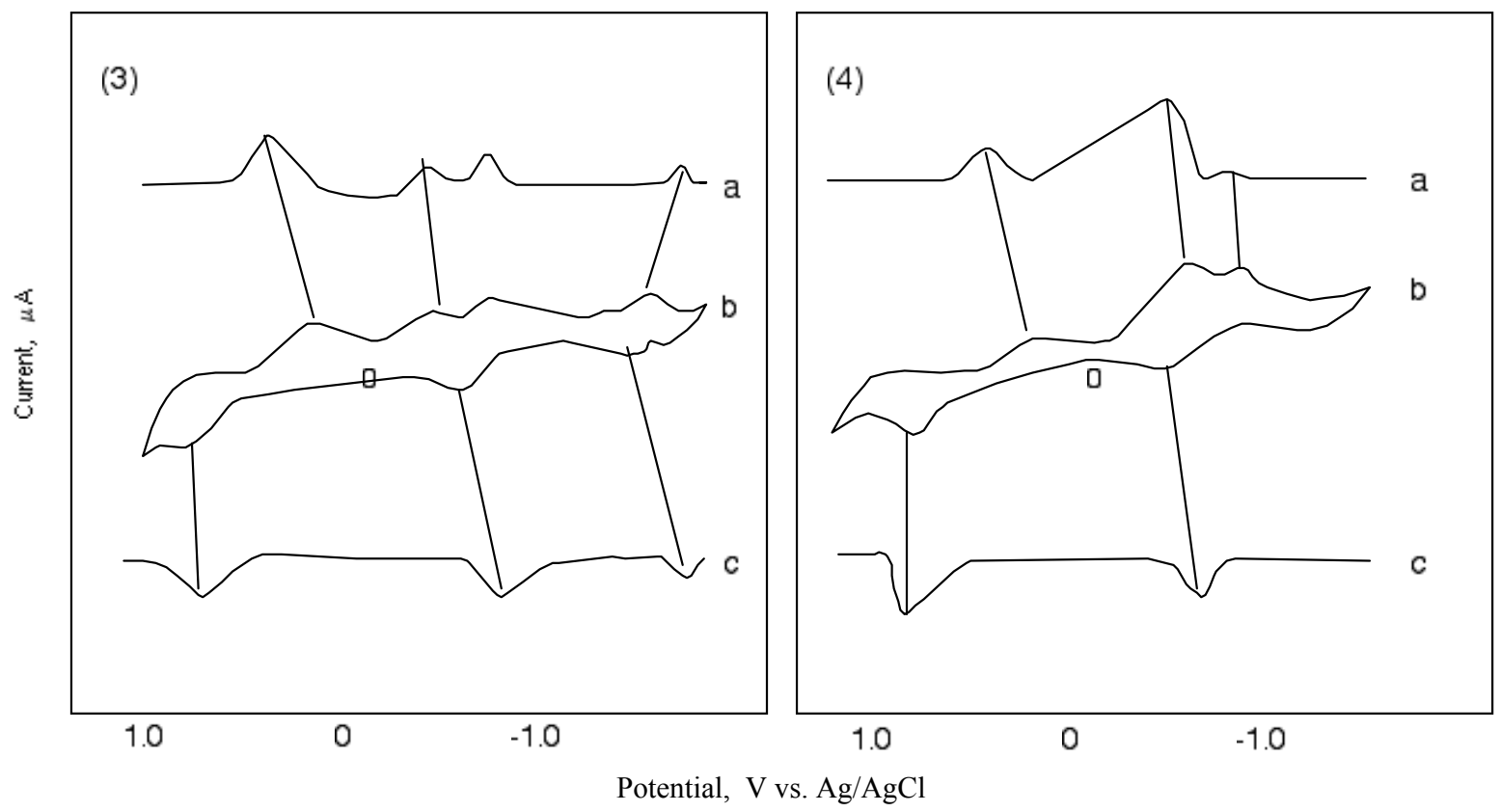

The CV of cobalt-3 showed four cathodic peaks at $0.16,-0.49,-0.73$ and $-1.54 \mathrm{~V}$ vs. $\mathrm{Ag} / \mathrm{AgCl}$, and three anodic peaks at $0.73,-0.61$ and $-1.47 \mathrm{~V}$ vs. $\mathrm{Ag} / \mathrm{AgCl}$. Cobalt-3 has two irreversible oxidations at 0.16 and $0.73 \mathrm{~V}$ vs. $\mathrm{Ag} / \mathrm{AgCl}$, and two pairs of reversible reduction potential. Since the hexyloxymethyl substituent is an electron-donating group, the negative charge on the phthalocyanine ring is expected to increase. 
The CV of cobalt-4 showed a unique shape in comparison with the other compounds cobalt-1, 2 and 3. The shape of the CV for cobalt-4 showed three cathodic peaks at $0.19,-0.69$ and $-0.95 \mathrm{~V}$ vs. $\mathrm{Ag} / \mathrm{AgCl}$, and two anodic peaks at 0.87 and $-0.58 \mathrm{~V}$ vs. $\mathrm{Ag} / \mathrm{AgCl}$. Cobalt-4 has almost one pair of reversible potential.

The $\Delta \mathrm{E}$ values in Table 5 are the anodic peak to cathodic peak separation located in the oxidation (negative) potential region. The $\Delta \mathrm{E}$ values, except for cobalt-2, are around $100 \mathrm{mV}$ and the redox processes are the same for these molecules.

Table 5. Redox potentials of cobalt phthalocyanine derivatives.

\begin{tabular}{|c|c|c|c|c|c|c|c|c|}
\hline \multirow{2}{*}{\multicolumn{2}{|c|}{ Compound }} & \multicolumn{7}{|c|}{ Potential / V vs. Ag/AgCl } \\
\hline & & \multicolumn{4}{|c|}{ Reduction } & \multicolumn{3}{|c|}{ Oxidation } \\
\hline \multirow[t]{3}{*}{1} & & - & -0.95 & -0.62 & & $0.67^{*}$ & $0.89 *$ & \\
\hline & & $1.63 *$ & & & & & & \\
\hline & $\Delta \mathrm{E}^{* *}$ & & 0.98 & 0.34 & & & & \\
\hline & & -1.39 & & -0.66 & -0.24 & $0.67 *$ & $0.87^{*}$ & $1.06^{*}$ \\
\hline & $\Delta \mathrm{E}^{* *}$ & 1.60 & & 2.27 & 0.84 & & & \\
\hline \multirow[t]{2}{*}{3} & & -1.50 & $-1.25^{*}$ & -0.67 & $-0.49 *$ & $0.16^{*}$ & $0.73 *$ & \\
\hline & $\Delta \mathrm{E}^{* *}$ & 0.88 & 1.27 & & & & & \\
\hline \multirow[t]{3}{*}{4} & & - & -0.63 & & & $0.19^{*}$ & $0.87 *$ & \\
\hline & & $0.95^{*}$ & & & & & & \\
\hline & $\Delta \mathrm{E}^{* *}$ & & 1.07 & & & & & \\
\hline
\end{tabular}

Potentials of reversible wave are midpoint of anodic and cathodic praks for each couple, $\mathrm{E}_{1 / 2}$.

*Irreversible peak; ** The anodic peak to cathodic peak separation for reversible couple.

Kadish et al. have suggested that the potential difference between the reduction and oxidation is expressed in the HOMO - LUMO energy gap [44]. This potential difference decreases from $1.36 \mathrm{~V}$ for cobalt-2 to $0.65 \mathrm{~V}$ for cobalt-7. The values of $\lambda_{\max }$ in the $\mathrm{Q}$ band shown in Table 5 correlate with the potential difference between the reduction and oxidation of cobalt-1, 2, 3 and 4 .

Figure 6 shows the change in the ratio of anodic peak current to the cathodic current of cobalt-1, 2, $\mathbf{3}$ and $\mathbf{4}$ with a scan rate, $v$. Nicholson and his co-worker have been studied the relationship between the ratio of anodic to cathodic peak current, $i_{a} / i_{c}$ and the scan rate, $v$ [45]. When the relationship is unity, the system involves a reversible or catalytic reaction. This relationship between the anodic to cathodic peak current ratio of a reversible couple, $i_{a} / i_{c}$ and the scan rate, $v$ serves as a quick test for electrochemical mechanism associated with a preceding or succeeding reversible or irreversible chemical equilibrium. The scan rate varied from 0.05 to $0.3 \mathrm{Vs}^{-1}$ in this work.

It is shown that the ratio of anodic to cathodic peak current, $i_{a} / i_{c}$ decreased continuously with an increasing scan rate, $v$ for all reversible couples of cobalt-1, 2, 3 and 4 . The reversible reduction couples of cobalt-1, 2, 3 and $\mathbf{4}$ are characterized as a fast reversible electron transfer followed by a reversible chemical reaction. The value of anodic to cathodic peak current ratio, $i_{a} / i_{c}$ converges when the ratio is extrapolated to zero of scan rate, $v$. 
Figure 6. Change in the anodic to cathodic current ratio with scan rate for cobalt phthalocyanine derivatives. (1) Cobalt phthalocyanine tetrasulfonic acid. (2) Cobalt phthalocyanine octacarboxylic acid. (3) Cobalt octakis(hexoxymethyl)phthalocyanine. (4) Cobalt anthraquinocyanine. $\square$ : First redox couple. : Second redox couple. $\bigcirc$ : Third redox couple.
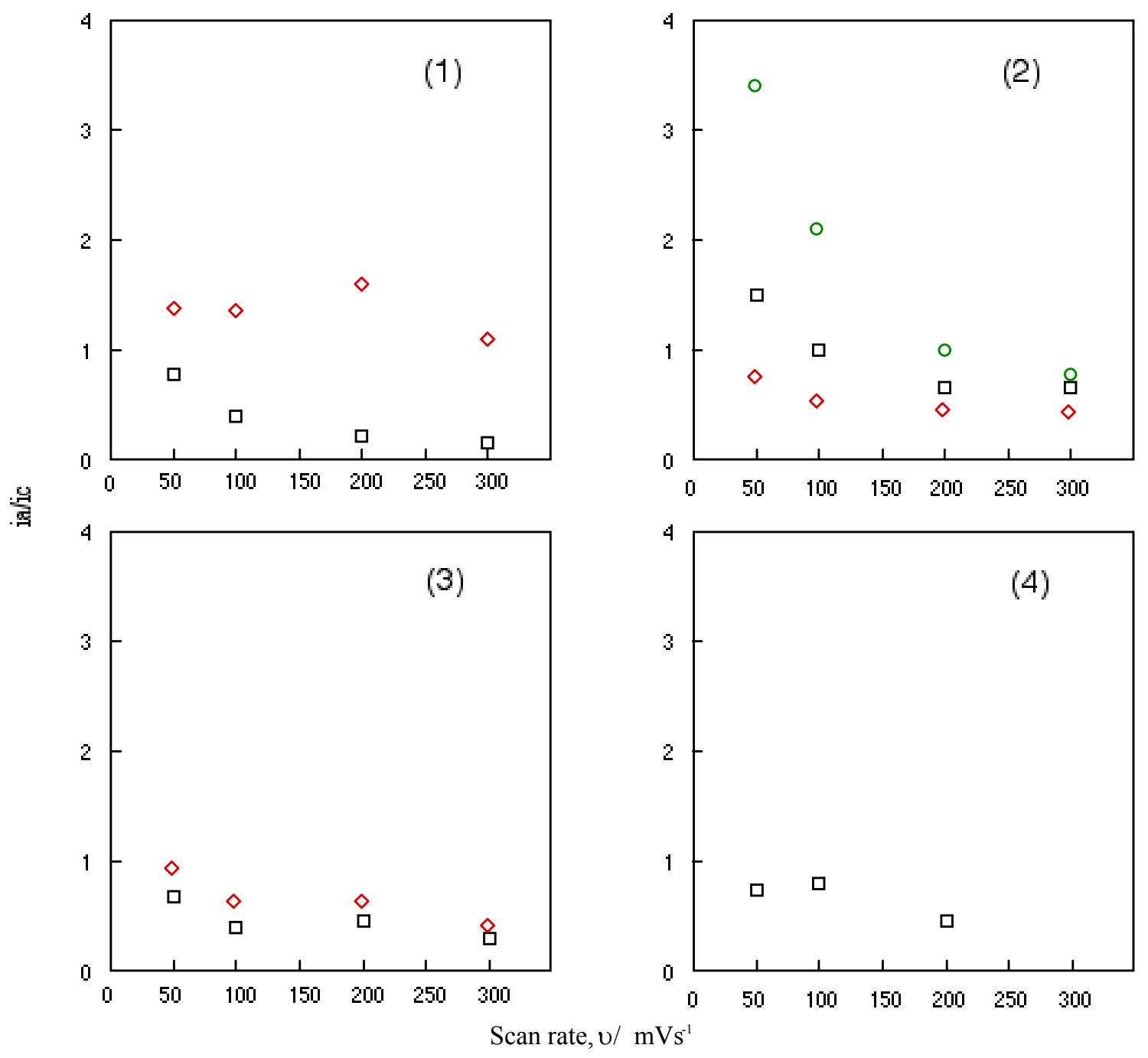

The potentials of anodic to cathodic peak potential $\Delta \mathrm{E}$ are around $100 \mathrm{mV}$, except for cobalt-2. Extrapolated to zero scan rate, $v$, the $\Delta \mathrm{E}$ values approach close to $60 \mathrm{mV}$. These data suggest that the electrode processes of cobalt-1, 2, 3 and $\mathbf{4}$ take place by almost one-electron transfer. The midpoint potential of cathodic to anodic peak, $E_{\text {mid }}$ is independent of scan rate, $v$ and have constant values. Consequently, it is thought that these electrode processes are complicated diffusion-controlled electron transfers involving some weak adsorption with the oxide of cobalt-1, 2, 3 and 4.

Figure 7 shows chronoamperometry and the slope calculated from Cottrell plots of cobalt-1 and 2. The current of the Cottrell plot is a measurement of the rate for electrolysis at the electrode surface. Electrolysis is controlled with a mass transfer by diffusion on the electrode so that the diffusion constant implies the rate of electrolysis. The slope means the diffusion constant in each step, and the forward step indicates the reduction reaction and the reverse step is oxidation. The oxidation processes 
of cobalt-1 and $\mathbf{2}$ are slower than the reduction. The oxidation of cobalt-1 was lower than cobalt-2, while cobalt-2 was lower reduction ability than cobalt-1.

Figure 7. Chronoamperometry and the slope calculated from Cottrell plot of cobalt phthalocyanine tetrasulfonic acid. Potential step; $-1.2-1.6 \mathrm{~V}$ vs. $\mathrm{Ag} / \mathrm{AgCl}$, time interval: $250 \mathrm{~ms}$. (1) Cobalt phthalocyanine tetrasulfonic acid. (2) Cobalt phthalocyanine octacarboxylic acid.

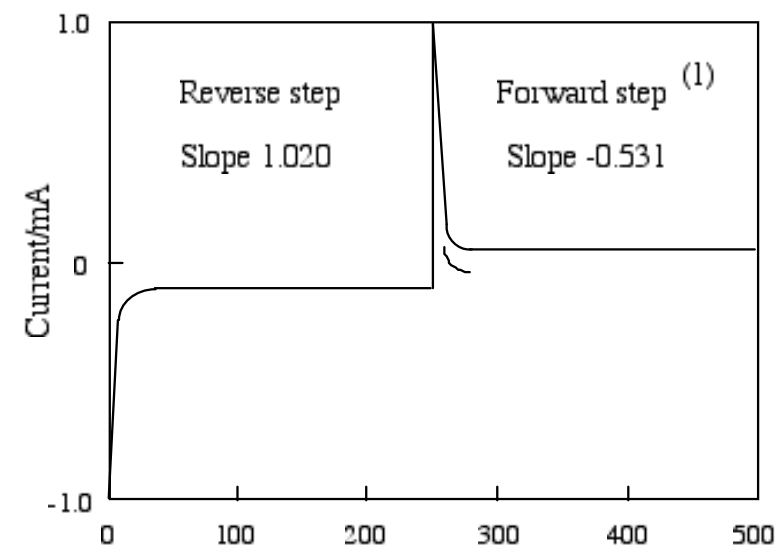

Time/ms

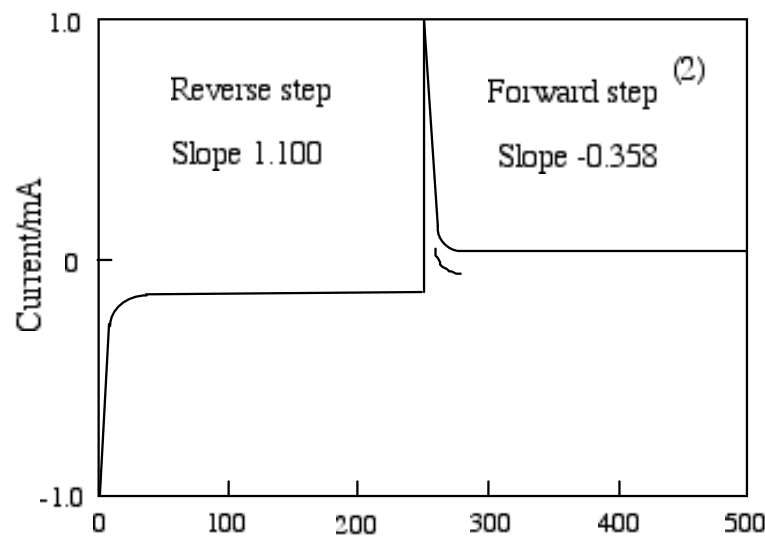

Time/ms

The chronocoulometry was measured by a chronoamperometry treatment in which the current response was integrated to give a response to the charge. The charge-time curve of the forward step for chronocoulometry is the chronoamperometric integral .

The extent of diffusion control increases systematically as the standard potential becomes positive for cobalt-1 and 2. In the case of cobalt-1, the electron charge was reached at about $30 \mu \mathrm{C}$ in the forward step and was decreased to $15 \mu \mathrm{C}$, and reverse steps were attenuated to $0 \mu \mathrm{C}$ with $70 \mathrm{~ms}$ in the reduction side from -1200 to $0 \mathrm{mV}$ vs. $\mathrm{Ag} / \mathrm{AgCl}$ potential. In the oxidation side from the 0 to $+1,600 \mathrm{mV}$ vs. $\mathrm{Ag} / \mathrm{AgCl}$ step, chronocoulometry had a linear forward step and a flat reverse step indicating no faradic activity for all compounds. It is thought that reduction and oxidation take place in different pathways.

Figure 8 shows the chronoamperometry of cobalt-3 following applied voltage pulse from -1,200 to $0 \mathrm{mV}$ vs. $\mathrm{Ag} / \mathrm{AgCl}$ and from $-1,200$ to $+1,600 \mathrm{mV}$ vs. $\mathrm{Ag} / \mathrm{AgCl}$, and the reversible pulse. Chronoamperometry involves the measurement of the current-time response to a potential step excitation signal. A large cathodic current flows immediately when the potential is stepped up from the initial value, after that it slowly attenuates. The reduction step exhibited the same behavior in comparison with both potential steps.

The current - time curve for chronoamperometry is expressed by the Cottrell Equation (1):

$$
\mathrm{i}=\frac{\mathrm{nFACD}^{1 / 2}}{\pi^{1 / 2} \mathrm{t}^{1 / 2}}=\mathrm{Kt}^{-1 / 2}
$$


where, i: current (A), n: number of electrons transferred per ion or molecule $\left(\mathrm{mol}^{-1}\right)$, F: Faraday's constant $(96,485 \mathrm{C} / \mathrm{mol})$, A: electrode area $\left(2.0 \cdot 10^{-2} \mathrm{~cm}^{2}\right), \mathrm{C}$ : concentration $\left(\mathrm{mol} / \mathrm{cm}^{3}\right)$, D: diffusion constant $(\mathrm{cm} / \mathrm{s})$, t: time $(\mathrm{s})$.

Figure 8. Chronoamperometry of cobalt phthalocyanine tetrasulfonic acid. (A) Potential step; -1.2-0.0 V vs. $\mathrm{Ag} / \mathrm{AgCl}$, step width: $250 \mathrm{~ms}$. (B) Potential step; -1.2-1.6 V vs. $\mathrm{Ag} / \mathrm{AgCl}$, step width: $250 \mathrm{~ms}$.

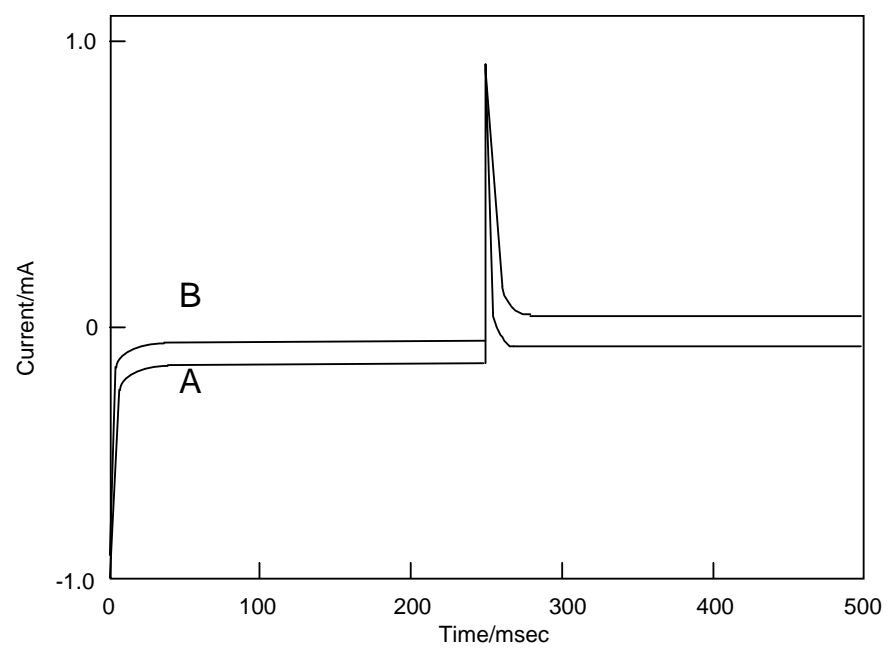

Electron processes in the systems are the diffusion-controlled electron transfers mentioned above. Relationships between the current and square root of time are considered to respresent a finite diffusion for cobalt-1, 2, 3 and 4. Table 6 shows the slope of the relationships between the current and square root of time (Cottrell plots). The current of the Cottrell plot is a measure of the rate for electrolysis at the electrode surface. Electrolysis is controlled with a mass transfer by diffusion on the electrode so that the diffusion constant implies the rate of electrolysis. In this table, the slope means the diffusion constant in each step, and the forward step indicates the reduction reaction and the reverse step is oxidation. The oxidation processes of cobalt-1, 2, $\mathbf{3}$ and $\mathbf{4}$ are faster than the reduction. The oxidation was decreased in the following order: cobalt-2, 1, 3 and 4. On the other hand, the reduction decreased in the following order: cobalt-3, 1, 2 and 4.

Table 6. The slope and intercept of Cottrell plot for cobalt phthalocyanine derivatives.

\begin{tabular}{ccccc}
\hline \multirow{2}{*}{ Compound } & \multicolumn{2}{c}{ Forward step / mA } & \multicolumn{2}{c}{ Reverse step / mA } \\
\cline { 2 - 5 } & Slop & Intercept & Slop & Intercept \\
\hline $\mathbf{1}$ & -0.531 & -0.0631 & 1.020 & 0.00596 \\
$\mathbf{2}$ & -0.358 & -0.106 & 1.100 & -0.00274 \\
$\mathbf{3}$ & -0.525 & -0.0360 & 0.670 & -0.000172 \\
$\mathbf{4}$ & -0.322 & -0.0632 & 0.698 & 0.00547 \\
\hline
\end{tabular}


Chronocoulometry was measured by a chronoamperometry treatment in which the current response was integrated to give a response of the charge. The charge-time curve of the forward chronocoulometry step for $\mathrm{c}$ is the integral of Equation (1):

$$
\mathrm{Q}=\frac{2 \mathrm{nFACD}}{\pi^{1 / 2} \mathrm{t}^{1 / 2}}=2 \mathrm{Kt}^{1 / 2}
$$

This is called the Anson Equation (2).

The reverse step is the following equation:

$$
\mathrm{Q}_{\mathrm{r}}=\frac{2 \mathrm{nFACD} \mathrm{D}^{1 / 2}}{\pi^{1 / 2}}\left\{\tau^{1 / 2}+(\mathrm{t}-\mathrm{r})^{1 / 2}-\mathrm{t}^{1 / 2}\right\}
$$

Figure 9 shows the chronocoulometry of cobalt-1, 2, 3 and 4. The initial potential in each case was $1,200 \mathrm{mV}$ vs. $\mathrm{Ag} / \mathrm{AgCl}$ and the step width was $250 \mathrm{~ms}$. The step potential was $+1,600 \mathrm{mV}$ vs. $\mathrm{Ag} / \mathrm{AgCl}$.

Figure 9. Chronocoulometry of cobalt phthalocyanine tetrasulfonic acid. Potential step; -1.2-1.6 V vs. $\mathrm{Ag} / \mathrm{AgCl}$, time interval: $250 \mathrm{~ms}$. (1) Cobalt phthalocyanine tetrasulfonic acid. (2) Cobalt phthalocyanine octacarboxylic acid. (3) Cobalt octakis(hexoxymethyl)phthalocyanine. (4) Cobalt antraquinocyanine.
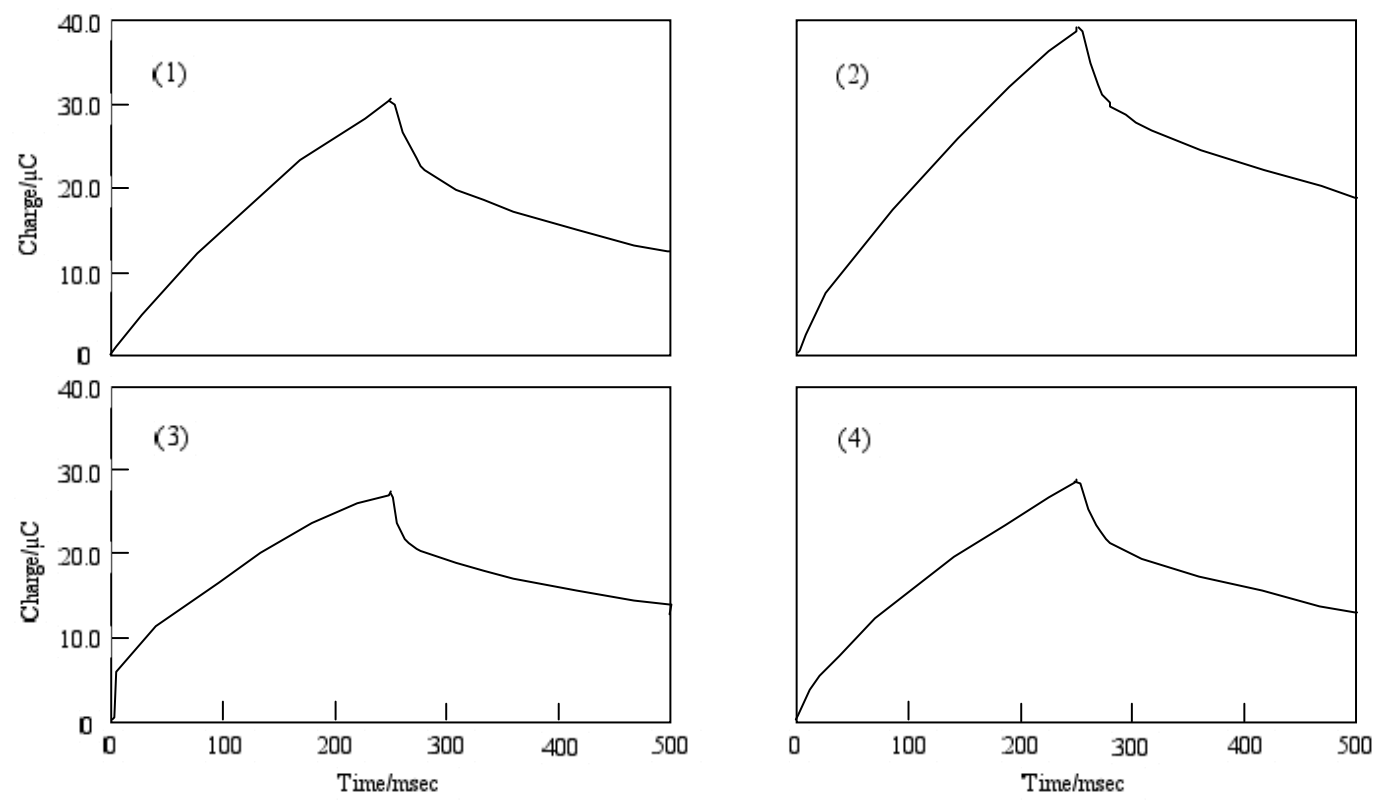

For cobalt-1, 2, 3 and 4, the extent of diffusion control increases systematically as the standard potential becomes positive. The electron charge was reached at about $30 \mu \mathrm{C}$ in the forward step and was decreased to $15 \mu \mathrm{C}$, except for cobalt-2. In the chronocoulometry of the reduction side from 1,200 to $0 \mathrm{mV}$ vs. $\mathrm{Ag} / \mathrm{AgCl}$ potential, reverse steps were attenuated to $0 \mu \mathrm{C}$ with $70 \mathrm{~ms}$, except for cobalt-2. In the oxidation side from the 0 to $+1600 \mathrm{mV}$ vs. $\mathrm{Ag} / \mathrm{AgCl}$ step, chronocoulometry had a linear forward step and a flat reverse step indicating no faradic activity for all compounds. 
Figure 10 shows Anson plots, which are converted from the charge-time curve of chronocoulometry into the relation between charge and square root of time. Only the value of solution species (Q) in three terms depends upon the scanning time. The intercept of the Anson plot expresses the sum of a double layer charging $\left(\mathrm{Q}_{\mathrm{dl}}\right)$ and electrolysis of adsorbed $\left(\mathrm{Q}_{\mathrm{ads}}\right)$. Since double step chronocoulometry is used in this work, $Q_{\text {ads }}$ can take away $Q_{\mathrm{dl}}$ which is a value of the difference of intercepts between forward and reverse steps. When no adsorption of reactant or product, the intercept of Anson plot for both forward and reverse steps are $\mathrm{Q}_{\mathrm{d} \mathrm{l}}$. While reactant adsorbs but product does not, the intercept of the reverse is a measure of $\mathrm{Q}_{\mathrm{dl}}$ in the presence of adsorbed reactant, and the intercept of the forward step contains both $\mathrm{Q}_{\mathrm{dl}}$ and $\mathrm{Q}_{\mathrm{ads}}$ for adsorbed reactant.

Figure 10. Anson plots of cobalt phthalocyanine tetrasulfonic acid (1) and cobalt phthalocyanine octacarboxylic acid (2).
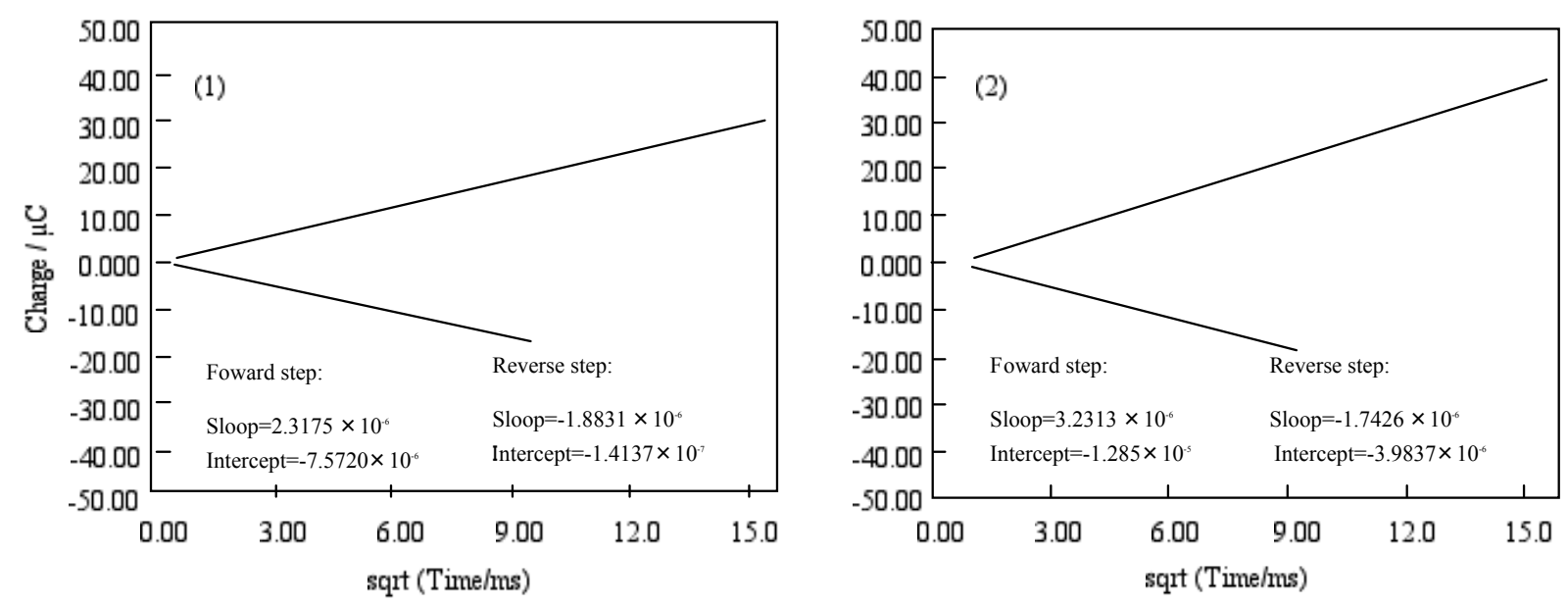

The chronocoulometry of cobalt-1 and $\mathbf{2}$ shows that the reactant is adsorbed but not the product. The $\mathrm{Q}_{\mathrm{ads}}$ was found from the calculation to be 7.40 and $8.92 \mu \mathrm{C}$ for cobalt-1 and 2, respectively. Hence, the $\mathrm{Q}_{\mathrm{dl}}$ was estimated to be $0.53 \mu \mathrm{C}$ at $0 \mathrm{~ms}$ of the chronocoulometry for cobalt-1 and 2 .

The relation between $\mathrm{Q}_{\mathrm{r}} / \mathrm{Q}_{\mathrm{f}}$ and the square root of time can be estimated by the mechanism and rate of the following chemical reaction. The value $\mathrm{Q}_{\mathrm{r}} / \mathrm{Q}_{\mathrm{f}}$ indicates the base line for the chronocoulometry of the reverse step charge $Q_{\mathrm{r}}$ divided by the final value of forward step $\mathrm{Q}_{\mathrm{f}}$. It was found that the following chemical reaction obeyed first-order kinetics, which found the calculation to be 0.20 and $0.26 \mathrm{~s}^{-1}$ for cobalt-1 and 2. It is thought that reduction and oxidation take place in different pathways, where especially cobalt-2 exhibits characteristic behavior.

Chronocoulometry gives rise to $\mathrm{Q}_{\mathrm{dl}}$, and $\mathrm{Q}_{\mathrm{ads}}$ and $\mathrm{Q}$ in the initial potential step:

$$
\begin{gathered}
\mathrm{Q}_{\text {total }}=\frac{2 \mathrm{nFACD}{ }^{1 / 2} \mathrm{t}^{1 / 2}}{\pi^{1 / 2}}+\mathrm{Q}_{\mathrm{dl}}+\mathrm{Q}_{\mathrm{abs}} \\
\mathrm{Q}_{\mathrm{abs}}=\mathrm{nF} \mathrm{A} \Gamma
\end{gathered}
$$

where, $\mathrm{Q}_{\mathrm{dl}}$ : double layer charge $(\mathrm{C}), \mathrm{Q}_{\mathrm{ads}}$ : absorbed species charge $(\mathrm{C}), \Gamma$ : amount of adsorbed $\left(\mathrm{mol} / \mathrm{cm}^{3}\right)$. 
With regards to the adsorption using equations (2) and (3), the $\mathrm{Q}_{\mathrm{abs}}$ was found from calculation to be 7.40, 8.92, 2.81 and $7.07 \mu \mathrm{C}$ for cobalt-1, 2, 3 and 4, respectively. Hence, the $\mathrm{Q}_{\mathrm{dl}}$ was estimated to be $0.53 \mu \mathrm{C}$ at $0 \mathrm{~ms}$ of the chronocoulometry for cobalt-1, 2, 3 and 4 .

Figure 11 shows the relationships between $\mathrm{Q}_{\mathrm{r}} / \mathrm{Q}_{\mathrm{f}}$, the baseline for the measurement of the reverse step charge $\mathrm{Q}_{\mathrm{r}}$ divided by the final value of the forward step $\mathrm{Q}_{\mathrm{f}}$, and the square root of time. This relationship can be estimated by the mechanism and rate of the following chemical reaction. It is found that the following chemical reaction obeyed first-order kinetics. The kinetic constants are found from calculation to be $0.20,0.26,0.30$ and $0.30 \mathrm{~s}^{-1}$ for cobalt-1, 2, 3 and 4, respectively.

Figure 11. Variatuon of $\mathrm{Q}_{\mathrm{r}} / \mathrm{Q}_{\mathrm{f}}$ with squareroot of time for covalt phthalocyanine derivatives. Potential step; $-1.2-1.6 \mathrm{~V}$ vs. $\mathrm{Ag} / \mathrm{AgCl}$, step width: $250 \mathrm{~ms}$. $\mathrm{Q}_{\mathrm{f}}$ forward step of chronocoulometry; $\mathrm{Q}_{\mathrm{r}}$ forward step of chronocoulometry. $\square$ Cobalt phthalocyanine tetrasulfonic acid; Cobalt phthalocyanine octacarboxylic acid; $\bigcirc$ Cobalt octakis(hexoxymethyl)phthalocyanine; $\triangle$ Cobalt anthraquinocyanine.

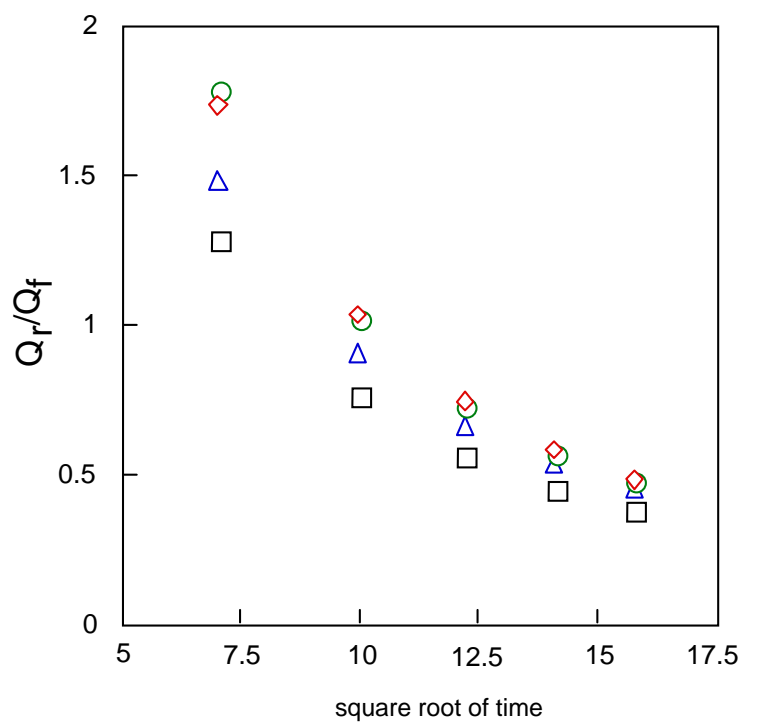

The oxidation of M-PCs having transition metal are electrochemically irreversible [41,46,47] and electrons are added to the orbital of phthalocyanine ring or the central metal depending on the redox potential for reduction process $[47,48,49]$. Consequently, it is considered that electron transfer mechanisms are proposed as the following, for cobalt-1 [50]:

Oxidation step is:

$$
\mathrm{Co}(\mathrm{II})-\mathrm{PC}\left(\mathrm{SO}_{3} \mathrm{H}\right)_{4} \longrightarrow\left[\mathrm{Co}(\mathrm{III})-\mathrm{PC}\left(\mathrm{SO}_{3} \mathrm{H}\right)_{4}\right]^{+}+\mathrm{e}
$$

Reduction steps are:

$$
\begin{aligned}
& \mathrm{Co}(\mathrm{II})-\mathrm{PC}\left(\mathrm{SO}_{3} \mathrm{H}\right) 4+\mathrm{e} \rightleftharpoons\left[\mathrm{Co}(\mathrm{II})-\mathrm{PC}\left(\mathrm{SO}_{3} \mathrm{H}\right)_{4}\right]^{-} \\
& {\left[\mathrm{Co}(\mathrm{II})-\mathrm{PC}\left(\mathrm{SO}_{3} \mathrm{H}\right) 4\right]^{-}+\mathrm{e} \rightleftharpoons\left[\mathrm{Co}(\mathrm{II})-\mathrm{PC}\left(\mathrm{SO}_{3} \mathrm{H}\right)_{4}\right.} \\
& {\left[\mathrm{Co}(\mathrm{II})-\mathrm{PC}\left(\mathrm{SO}_{3} \mathrm{H}\right) 4\right]^{2-}+\mathrm{e} \longrightarrow\left[\mathrm{Co}(\mathrm{I})-\mathrm{PC}\left(\mathrm{SO}_{3} \mathrm{H}\right) 4\right]^{3-}}
\end{aligned}
$$


For cobalt-2 [50]:

Oxidation steps are:

$$
\begin{aligned}
& \mathrm{Co}(\mathrm{II})-\mathrm{PC}(\mathrm{COOH}) 8 \longrightarrow[\mathrm{Co}(\mathrm{III})-\mathrm{PC}(\mathrm{COOH}) 8]^{+}+\mathrm{e} \\
& {[\mathrm{Co}(\mathrm{III})-\mathrm{PC}(\mathrm{COOH}) 8]^{+} \longrightarrow[\mathrm{Co}(\mathrm{III})-\mathrm{PC}(\mathrm{COOH}) 8]^{2+}+\mathrm{e}} \\
& {[\mathrm{Co}(\mathrm{III})-\mathrm{PC}(\mathrm{COOH}) 8]^{2+} \rightarrow[\mathrm{Co}(\mathrm{IV})-\mathrm{PC}(\mathrm{COOH}) 8]^{3+}+\mathrm{e}}
\end{aligned}
$$

Reduction steps are:

$$
\begin{aligned}
& \mathrm{Co}(\mathrm{II})-\mathrm{PC}(\mathrm{COOH}) 8+\mathrm{e} \longrightarrow[\mathrm{Co}(\mathrm{II})-\mathrm{PC}(\mathrm{COOH}) 8]^{-} \\
& {[\mathrm{Co}(\mathrm{II})-\mathrm{PC}(\mathrm{COOH}) 8]^{-}+\mathrm{e} \rightleftharpoons[\mathrm{Co}(\mathrm{II})-\mathrm{PC}(\mathrm{COOH}) 8]^{2}} \\
& {[\mathrm{Co}(\mathrm{II})-\mathrm{PC}(\mathrm{COOH}) 8]^{2-}+\mathrm{e} \rightleftharpoons[\mathrm{Co}(\mathrm{I})-\mathrm{PC}(\mathrm{COOH}) 8]^{3-}}
\end{aligned}
$$

For cobalt-3 [51, 52]:

Oxidation steps are:

$$
\begin{aligned}
& \mathrm{Co}(\mathrm{II})-\mathrm{PC}\left(\mathrm{CH}_{2} \mathrm{OC}_{6} \mathrm{H}_{13}\right) 8 \longrightarrow\left[\mathrm{Co}(\mathrm{III}) \mathrm{PC}\left(\mathrm{CH}_{2} \mathrm{OC}_{6} \mathrm{H}_{13}\right) 8\right]^{+}+\mathrm{e} \\
& {\left[\mathrm{Co}(\mathrm{II})-\mathrm{PC}\left(\mathrm{CH}_{2} \mathrm{OC}_{6} \mathrm{H}_{13}\right) 8\right]^{+} \longrightarrow\left[\mathrm{Co}(\mathrm{III})-\mathrm{PC}\left(\mathrm{CH}_{2} \mathrm{OC}_{6} \mathrm{H}_{13}\right) 8\right]^{2+}+\mathrm{e}}
\end{aligned}
$$

Reduction steps are:

$$
\begin{aligned}
& \mathrm{Co}(\mathrm{II})-\mathrm{PC}\left(\mathrm{CH}_{2} \mathrm{OC}_{6} \mathrm{H}_{13}\right) 8 \longrightarrow\left[\mathrm{Co}(\mathrm{I})-\mathrm{PC}\left(\mathrm{CH}_{2} \mathrm{OC}_{6} \mathrm{H}_{13}\right) 8\right]^{-} \\
& {\left[\mathrm{Co}(\mathrm{I})-\mathrm{PC}\left(\mathrm{CH}_{2} \mathrm{OC}_{6} \mathrm{H}_{13}\right) 8\right]^{-}+\mathrm{e} \rightleftarrows\left[\mathrm{Co}(\mathrm{I})-\mathrm{PC}\left(\mathrm{CH}_{2} \mathrm{O}_{6} \mathrm{H}_{13}\right) 8\right]^{2-}} \\
& \left.\left[\mathrm{Co}(\mathrm{I})-\mathrm{PC}\left(\mathrm{CH}_{2} \mathrm{OC}_{6} \mathrm{H}_{13}\right) 8\right]^{2-}+\mathrm{e} \rightleftarrows\left[\mathrm{Co}(\mathrm{I})-\mathrm{PC}^{2} \mathrm{CH}_{2} \mathrm{OC}_{6} \mathrm{H}_{13}\right) 8\right]^{3-}
\end{aligned}
$$

For cobalt-4 [51,52]:

Oxidation steps are:

$$
\begin{aligned}
& \mathrm{Co}(\mathrm{II})-\mathrm{AQC} \longrightarrow[\mathrm{Co}(\mathrm{III})-\mathrm{AQC}]^{+}+\mathrm{e} \\
& {[\mathrm{Co}(\mathrm{III})-\mathrm{AQC}]^{+} \longrightarrow[\mathrm{Co}(\mathrm{III})-\mathrm{AQC}]^{2+}+\mathrm{e}}
\end{aligned}
$$

Reduction steps are,

$$
\begin{aligned}
& \mathrm{Co}(\mathrm{II})-\mathrm{AQC}+\mathrm{e} \rightleftharpoons[\mathrm{Co}(\mathrm{II})-\mathrm{AQC}]^{-} \\
& {[\mathrm{Co}(\mathrm{II})-\mathrm{AQC}]^{-}+\mathrm{e} \rightleftharpoons[\mathrm{Co}(\mathrm{I})-\mathrm{AQC}]^{2-}}
\end{aligned}
$$

The chemical reaction following the reversible redox process is an interaction between the anion of the phthalocyanine ring and a solvent molecule. It is thought that the ring current of M-PCs such as $\mathbf{1}$, $\mathbf{2}$ and $\mathbf{3}$ consists of five components, corresponding to one porphyrazine and four phenylene rings, as shown in Figure 12(a).

The molecules of $\mathbf{4}$ are also planar, symmetrical and possess a highly aromatic organic system due to the presence of its highly conjugated $\pi$ electron system. For this reason, 4 can be expected to have an effect on the electron transfer for anthraquinone units in the molecules. Anthraquinone-like 
properties were not observed for 4, which showed reversible two step one-electron redox reactions, and were similar to $\mathbf{1}$ and 2, so the anthraquinone units in $\mathbf{4}$ apparently had no effect on the electron transfer ability in itself, so we may conclude that the ring current constituents of $\mathbf{4}$ are different from those of M-PCs. It is believed that the $\pi$ electron ring current of metal anthraquinocyanines is not made up of five loops. As the $\mathbf{4}$ are also conjugated planer molecules, the $\pi$ electrons of the anthraquinone units are incorporated into the macrocyclic conjugated path of the porphyrazine ring shown in Figure 12(b). As a result of the formation of a simple loop current on 4, the redox property of anthraquinone covers the macrocyclic delocalized $\pi$ electrons.

Figure 12. Ring current model of phthalocyanine ring and anthraquinocyanone ring. (a) Five-loop model. (b) Single-loop model.

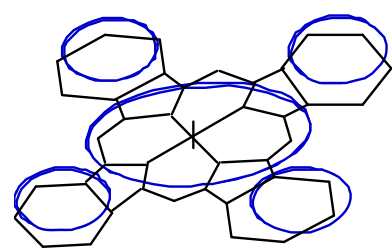

(a)

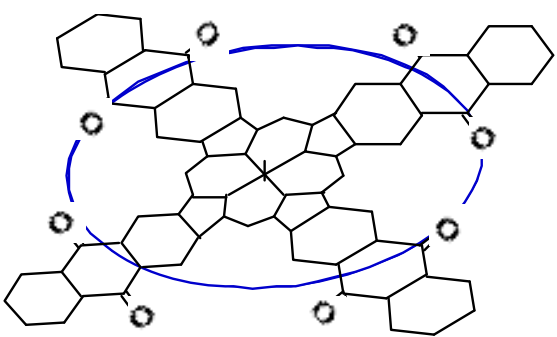

(b)

The important parameters of a CV are the reduction and oxidation potentials for irreversible peaks, and the mid-point potential for a reversible couple, $E_{\text {mid }}$ (Table 7). Before separation of positional isomers, the reduction and oxidation potentials of $5 \mathrm{c}$ are sorted into six irreversible peaks.

After separation, fractions 1 - 3 have one pair of reversible oxidation potential and four irreversible peaks. Fraction 4 has one pair of reversible oxidation and three irreversible reduction waves. The reduction and oxidation of M-PCs are due to the interaction between the phthalocyanine ring and the central metal $[49,53,54]$.

Table 7. Redox potentials of $5 \mathrm{c}$ and its regioisomers.

\begin{tabular}{|c|c|c|c|c|c|c|c|}
\hline \multirow{3}{*}{\multicolumn{2}{|c|}{$\begin{array}{l}\text { Compound } \\
\text { 5c, before regioisomer separation }\end{array}$}} & \multicolumn{6}{|c|}{ Potential / V vs. Ag/AgCl } \\
\hline & & \multicolumn{4}{|c|}{ Reduction } & \multicolumn{2}{|c|}{ Oxidation } \\
\hline & & $-0.97 *$ & $-0.71 *$ & $-0.45^{*}$ & $0.15^{*}$ & $0.37 *$ & $0.93 *$ \\
\hline \multirow[t]{2}{*}{ Fraction 1} & & $-1.00^{*}$ & $-0.58 *$ & $-0.24 *$ & & 0.44 & $0.93 *$ \\
\hline & $\Delta \mathrm{E}^{* *}$ & & & & & 0.17 & \\
\hline \multirow{2}{*}{ Fraction 2} & & $-1.05^{*}$ & $-0.60 *$ & $-0.19^{*}$ & & 0.37 & 0.90 \\
\hline & $\Delta \mathrm{E}^{* *}$ & & & & & 0.10 & \\
\hline \multirow{2}{*}{ Fraction 3} & & $-0.96^{*}$ & $-0.65^{*}$ & $-0.22 *$ & & 0.37 & $0.89^{*}$ \\
\hline & $\Delta \mathrm{E}^{* *}$ & & & & & 0.13 & \\
\hline \multirow[t]{2}{*}{ Fraction 4} & & $-0.87 *$ & $-0.63 *$ & $-0.21 *$ & & 0.34 & \\
\hline & $\Delta \mathrm{E}^{* *}$ & & & & & 0.01 & \\
\hline
\end{tabular}

Potentials of reversible wave are midpoint of anodic and cathodic praks for each couple, $\mathrm{E}_{1 / 2}$.

*Irreversible peak. ${ }^{* *}$ The anodic peak to cathodic peak separation for reversible couple. 
The porphyrazine ring in the molecules of metal phthalocyanine derivatives or analogues is influenced by the $\pi$ electrons around the closed system [16,27,32,51,55]. Although the $\pi$ electron systems of 5c and fractions 1-4 consist of one porphyrazine, two pyridinoids and two didecylsubstituted phenylene rings, the locations of these rings, except for the porphyrazine, are different for each positional isomer. The irreversible peaks are attributed to the oxidation of the central metal and the reversible couples represent the redox of the phthalocyanine ring [53].

Substituents and pyridinoid rings influenced the $\pi$ electron environment in the compounds $\mathbf{5 c}$ and fractions 1-4. It is thought that the effect of pyridinoid rings gives rise to changes of the electron density of the M-PCs. The difference of reduction and oxidation peaks between fractions 1-4 is attributed to the effect of the variation of the interaction between the central metal and the alkylbenzoporphyrazine. Then, the difference of CV between the $5 c$ and fractions $1-4$ is also the effect of the interaction, since $\mathbf{5 c}$ is a mixture of its positional isomers.

The $\Delta \mathrm{E}$ values are the anodic peak to cathodic peak separation located in the oxidation potential region. The $\Delta \mathrm{E}$ values are around $100 \mathrm{mV}$ and the redox processes are the same for positional isomers, except for fraction 4 . This means that the electron process of position isomers between fractions 1-3 involve approximately one electron transfer. The $\Delta \mathrm{E}$ values of fraction 4 show different behavior in comparison to the others. It is thought that the different behavior for fraction 4 is attributable to the mixture of two types of $C_{2 v}$ positional isomers. In other words, the reduction and oxidation potentials of fraction 4 are based on the interaction between two types of $C_{2 v}$ positional isomers. No observation on the reversible couple in $5 \mathbf{c}$ resulted in any interaction between the positional isomers.

The potential difference between the reduction and oxidation is expressed in the HOMO - LUMO energy gap [41]. The values of $\lambda_{\max }$ in the $\mathrm{Q}$ band correlated with the potential difference between the reduction and oxidation. Figure 13 shows CVs of $\mathbf{6 a}$ and $\mathbf{6 f}$. The reduction and oxidation potentials of 6 are summarized in Table 8. The reported potentials are the midpoint potential of the anodic and cathodic peaks for each couple $\mathrm{E}_{\text {mid, }}$, and the peak potential for an irreversible step.

Figure 13. Cyclic voltammograms of subphthalocyanine derivatives in acetonitrile with tetrabutylammonium perchlorate. (1) Subphthalocyanine 6a. (2) hexakis(S-phenyl)hexafluorosubphthalocyanine $\mathbf{6 d}$.
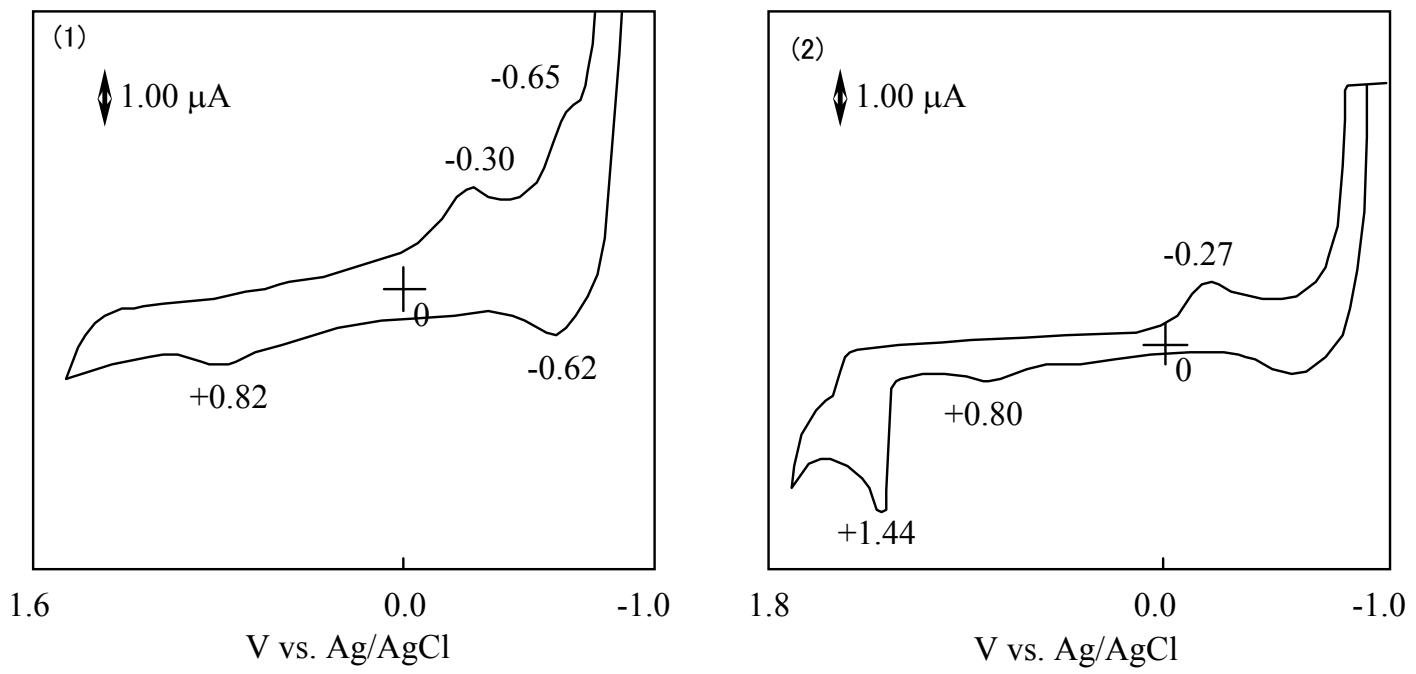
Table 8. Reduction and reduction potentials of $\mathbf{6}$.

\begin{tabular}{|c|c|c|c|c|c|c|}
\hline \multirow{2}{*}{\multicolumn{2}{|c|}{ Compound }} & \multicolumn{5}{|c|}{ Potential / Vvs. Ag/AgCl } \\
\hline & & \multicolumn{2}{|c|}{ Reduction } & \multicolumn{3}{|c|}{ Oxidation } \\
\hline \multirow[t]{2}{*}{$6 a$} & & -0.64 & $-0.30 *$ & & $0.82 *$ & \\
\hline & $\Delta \mathrm{E}^{* *}$ & 0.03 & & & & \\
\hline $6 \mathbf{b}$ & & $-0.51^{*}$ & & $0.25^{*}$ & $0.79^{*}$ & \\
\hline \multirow[t]{2}{*}{$6 c$} & & $-0.56^{*}$ & $-0.28 *$ & & 0.83 & \\
\hline & $\Delta \mathrm{E}^{* *}$ & & & & 0.03 & \\
\hline 6d & & $-0.61 *$ & $-0.37 *$ & $0.18^{*}$ & & \\
\hline $6 e$ & & & $-0.27 *$ & & $0.80^{*}$ & $1.44 *$ \\
\hline $6 f$ & & $-0.57 *$ & $-0.36^{*}$ & $0.18^{*}$ & & \\
\hline
\end{tabular}

Potentials of reversible wave are midpoint of anodic and cathodic praks for each couple, $\mathrm{E}_{1 / 2}$ * Irreversible peak. $* *$ The anodic peak to cathodic peak separation for reversible couple.

The cyclic voltammogram of $\mathbf{6 a}$ showed two cathodic peaks at -0.30 and $-0.65 \mathrm{~V} \mathrm{vs}$. $\mathrm{Ag} / \mathrm{AgCl}$, and two anodic peaks at 0.82 and $-0.62 \mathrm{~V}$ vs. $\mathrm{Ag} / \mathrm{AgCl}$. Compound $6 \mathrm{a}$ has two irreversible oxidation and reduction at 0.82 and $-0.30 \mathrm{~V}$ vs. $\mathrm{Ag} / \mathrm{AgCl}$, and one pair of reversible reduction potential at $-0.64 \mathrm{~V}$ vs. $\mathrm{Ag} / \mathrm{AgCl}$.

The reduction and oxidation behavior of $\mathrm{M}-\mathrm{PCs}$ are due to the interaction between the phthalocyanine ring and the central metal [55]. In the case of M-PCs having cobalt as the central metal, phthalocyanine ring oxidation occurred after the central metal, and this reduction was followed by the reduction of the central metal $[50,54,56]$.

In the case of M-PCs, the porphyrazine ring in the molecule is influenced by the $\pi$ electrons around the closed system. The $\pi$ electron system of M-PCs consists of one porphyrazine and four phynylene rings $[27,32,50]$. Substituents on the M-PCs influence the $\pi$ electron environment in the molecule, especially the four phynylene rings. It is thought that the effect of substituents gives rise to the change of electron density of the four phynylene rings in the molecules of M-PCs. Electron transfer properties of M-PCs depend on the kind of the substituents.

In the case of 6, redox potentials had various values, but one irreversible reduction potential certainly appeared around $-0.3 \mathrm{~V}$ vs. $\mathrm{Ag} / \mathrm{AgCl}$. In $\mathrm{SubPC}$, the reduction potentials showed at $-0.64 \mathrm{~V}$ vs. $\mathrm{Ag} / \mathrm{AgCl}$ and the oxidation potential appeared at $0.82 \mathrm{~V}$ vs. $\mathrm{Ag} / \mathrm{AgCl}$. It is concluded that the irreversible peaks around $-0.3 \mathrm{~V}$ vs. $\mathrm{Ag} / \mathrm{AgCl}$ can be attributed to the reduction of the subphthalocyanine ring. The difference of cyclic voltammogram between SubPCs is attributed to the variation of the substituents that depends on the SubPC ring.

\subsection{Photochemistry}

Figure 14 shows the Jablonski diagram, which is a scheme of radiationless transition process and emission of radiation (fluorescence and phosphorescence). In general, photochemical reactions occur in triplet states. Triplet state lifetimes are known to be between $100 \mathrm{~ns}$ and $10 \mathrm{~s}$. The lifetime of excited 
singlet states is too short for a typical chemical reactions. Photochemical properties were measured the triplet state lifetime using laser-flash photolysis.

Laser-flash photolysis in film was performed using a total reflection sapphire cell $(10 \cdot 30 \mathrm{~mm}, 1$ $\mathrm{mm}$ thickness, and both side were cut at a 45 degree angle) [57,58], which was spin-coated with a thick of $1.2 \mu \mathrm{m}$ SubPC containing 10\% poly(methylmethacrylate) (PMMA) in cyclohexane photopolymer film as shown in Figure 15. The excitation light pulse from a Spectron Laser System Model SL402 YAG laser was expanded five-fold over the entire sample cell. A xenon lamp was used as a monitoring beam $[57,58]$.

The measurement was repeated five times with less than $3 \mathrm{wt} \%$ of 6 and 2,4,6-tris(trichloromethyl)1,3,5-triazine (TCT) as a quencher; more than $90 \%$ of the $355 \mathrm{~nm}$-laser light absorbed in the sample film was absorbed by 6 .

Films were prepared as follows; the compounds $\mathbf{6}$ were added to this solution either by dissolving the dyes directly in polymer solution or by mixing a potion of concentrated dye solution. Films were adjusted to be $1.2 \mu \mathrm{m}$ thick by spin-coating a solution onto a sample cell.

Figure 14. Jablonski diagram.

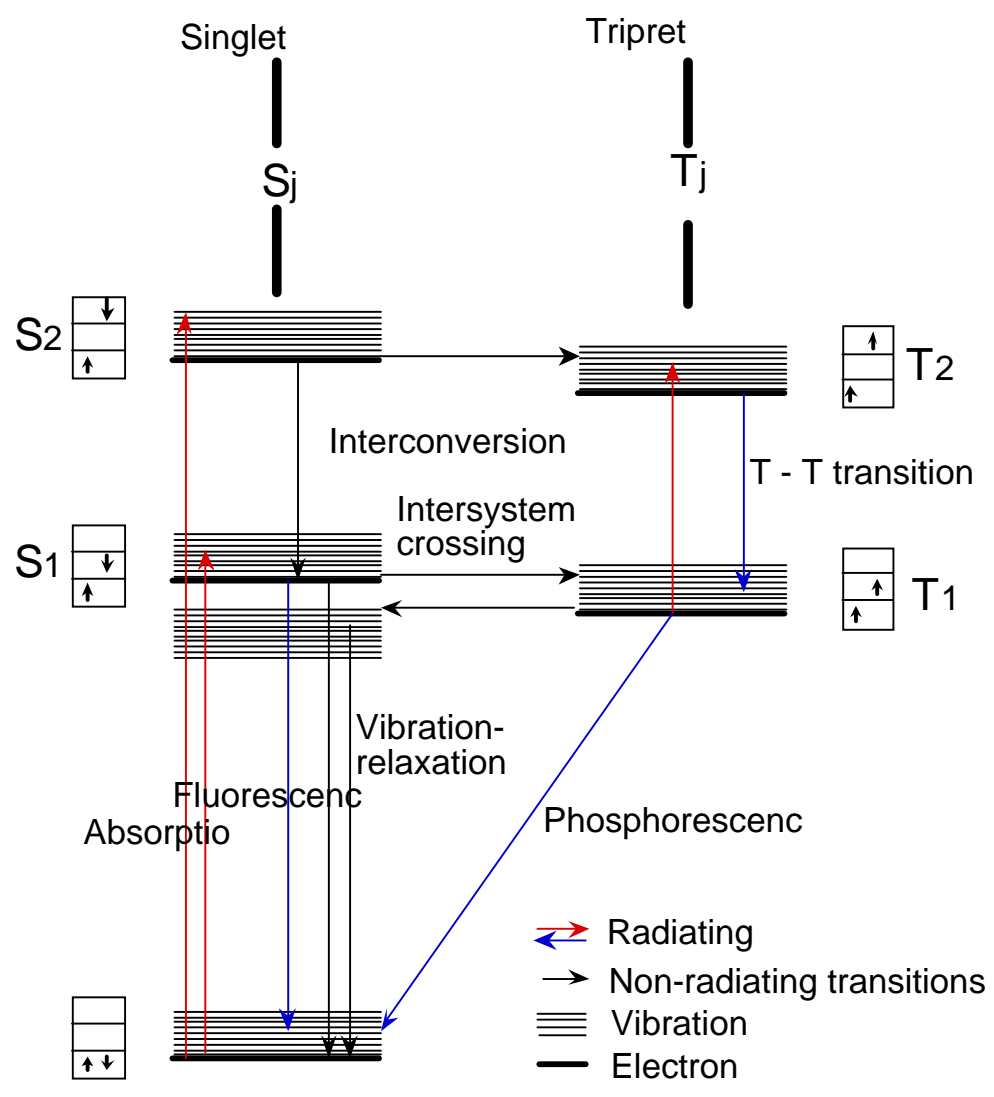

Light absorption $10^{15} \mathrm{~s}^{-1}$

Phosphorescence $10^{-2}$ to $10^{4} \mathrm{~s}^{-1}$

Fluorescence $10^{6}$ to $10^{9} \mathrm{~s}^{-1} \quad$ (Lifetime $10^{-7}$ to $10^{-2} \mathrm{~s}$ in liquid)

(Lifetime $10^{-9}$ to $10^{-7} \mathrm{~s}$ ) (Lifetime $10^{-3}$ to $10^{1} \mathrm{~s}$ in solid) 
Figure 15. Laser flash photolysis in film.

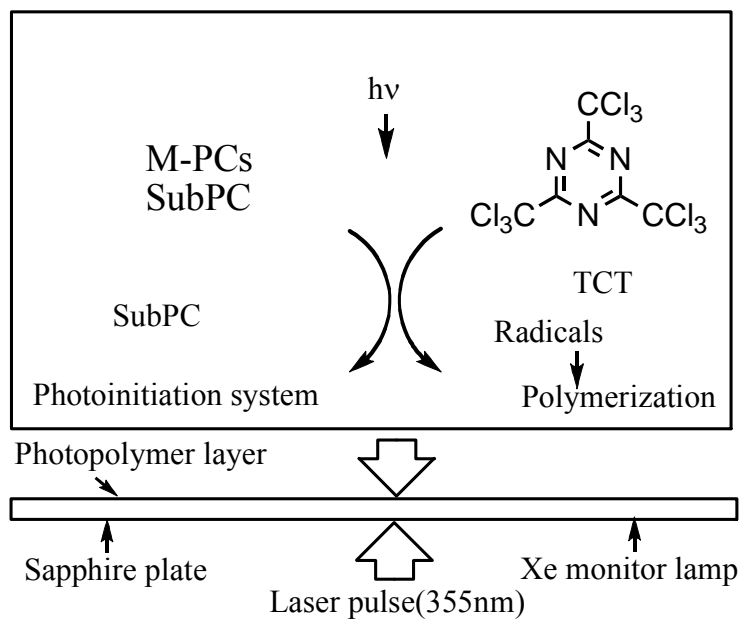

The photosensitivity of the photoinitiator system was measured as follows; the sensitive layer which was prepared by coating a cyclohexane solution of the photosensitive composition containing $5 \mathrm{wt} \%$ of the 6, $5 \mathrm{wt} \%$ of TCT, $45 \mathrm{wt} \%$ of trimethylrolpropane triacrylate and $45 \mathrm{wt} \%$ of PMMA (90:10 $\mathrm{mol} \%, \mathrm{MW}=50,000$ ) onto a grained aluminium plate and exposed at $550 \mathrm{~nm}$ by the use of a xenon lamp, which was isolated using a monochrometer.

In the case of laser-flash photolysis of 5c [59], the films were prepared as follows: a $10 \mathrm{wt} \%$ PMMA solution was made up in cyclohexanone, allylbenzopyridoporphyrazines were added to this solution by dissolving to a thickness of $1.2 \mu \mathrm{m}$ thick by spin-coating a solution onto a sapphire cell. After that the films were covered with a poly(vinyl alcohol) (PVA) solution. Figure 16 shows the time profiles of the triplet state for one of the alkylbenzopyridoporphyrazines, 5c in PMMA was observed using laser-flash photolysis.

Figure 16. Decay trace of 5c in PMMA film on $560 \mathrm{~nm}$. Excitation wavelength: $355 \mathrm{~nm}$ in the presence and absence of PVA over coatings.
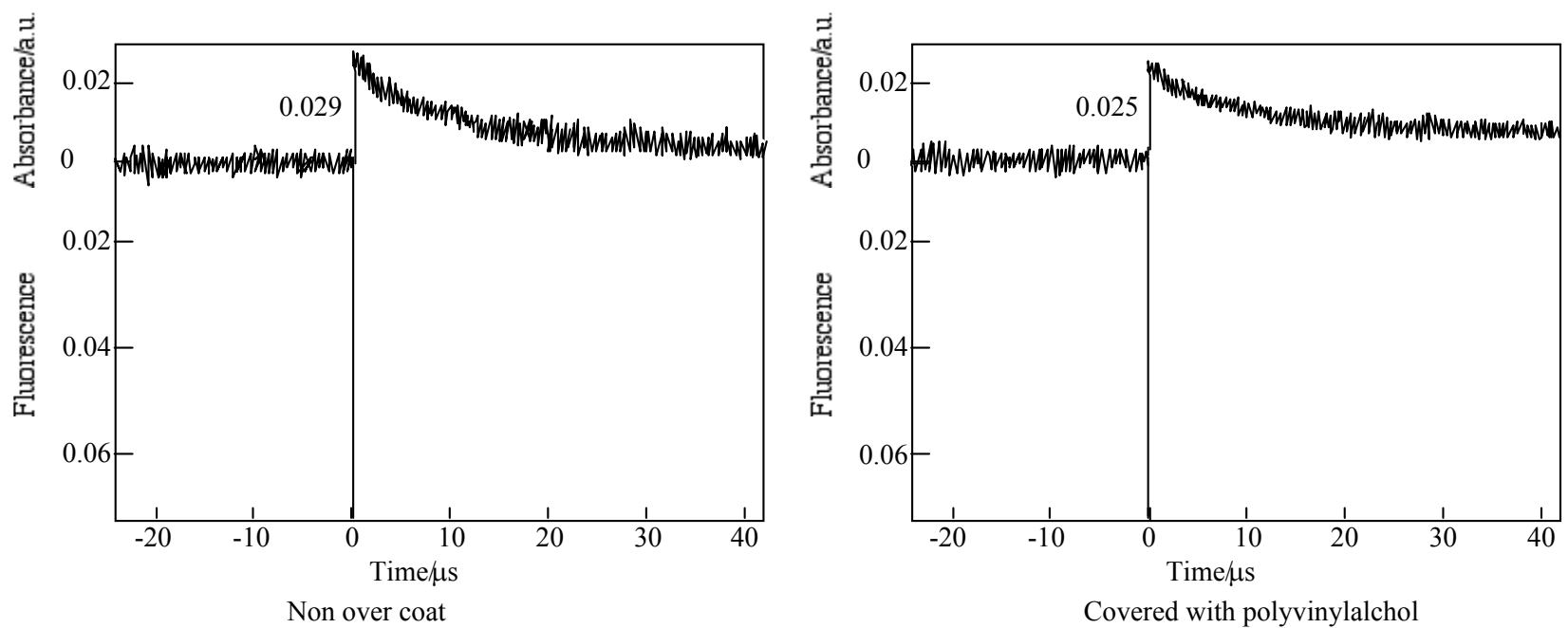

The triplet state lifetimes of alkylbenzopyridoporphyarazines, $\mathbf{5 b}-\mathbf{5} \mathbf{d}$ and $\mathbf{5 e}$ are summarized in Table 9. 
Table 9. Triplet lifetime of alkylbenzopyridoporphyarazines, $\mathbf{5 b}$ - $\mathbf{5 d}$ and $\mathbf{5 e .}$

\begin{tabular}{cccc}
\hline \multirow{2}{*}{ Compound } & Q band / nm & \multicolumn{2}{c}{ Lifetime / $\boldsymbol{\mu s}$} \\
\cline { 2 - 4 } & in PMMA film & Non over coat & Over coat \\
\hline 5b & 675.2 & 11.4 & 51.8 \\
$5 \mathbf{c}$ & 717.6 & 10.1 & 46.9 \\
$5 \mathbf{d}$ & 670.0 & 5.7 & 18.2 \\
5e & 703.9 & 2.6 & 17.9 \\
\hline
\end{tabular}

In each alkylbenzopyridoporphyrazine, it is shown that $\mathbf{5 b}$ and $\mathbf{5 c}$ have longer triplet lifetimes than 5d and 5e. The length of the triplet lifetime for alkylbenzopyridoporphyrazine depends upon its molecular structure. The triplet lifetime of alkylbenzopyridoporphyrazines increased with increasing pyridine numbers in the molecule. It seems that if tetrapyridoporphyrazine 5 a can be soluble in common solvents and measured for laser-flash photolysis, its triplet lifetime will be shown the longest value.

The photoexcited triplet state lifetimes of $\mathbf{5 b}$ and 5c in PMMA without a PVA coating were estimation to be 11.4 and $10.1 \mu \mathrm{s}$, respectively. While covered with a PVA coating, the photoexcited triplet state lifetimes of $\mathbf{5 b}$ and $\mathbf{5 c}$ were estimated as 51.8 and $46.9 \mu \mathrm{s}$, respectively. Compared with each compound, the triplet state lifetime in PMMA covered with PVA was longer than without the PVA coating.

The Q band absorption of alkylbenzopyridoporphyrazines in PMMA films was similar to that in solution, but the profile of Q band in PMMA film became wider than that in solution and moved to a longer wavelength, except for $5 \mathbf{e}$.

Non-transition M-PCs were known to be excellent photosensitizers because of their chemical stability and high absorbance in the $650-700 \mathrm{~nm}$ region [60]. In the presence of a photosensitizer, photooxidation progresses via singlet state oxygen [61-71]. M-PCs in the excited triplet state react with ground triplet state dioxygen. The triplet state dioxygen generated singlet excited state oxygen. The singlet excited oxygen reacts with a substrate to produce oxide, Equations 25 - 27 [33,72].

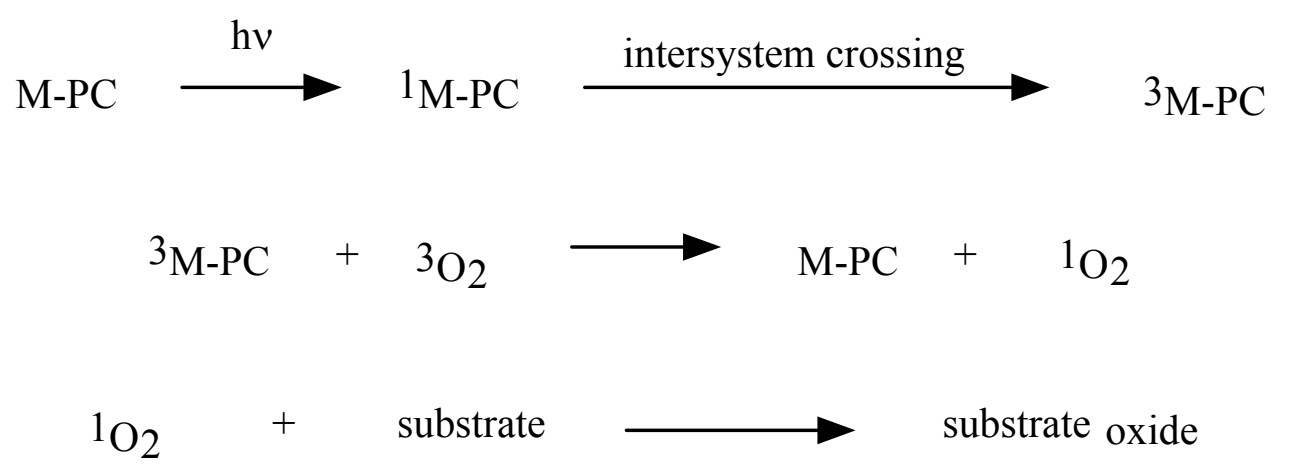

Both covered with a coating and without PVA, the photooxidation proceeded by the same mechanism. However, in the case of being covered with PVA, the photoexited triplet state lifetimes of alkylbenzopyridoporphyrazines, $\mathbf{5 b}-\mathbf{5} \mathbf{d}$ and $\mathbf{5 e}$, were longer than in the case of non-overcoating with PVA. In the case of non-coated with PVA the shorter decay time was considered due to M-PC quenching by oxygen existing in an air atmosphere. While under the coated state with PVA, they 
suppressed the oxygen-permeation from the air atmosphere into the photopolymer layer. As a result, grand triplet state dioxigen was not furnished from the surrounding to the system. Alkylbenzopyridoporphyrazines in the case of being covered with PVA behaved as a model for a practical photosensitizer in tumors or cancer cells.

In comparison with $\mathbf{5 b}$ and $\mathbf{5 c}$, the photoexcited triplet lifetime of $\mathbf{5 b}$ was slightly longer than $\mathbf{5 c}$, the absorption intensities for $\mathbf{5 c}$ were stronger than $\mathbf{5 b}$. So that in these aspects, there is little to choose as a sensitizer for PDT between the two. As Py rings in the molecule of alkylbenzopyridoporphyrazines increased, the water-solubility is expected to increase. In the case of the $N, N^{\prime}, N^{\prime \prime}, N^{\prime \prime \prime}, N^{\prime \prime \prime \prime}$-tetramethylated quaternized forms of tetrapyridoporphyrazines, it was reported that the complexes do not form an aggregation in an aqueous solution [72-74]. Although the long alkylchain substituents in $\mathbf{5 b}$ and $\mathbf{5 c}$ will occur in aggregation, $\mathbf{5 b}$ and $\mathbf{5 c}$ are expected to rapidly undergo photodecomposition after the photooxidation process, similar to alkyl phthalocyanine derivatives [9].

Consequently, since $\mathbf{5 b}$ and $\mathbf{5 c}$ have the most intense absorption and a longer triplet state lifetime, we think 5b and 5c could become useful sensitizers for PDT. The photosensitizer should be made in isomerically pure form [9]. Isomers of $\mathbf{5 b}$ have not been reported yet, but $\mathbf{5} \mathbf{c}$ has been separated and identified [33]. Thereupon, regioisomers of 5c were examined by laser- flash photolysis, and $\mathbf{5 b}$ will be reported in the near future. As mentioned above, the regioisomers of the compound, 5c were separated into four green- to blue-colored fractions by TLC [33]. The four fractions have a different ${ }^{1} \mathrm{H}-\mathrm{NMR}$, UV-VIS and fluorescent spectra. The four fractions separated by TLC have been attributed to four of the five possible region- isomers of $5 \mathbf{c}$.

Figure 17 shows the fluorescence and excitation spectra of 5c. The excitation spectra of $\mathbf{5 c}$ and its fractions have almost the same profile. No significant change on the fluorescence spectra was observed for $5 c$ and its fractions.

Figure 17. Fluorescence and excitationspectra of 5c in DMF. A; Excitation spectrum, B; Fluorescence spectrum.

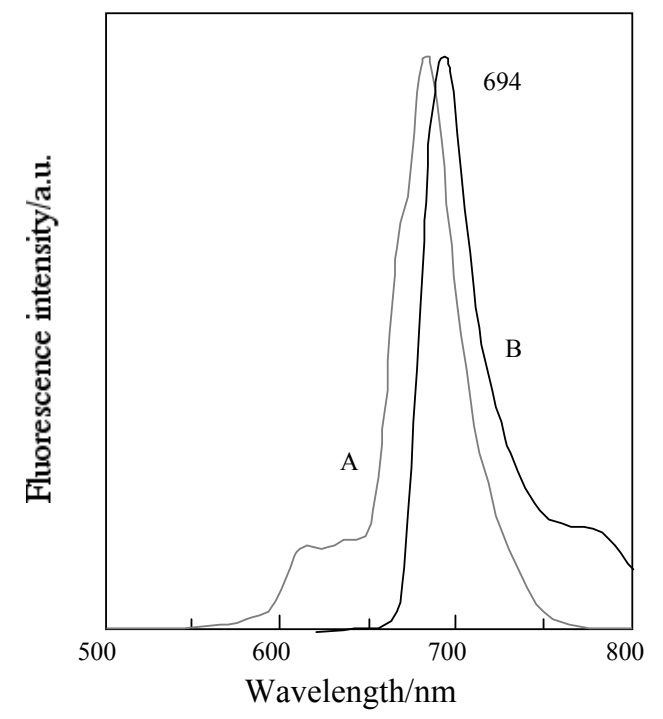

Table 10 shows the $\mathrm{Q}$ band and fluorescent maximum of fractions of 5c. The assignment of the Q band from each fraction was carried out on the theory of the relationship between symmetry and the $Q$ 
band [1,4,74-77]. The Q band splits into two peaks of the highest isomer symmetry, the splitting Q band is decreased with a decreasing symmetry [78]. The symmetry of the position isomer of 5c was decreased in orders of $C_{2 h}, D_{2 h}, C_{2 v}, C_{S}$ [79]. The regioisomers of 5c had molecular structures with $D_{2 h}, C_{2 h}, C_{S}$ and $C_{2 v}$ symmetry for fractions $1,2,3$ and 4, respectively [33]. Two types of $C_{2 v}$ isomers could not be isolated [33].

Table 10. Absorption and fluorescence maxima for each fraction of 5c in solution.

\begin{tabular}{cccc}
\hline Compound & Symmetry & Q band /nm & Fluorescence / nm \\
\hline Fraction 1 & $D 2 h$ & $627,690, \underline{705}$ & 704 \\
Fraction 2 & $C 2 h$ & $609, \underline{673}, 708$ & 706 \\
Fraction 3 & $C s$ & $619, \underline{689}$ & 695 \\
Fraction 4 & $C 2 v$ & $610,638, \underline{671}, 688$ & 701 \\
\hline
\end{tabular}

Under line; mostintense peak.

Table 11 shows the photoexcited triplet lifetime of fractions separated from 5c. In spite of the presence or absence of PVA coatings, the triplet lifetime was increased with a decreasing symmetry of position isomers, which were ordered as $C_{2 h}, D_{2 h}, C_{2 v}$ and $C_{S}$ for fractions $2,1,4$ and 3, respectively. The photoexcited triplet state lifetimes of fraction 3 in PMMA absence and presence of a PVA coating were estimated to be 14.29 and $25.97 \mu$ s, respectively. Of each fraction except for fraction 3 , the length of the lifetime was shorter than $5 c$, and the sensitivities of triplet-triplet (T-T) absorptions were observed as very low.

Table 11. Triplet lifetime of each fraction of $5 c$.

\begin{tabular}{cccc}
\hline \multirow{2}{*}{ Compound } & Q band / nm & \multicolumn{2}{c}{ Lifetime / $\boldsymbol{\mu s}$} \\
\cline { 2 - 4 } & in PMMA film & Non over coat & Over coat \\
\hline Fraction 1 & $782.2,681.6,653.5$ & 7.0 & 11.3 \\
Fraction 2 & 670.0 & 0.9 & 1.6 \\
Fraction 3 & 696.4 & 14.29 & 25.97 \\
Fraction 4 & 665.5 & 6.4 & 9.2 \\
\hline
\end{tabular}

Although the length of the triplet lifetime of 5c was observed to be approximately four times that seen in the absence of a PVA overcoating, the fractions of 5c were only had about 1.5 times as long as triplet lifetimes in comparison with the absence and presence of PVA coatings.

Unfortunately, a precise explanation for this cannot be provided, but it seems to be due to the following phenomenon: phthalocyanine derivatives were well known to aggregate in water and noncoordinating solvents. Zinc non-peripheral phthalocyanine derivatives having long side chains formed an aggregation at least $10^{-5} \mathrm{~mol} \cdot \mathrm{L}^{-1}$ in cyclohexane [9,78]. It is enough thought that the samples in this study for laser-flash photolysis were formed in aggregation in the experimental condition. The aggregation degrees for $\mathbf{5 c}$ and its isomers are different from each other, so the aggregation ability of 5c and each of its isomers is different and complicated. Since compounds $\mathbf{5 b}$ and $\mathbf{5 c}$ consisted of mixtures of their isomers, the aggregation and relationships of the energy levels between samples and 
the triplet state of dioxygen became a complication. For this reason, compounds $\mathbf{5 b}$ and $\mathbf{5 c}$ could give relatively long lifetimes. The molecular structure of fraction 3 is suitable to occur in the T-T absorption in the system.

In order to estimate the photoexcitation mechanism, the triplet lifetime of each fraction was measured, containing $N, N$ '-tetramethyl-4,4'-diaminobenzophenone (Michler's ketone) as an additional quencher. Using Micher's ketone, the lifetimes without PVA coatings were estimated as 21.19 and $14.03 \mu$ s for fractions 3 and 4, respectively (Table 12). These values of lifetime were longer than in the absence of Micher's ketone. In the case of fractions 1 and 2, no T-T absorption occurred. The results were thought to be that each fraction has different energy levels of grand and excited states. The T-T absorption took place via the interactions between the energy levels of grand or excited states of fractions and the triplet of dioxygen or Michler's ketone.

The time profiles of the triplet state for 6 in PMMA film are shown in Figure 18. The fluorescence peak and transient decay were observed upon the excitation at $355 \mathrm{~nm}$ pulse of a PMMA film containing 6. The photoexcited triplet state lifetime of $\mathbf{6}$ was estimated for $20 \mathrm{~s}$ laser pulse. The transient absorption was assigned to a triplet state [78].

Table 12. Triplet lifetime of each fraction of 5c using Micher's ketone as a quencher.

\begin{tabular}{lcc}
\hline \multirow{2}{*}{ Compound } & \multicolumn{2}{c}{ Lifetime / $\boldsymbol{\mu s}$} \\
\cline { 2 - 3 } & Non over coat & Over coat \\
\hline Fraction 1 & - & - \\
Fraction 2 & - & - \\
Fraction 3 & 21.19 & 72.72 \\
Fraction 4 & 14.03 & 47.32 \\
\hline
\end{tabular}

Figure 18. Decay trace of 6 in PMMA film on $450 \mathrm{~nm}$. Excitation wavelength: $355 \mathrm{~nm}$ in the presence and absence of TCT. Substance concentration; $0.15 \mathrm{~mol} \cdot \mathrm{L}^{-1}$; Excitation wavelength; $355 \mathrm{~nm}$.

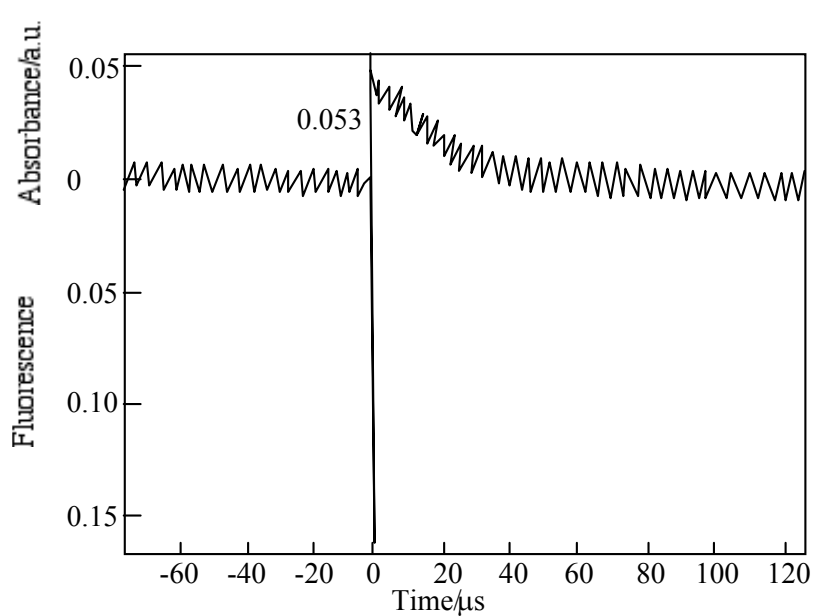

In the absence of TCT

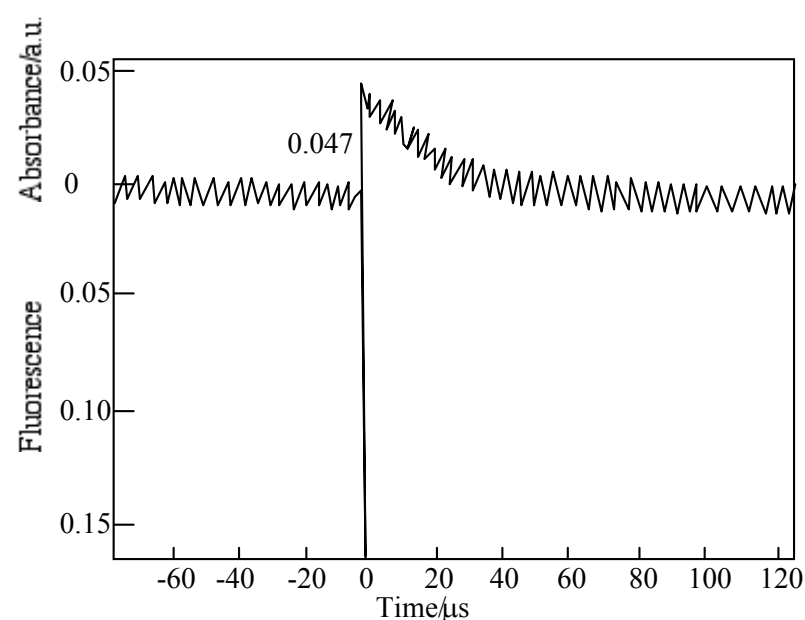

In the presence of $0.061 \mathrm{~mol} \mathrm{dm}^{-3}$ of TCT 
Figure 19. Quenching of 6 by TCT in PMMA. (a) Fluorescence on $572 \mathrm{~nm}$. Substance concentration: $0.03 \mathrm{~mol} \cdot \mathrm{L}^{-1}$; Excitation wavelength: $550 \mathrm{~nm}$; (b) Triplet absorption intensity on $450 \mathrm{~nm}$. Substance concentration: $0.15 \mathrm{~mol} \mathrm{dm}{ }^{-3}$; Excitation wavelength: $355 \mathrm{~nm}$.
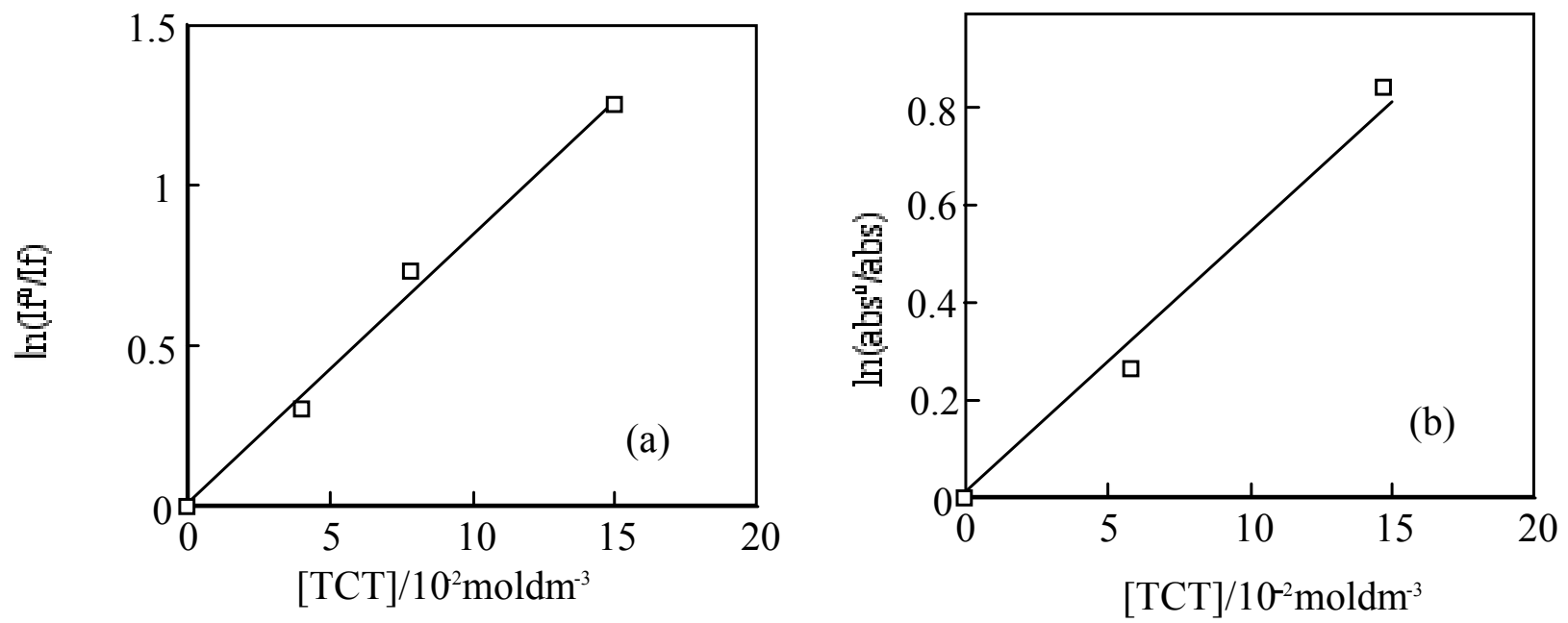

For the laser excitation of PMMA film at excitation of $550 \mathrm{~nm}$ using fluorescence spectrometer, the strongest fluorescence of $\mathbf{6}$ was efficiently quenched by TCT The fluorescence intensity was reduced with the concentration of TCT from 0 to $0.15 \mathrm{M}$. The fluorescence intensity is in direct proportion to the concentration of the TCT [80], the relationship gives a good straight line and it exhibits the Perrin type static quenching process [81] (Figure 19). The quenching radius $\left(\mathrm{R}_{\mathrm{f}}\right.$ was determined from the slope of the logarithmic plot, and was estimated to be $15 \mathrm{~nm}$.

The sensitization mechanisums between SubPC derivatives and TCT are thought as equations (2841), where $\mathrm{I}_{\mathrm{f}}^{0}$ and $\mathrm{I}_{\mathrm{f}}$ are the fluorescence intensities in the absence and presence of the quencher TCT, $\tau_{\mathrm{f}}^{0}$ is the lifetime in the absence of quencher, $\mathrm{k}_{\mathrm{q}}$ is the dynamic quenching rate constant, $\mathrm{k}_{\mathrm{q}}{ }^{\mathrm{i}}$ is the static quenching constant, $\mathrm{V}$ is the quenching shere, $\mathrm{V}=4 \pi \mathrm{Rf} / 3, \mathrm{~N}$ is Avogadro's number, $\mathrm{Rf}$ is the quenching radius, $\mathrm{X}=\mathrm{K}_{\mathrm{i}} \Sigma[(\mathrm{SubPC}-(\mathrm{i}-1) \mathrm{TCT})]+1$. The mutistep equibrium between $\mathbf{6}$ derivatives and TCT is shown in Equations (28) and (29):

$$
\begin{gathered}
{[\text { Subpc }-(\mathrm{i}-1) \mathrm{TCT}]+\mathrm{TCT} \underset{\mathrm{K}}{\stackrel{\mathrm{K}}{\longrightarrow}(\text { SubPC-iTCT) }} \underset{\mathrm{i}=1,2,3 \ldots}{\longrightarrow}} \\
\mathrm{Ki}=[\text { SubPC-iTCT }] /\{[\text { SubPC }][\text { SubPC-(i-1)TCT }]\} \\
\mathrm{i}=1,2,3 \ldots
\end{gathered}
$$

Equation (30) implies that SubPC derivatives and (SubPC-iTCT) are excited to an excited state *SubPC by absorbing laser pulse. Equations (31) and (32) mean that the *SubPC undergoes nonradiative and radiative deactivation. Then, the *SubPC reacted with TCT forms radicals such as chloro or dichloromethyl radicals as shown in Equation (33). Further, the SubPC becomes triplet state by intersystem crossing in Equation (34). The (SubPC-iTCT) also undergones (*SubPC-iTCT) by absorbing laser pulse (Equation 35$)$. The activate state (*SubPC-iTCT) takes statically sensitized decomposition of TCT (Equation 36). Then, (*SubPC-iTCT) undergoes radiative, monoradiative deactivation and intercrossing as described in Equatons (38) and (39). The attention of fluorescence 
with the concentration of TCT in film is described as Equation (40). When (*SubPC-iTCT) does not emit fluorescence, meaning $\mathrm{k}_{\mathrm{q}}{ }^{\mathrm{i}}$ is much larger than any decay rate. Equation (40) is described Equation (41) of the dynamic and static quenching terms.

$$
\begin{aligned}
& \text { SubPC } \stackrel{\text { ho }}{\longrightarrow} \text { *SubPC } \\
& \text { *SubPC } \stackrel{\mathrm{k}_{\mathrm{d}}}{\longrightarrow} \text { SubPC } \\
& \text { *SubPC } \longrightarrow \text { SubPC }+ \text { huf } \\
& * \mathrm{SubPC}+\mathrm{TCT} \stackrel{\mathrm{k}_{\mathrm{q}}}{\longrightarrow} \mathrm{SubPC}+\text { radicals } \\
& \text { *SubPC } \longrightarrow \text { Triplet } \\
& (\text { SubPC-iTCT }) \stackrel{\text { hu }}{\longrightarrow} \text { (*SubPC-iTCT) } \\
& \left({ }^{*} \text { SubPC-iTCT }\right) \longrightarrow(\text { SubPC }+(\mathrm{i}-1) \mathrm{TCT})+\text { radicals } \\
& \left({ }^{*} \text { SubPC-iTCT }\right) \longrightarrow(\text { SubPC-iTCT })+\text { huf } \\
& \left(* \text { SubPC-iTCT) } \stackrel{\mathrm{kd}^{\mathrm{i}}}{\longrightarrow}\right. \text { (SubPC-iTCT) } \\
& \text { (*SubPC-iTCT) } \stackrel{\mathrm{kisc}^{\mathrm{i}}}{\longrightarrow} \text { (Triplet-iTCT) } \\
& \mathrm{I}_{\mathrm{f}}^{0} / \mathrm{If}=\left\{\left(1+\mathrm{k}_{\mathrm{q}} \tau \mathrm{f}^{0}[\mathrm{TCT}]\right)\left(\mathrm{X}+\mathrm{kq}_{\mathrm{q}} \tau \mathrm{f}^{0}\right)\right\} /\{\mathrm{X}+ \\
& \mathrm{k}_{\mathrm{q}} \tau_{\mathrm{f}}^{0}[\mathrm{TCT}]+\left[\mathrm{Xk}_{\mathrm{q}} \mathrm{i}_{\tau} \mathrm{f}^{0}-\mathrm{k}_{\mathrm{q}} \tau^{0} \mathrm{f}^{0}[\mathrm{TCT}] \exp (-\mathrm{VN}[\mathrm{TCT}])\right\} \\
& \mathrm{If}_{\mathrm{f}}^{0} / \mathrm{I}_{\mathrm{f}}=\left(1+\mathrm{k}_{\mathrm{q}} \tau \mathrm{f}^{0}[\mathrm{TCT}] \exp (\mathrm{VN}[\mathrm{TCT}])\right.
\end{aligned}
$$

The triplet state of $\mathbf{6}$ in a PMMA films was also quenched by TCT. The initial absorptions were decreased with the concentration of TCT. The triplet life times measured almost the same. The logarithmic plots of the initial absorption at various concentration of TCT were fitted to the Perrin equation, the triplet quenching radius (Rt) were calculation to be $1.3 \mathrm{~nm}$, which was almost same as $\mathrm{R}_{\mathrm{f}}$. The results indicate the triplet initial absorption was not quenched by TCT, since the triplet state 
generally came from the fluorescent singlet state, and the triplet is apparently reduced with the decrease of the singlet state.

The reduction and oxidation behavior of M-PCs are due to the interaction between the phthalocyanine ring and the central metal [40]. In the case of M-PCs, the porphyrazine ring in the molecule is influenced by the $\pi$ electrons around the closed system. The $18-\pi$ electron system of MPCs consists of one porphyrazine and four phynylene rings [27,32,50]. Substituents of M-PCs influence the $18 \pi$ electron environment in the molecule of the four phynylene rings, and are dependent on electron transfer properties of M-PCs. In the case of SubPC and its derivatives, redox potentials had various values. This implies the possibility of an electron transfer from the singlet to an excited state of 6 to the higher TCT state. The derivatives of $\mathbf{6}$ derivatives present similar phenomena to $\mathbf{6}$. It is suggested that the static-singlet-quenching process from the singlet photoexcited $\mathbf{6}$ to TCT is predominant in the sensitization.

\subsection{Near infrared absorptions of $\mathbf{1 5}$}

In substituted $\mathrm{M}$ - and $\mathrm{H}_{2}-\mathrm{PCs}$, a strong absorption, termed the $\mathrm{Q}$ band, is detected in the visible region between 650 and $690 \mathrm{~nm}$, and another in the UV-Vis between 320 and $370 \mathrm{~nm}$, called the Soret band. A typical value for the extinction coefficient $(\varepsilon)$ of the $\mathrm{Q}$ band is around $10^{5} \mathrm{~cm}^{2} \cdot \mathrm{mol}^{-1}$. The absorption spectra of the synthesized compounds 7 show typical shapes for M-PCs (Figures 20-22). They also displayed strong absorption peaks in the visible region at around $800 \mathrm{~nm}$. The strongest peaks in the visible region are assigned as the $\mathrm{Q}$ band, which were attributed to the allowed $\pi-\pi *$ transition of the phthalocyanine ring. The $\mathrm{Q}$ band absorption of synthesized compounds $\mathbf{1 5}$ shifted by $100-150 \mathrm{~nm}$ to a longer wavelength in comparison to unsubstituted M-PCs.

Figure 20. UV-Vis spectra of $\mathbf{1 5 a}$.

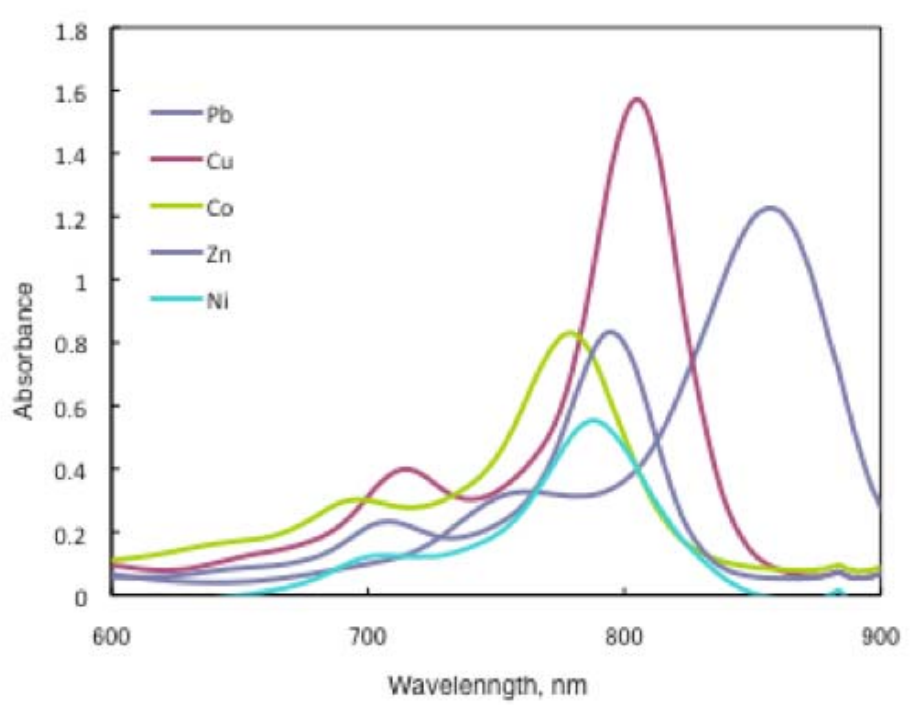


Figure 21. UV-Vis spectra of $\mathbf{1 5 b .}$

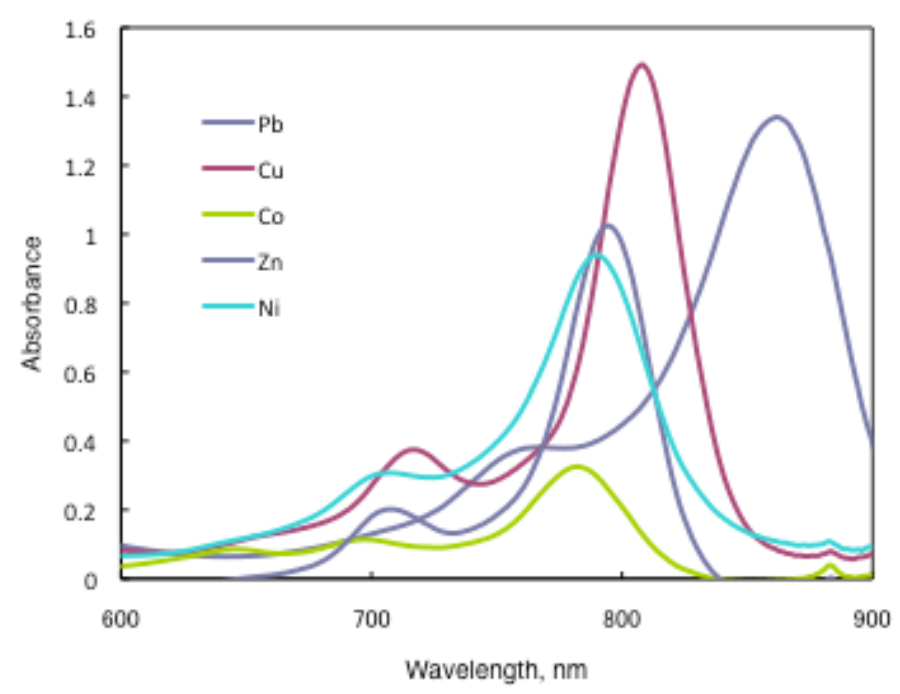

Figure 22. UV-Vis spectra of $\mathbf{1 5 c}$.

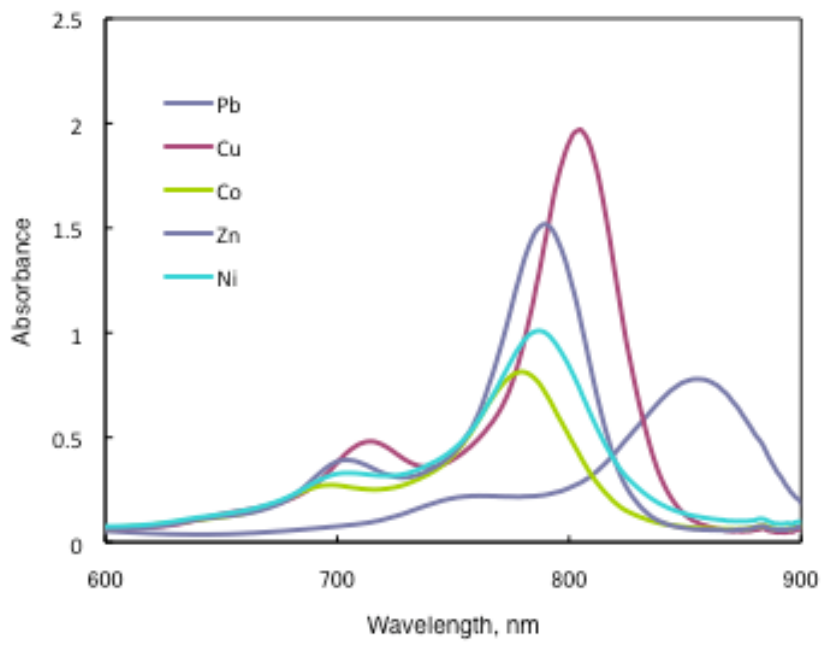

In the case of 15a, absorption maxima are moved to longer wavelengths in the order of $\mathrm{Co}, \mathrm{Ni}, \mathrm{Cu}$, $\mathrm{Zn}$, and $\mathrm{Pb}$. Compounds $\mathbf{1 5 b}$ and $15 \mathrm{c}$ show similar phenomena. In comparison to the same central metal, non-peripheral substituted phthalocyanines, 15a, 15b, and 15c show longer wavelengths than peripheral compounds. Metal-free 15a, 15b, and 15c were also synthesized. The Q band absorption peaks of 15a, 15b, and 15c respectively appeared at longer wavelengths of 815,820 , and $816 \mathrm{~nm}$. In general, $\mathrm{H}_{2}$-PCs show shorter wavelengths than corresponding M-PCs. Metal-free 15a, 15b, and 15c, which have remarkably bulky substituents, increase the distortion of the molecule because the four central cavity sizes cannot be fixed. Then, the Q band of metal-free 15a, 15b, and 15c were not split. The $\mathrm{Q}$ band is known to split into two peaks for high symmetry; the splitting $\mathrm{Q}$ band decreases with decreasing symmetry. Metal-free 15a, 15b, and 15c display decreased symmetry as a result of the 
molecular distortion. We leave a detailed discussion about these phenomena of $\mathrm{Q}$ band of metal-free 15a, 15b and 15c for another opportunity. The Q band absorption data of $\mathbf{1 5}$ are presented in Table 13.

Table 13. The Q band absorption data of $\mathbf{1 5 .}$

\begin{tabular}{lcccc}
\hline Solvent & Central metal & \multicolumn{3}{c}{$\lambda \max / \mathrm{nm} \log \varepsilon$} \\
\hline Chloroform & Metal-free & 8155.22 & 8205.33 & 8165.08 \\
Chloroform & $\mathrm{Pb}$ & 8575.09 & 8625.13 & 8554.89 \\
Chloroform & $\mathrm{Cu}$ & 8055.20 & 8085.17 & 8055.29 \\
Chloroform & $\mathrm{Ni}$ & 7884.74 & 7904.97 & 7875.00 \\
Chloroform & $\mathrm{Zn}$ & 7954.92 & 7955.01 & 7895.18 \\
Chloroform & $\mathrm{Co}$ & 7794.91 & 7834.51 & 7804.91 \\
Toluene & $\mathrm{Pb}$ & 8385.15 & 8465.18 & 8365.08 \\
Toluene & $\mathrm{Cu}$ & 7915.01 & 7965.06 & 7905.01 \\
Toluene & $\mathrm{Ni}$ & 7775.09 & 7825.10 & 7764.94 \\
Toluene & $\mathrm{Zn}$ & 7924.20 & 7904.34 & 7824.86 \\
Toluene & $\mathrm{Co}$ & 7754.71 & 7784.89 & 7744.89 \\
\hline
\end{tabular}

The Q band shifts depend upon the change in the electron distribution in the phthalocyanine ring caused by substituents and their position. These results suggest that the steric hindrance arising from the substituted $S$-aryl groups appears to be as significant, as reported by Kobayashi [39]. However, a difference of the Q band in $\mathbf{1 5}$ is low between substituents, methyl, methoxy and tert-butyl. In this case, electron-donating substituents only slightly affect the movement to a longer wavelength. Although the effect of the central metal on the energy of Q band is usually small [20], absorption maxima of $\mathbf{3}$ are moved to longer wavelengths, and apparently increase with the ionic radius of the central metal, particularly lead. Lead complexes of $\mathbf{1 5}$ showed amplified structural distortion.

Because non-peripheral $S$-aryl substituted phthalocyanines having $\mathrm{Pb}$ as the central metal have an absorption band near $500 \mathrm{~nm}, \mathbf{1 5 a}-\mathbf{P b}, \mathbf{1 5 b}-\mathbf{P b}$, and 15c-Pb give red solutions; the other central metals of 15a, 15b, and 15c give slightly reddish solutions.

\section{Experimental Section}

\subsection{Equipment}

UV-Vis spectra were measured on a Shimadzu UV-2400PC spectrometer. Each sample was prepared in toluene at $5.0 \times 10^{-5} \mathrm{~mol} \cdot \mathrm{L}^{-1}$, in chloroform at $5.0 \times 10^{-5} \mathrm{~mol} \cdot \mathrm{L}^{-1}$, in Py at $5.0 \times 10^{-5} \mathrm{~mol} \cdot \mathrm{L}^{-}$ 1 . Fluorescent spectra were recorded in DMF on a Nihon Bunko Jasco FP-6600 spectrofluorometer. The ${ }^{1} \mathrm{H}-\mathrm{NMR}$ spectra were measured at $400 \mathrm{MHz}$ on a Bruker Avance $400 \mathrm{~S}$ and $90 \mathrm{MHz}$ on a Nihon Denshi Joel EX-90 in dimethylsulfoxide- $d_{6}\left(\mathrm{DMSO}-d_{6}\right)$, benzene- $d_{6}$ or chloroform- $d\left(\mathrm{CDCl}_{3}\right)$ using tetramethylsilane (TMS) as the internal standard. Elemental analysis was carried out using a PerkinElmer 2400CHN instrument. Mass spectra were taken with a Nihon Denshi Joel JMS-AX500 mass 
spectrometer. Melting points were measured with a Stanford Research Systems MPA100 Optimelt automated system.

\subsection{Materials}

All chemicals were purchased from Aldrich or Tokyo Chemical Industry Co. Ltd. They were used as received without further purification. For chromatographic separation, silica gel was used (60, particle size 0.063-0.200 nm, 7734-grade; Merck).

\subsection{Synthesis of phthalocyanine tetrasulfonic acids 1-M (M = Fe, Co, Cu, Zn)}

A mixture of 4-sulfophthalic acid (12.3 g, $50 \mathrm{mmol})$, urea $(30.0 \mathrm{~g}, 0.50 \mathrm{~mol})$, metal chloride (30 $\mathrm{mmol})$ and DBU (1 g) as a catalyst dissolved in $150 \mathrm{~mL}$ of 1,2,4-trichlorobenzene as solvent was heated to $210{ }^{\circ} \mathrm{C}$ for $180 \mathrm{~min}$ (Scheme 1). The product was filtered, washed with benzene until all 1,2,4-trichlorobenzene was removed and then dried under vacuum to a constant weight; 1-Fe (75\%) Found: $\mathrm{C}, 43.20 \%$; $\mathrm{H}, 1.99 \%$; N, 12.45\%. Calcd. for $\mathrm{C}_{32} \mathrm{H}_{16} \mathrm{~N}_{8} \mathrm{O}_{12} \mathrm{~S}_{4} \mathrm{Fe}: \mathrm{C}, 43.25 \% ; \mathrm{H}, 1.81 \%$; , $12.60 \%$. IR (KBr): $v_{\max } / \mathrm{cm}^{-1} 3000\left(v_{\mathrm{C}-\mathrm{H}}\right), 1700\left(v_{\mathrm{C}-\mathrm{C}}\right), 1450\left(\delta_{\mathrm{C}-\mathrm{H}}\right), 1380\left(v_{\mathrm{S}-\mathrm{O}}\right), 1050\left(\delta_{\mathrm{C}-\mathrm{H}}\right)$, $770\left(\delta_{\mathrm{C}-\mathrm{H}}\right) . \mathrm{UV}-\mathrm{Vis}: \lambda_{\max } \mathrm{Py} / \mathrm{nm}$ : 688.5, 649.0, 354.0, 213.0; 1-Co (75\%) Found: C, 42.92\%; H, 2.08\%; $\mathrm{N}, 12.67 \%$. Calcd. for $\mathrm{C}_{32} \mathrm{H}_{16} \mathrm{~N}_{8} \mathrm{O}_{12} \mathrm{~S}_{4} \mathrm{Co}: \mathrm{C}, 43.10 \% ; \mathrm{H}, 1.80 \% ; \mathrm{N}, 12.56 \%$. IR (KBr): $v_{\max } / \mathrm{cm}^{-1}$ $\left.3000\left(v_{\mathrm{C}-\mathrm{H}}\right), 1700\left(v_{\mathrm{C}-\mathrm{C}}\right), 1450\left(\delta_{\mathrm{C}-\mathrm{H}}\right), 1380\left(v_{\mathrm{S}-\mathrm{O}}\right), 1050\left(\delta_{\mathrm{C}-\mathrm{H}}\right), 770\left(\delta_{\mathrm{C}-\mathrm{H}}\right) . \mathrm{UV}-\mathrm{V}\right)$ 649.0, 354.0, 213.0; 1-Cu (75\%) Found: C, 42.86\%; H, 1.67\%; N, 12.45\%. Calcd. for $\mathrm{C}_{32} \mathrm{H}_{16} \mathrm{~N}_{8} \mathrm{O}_{12} \mathrm{~S}_{4} \mathrm{Cu}: \mathrm{C}, 42.88 \% ; \mathrm{H}, 1.79 \%$; N, 12.50\%. IR (KBr): $v_{\max } / \mathrm{cm}^{-1} 3000\left(v_{\mathrm{C}-\mathrm{H}}\right), 1700\left(v_{\mathrm{C}-\mathrm{C}}\right)$, $1450\left(\delta_{\mathrm{C}-\mathrm{H}}\right), 1380\left(v_{\mathrm{S}-\mathrm{O}}\right), 1050\left(\delta_{\mathrm{C}-\mathrm{H}}\right), 770\left(\delta_{\mathrm{C}-\mathrm{H}}\right) . \mathrm{UV}-\mathrm{Vis}: \lambda_{\max } \mathrm{Py} / \mathrm{nm}:$ 688.5, 649.0, 354.0, 213.0; 1Zn (75\%) Found: C, 42.67\%; H, 1.80\%; N, 12.53\%. Calcd. for $\mathrm{C}_{32} \mathrm{H}_{16} \mathrm{~N}_{8} \mathrm{O}_{12} \mathrm{~S}_{4} \mathrm{Zn}: \mathrm{C}, 42.79 \%$; $\mathrm{H}$, $1.79 \%$; N,12.47\%. IR (KBr): $v_{\max } / \mathrm{cm}^{-1} 3000\left(v_{\mathrm{C}-\mathrm{H}}\right), 1700\left(v_{\mathrm{C}-\mathrm{C}}\right), 1450\left(\delta_{\mathrm{C}-\mathrm{H}}\right), 1380\left(v_{\mathrm{S}-\mathrm{O}}\right), 1050\left(\delta_{\mathrm{C}-\mathrm{H}}\right)$, $770\left(\delta_{\mathrm{C}-\mathrm{H}}\right)$. UV-Vis: $\lambda_{\max }$ Py/nm: 688.5, 649.0, 354.0, 213.0.

\subsection{Synthesis of phthalocyanine octacarboxylic acids 2-M (M = Fe, Co, Cu, Zn) (Scheme 2)}

A mixture of pyromellitic dianhydride $(2.50 \mathrm{~g}, 11.5 \mathrm{mmol})$, urea $(13.0 \mathrm{~g}, 0.22 \mathrm{~mol})$, metal chloride (23.5 mmol) and $0.1 \mathrm{~g}$ of DBU was heated to $250{ }^{\circ} \mathrm{C}$ until the reaction mixture was fused. The reaction product was washed with water, acetone and $6 \mathrm{M}$-hydrochloric acid ( $\mathrm{HCl})$. After drying, the solid obtained was hydrolyzed. Thirty grams of crude product, $30 \mathrm{~g}$ of $\mathrm{KOH}$ and $90 \mathrm{~mL}$ of water were heated for $480 \mathrm{~min}$ at $100{ }^{\circ} \mathrm{C}$. The mixture was diluted with $200 \mathrm{~mL}$ of water and filtered. The filtrate was acidified to $\mathrm{pH} 2$ with concentrated $\mathrm{HCl}$. At this point the product precipitated as a blue colored solid, which was separated from the solution by a centrifuge. The solid was washed with water three times, and dried. 2-Fe (yield: 30\%) Found: C, 52.11\%; H, 1.41\%; N, 12.25\%. Calcd. for $\mathrm{C}_{40} \mathrm{H}_{16} \mathrm{~N}_{8} \mathrm{O}_{16} \mathrm{Fe}: \mathrm{C}, 52.19 \%$; H, 1.75\%; N, 12.17\%. IR (KBr): $v_{\max } / \mathrm{cm}^{-1} 3300\left(v_{\mathrm{C}-\mathrm{H}}\right), 2900\left(v_{\mathrm{C}-\mathrm{H}}\right), 1750$ $\left(v_{\mathrm{C}-\mathrm{O}}\right), 1720\left(v_{\mathrm{C}-\mathrm{O}}\right), 1480\left(v_{\mathrm{C}-\mathrm{C}}\right), 1060\left(\delta_{\mathrm{C}-\mathrm{H}}\right), 720\left(\delta_{\mathrm{C}-\mathrm{H}}\right) . \mathrm{UV}-\mathrm{V}_{1}: \lambda_{\max } \mathrm{Py} / \mathrm{nm}: 684 ; 2-\mathrm{Co}$ (yield: $\left.30 \%\right)$ Found: $\mathrm{C}, 52.44 \% ; \mathrm{H}, 1.74 \%$; N, 12.25\%. Calcd. for $\mathrm{C}_{40} \mathrm{H}_{16} \mathrm{~N}_{8} \mathrm{O}_{16} \mathrm{Co}: \mathrm{C}, 52.04 \% ; \mathrm{H}, 1.74 \%$; , 12.13\%. IR (KBr): $v_{\max } / \mathrm{cm}^{-1} 3300\left(v_{\mathrm{C}-\mathrm{H}}\right), 2900\left(v_{\mathrm{C}-\mathrm{H}}\right), 1750\left(v_{\mathrm{C}-\mathrm{O}}\right), 1720\left(v_{\mathrm{C}-\mathrm{O}}\right), 1480\left(v_{\mathrm{C}-\mathrm{C}}\right), 1060$ $\left(\delta_{\mathrm{C}-\mathrm{H}}\right), 720\left(\delta_{\mathrm{C}-\mathrm{H}}\right) . \mathrm{UV}-\mathrm{Vis}: \lambda_{\max }$ Py/nm: 684; 2-Cu (yield: 30\%) Found: C, 52.03\%; H, 1.86\%; N, 
11.97\%. Calcd. for $\mathrm{C}_{40} \mathrm{H}_{16} \mathrm{~N}_{8} \mathrm{O}_{16} \mathrm{Cu}: \mathrm{C}, 51.76 \% ; \mathrm{H}, 1.73 \% ; \mathrm{N}, 12.07 \%$. IR (KBr): $v_{\max } / \mathrm{cm}^{-1} 3300$ $\left(v_{\mathrm{C}-\mathrm{H}}\right), 2900\left(v_{\mathrm{C}-\mathrm{H}}\right), 1750\left(v_{\mathrm{C}-\mathrm{O}}\right), 1720\left(v_{\mathrm{C}-\mathrm{O}}\right), 1480\left(v_{\mathrm{C}-\mathrm{C}}\right), 1060\left(\delta_{\mathrm{C}-\mathrm{H}}\right), 720\left(\delta_{\mathrm{C}-\mathrm{H}}\right) . \mathrm{UV}-\mathrm{V}_{1}: \lambda_{\max }$ Py/nm: 684; 2-Zn (yield: 30\%) Found: C, 51.60\%; H, 1.66\%; N, 12.16\%. Calcd. for $\mathrm{C}_{40} \mathrm{H}_{16} \mathrm{~N}_{8} \mathrm{O}_{16} \mathrm{Zn}$ : C, 51.66\%; H, 1.73\%; N, 12.04\%. IR (KBr): $v_{\max } / \mathrm{cm}^{-1} 3300\left(v_{\mathrm{C}-\mathrm{H}}\right), 2900\left(v_{\mathrm{C}-\mathrm{H}}\right), 1750\left(v_{\mathrm{C}-\mathrm{O}}\right), 1720\left(v_{\mathrm{C}-\mathrm{O}}\right)$, $1480\left(v_{\mathrm{C}-\mathrm{C}}\right), 1060\left(\delta_{\mathrm{C}-\mathrm{H}}\right), 720\left(\delta_{\mathrm{C}-\mathrm{H}}\right)$. UV-Vis: $\lambda_{\max }$ Py/nm: 684.

\subsection{Synthesis of octakis(hexoxymethyl)phthalocyanines 3-M (M=Fe, Co, Cu, Zn)}

Compounds 3 were synthesized from a metal chloride and 1,2-dicyano-4,5-bis(hexoxymethyl)benzene (10), which was synthesized from $o$-xylene via 1,2-dibromo-4,5-dimethylbenzene (7), 1,2dibromo-4,5-bis(bromo-methylbenzene) (8) and 1,2-dibromo-4,5-bis(hexoxymethyl)benzene (Scheme 3).

\subsubsection{Synthesis of 1,2-dibromo-4,5-dimethylbenzene (7)}

Bromine (500 g, $3.12 \mathrm{~mol}$ ) was added dropwise to a mixture of $o$-xylene (166 g, $1.56 \mathrm{~mol}$ ), iodine $(2 \mathrm{~g})$ and iron $(3 \mathrm{~g})$, during a $420 \mathrm{~min}$ period while stirring at $5-10{ }^{\circ} \mathrm{C}$. After the reaction, the reaction mixture was poured into water and filtered. The precipitate was washed with a $3 \%-\mathrm{NaOH}$ solution and recrystallized from methylcyclohexane; yield $49 \%$. mp $86.6^{\circ} \mathrm{C}$. Found: C, 36.18\%; H, 2.64\%. Calc for $\mathrm{C}_{8} \mathrm{H}_{8} \mathrm{Br}_{2}:$ C, 36.66\%; H, $3.08 \%$. IR (KBr): $v_{\max } / \mathrm{cm}^{-1} 2950$ ( $\left.v_{\mathrm{C}-\mathrm{H}}\right), 1601$ ( $\left.v_{\mathrm{C}-\mathrm{C}}\right), 1440$ ( $\left.v_{\mathrm{C}-\mathrm{C}}\right), 1340\left(v_{\mathrm{C}-\mathrm{C}}\right)$, $1120\left(v_{\mathrm{C}-\mathrm{C}}\right), 880\left(\delta_{\mathrm{C}-\mathrm{H}}\right), 640\left(\delta_{\mathrm{C}-\mathrm{H}}\right) .{ }^{1} \mathrm{H}-\mathrm{NMR}\left(\mathrm{CDCl}_{3}\right): \delta, \mathrm{ppm} 2.10(\mathrm{~s}, 6 \mathrm{H}), 7.36(\mathrm{~s}, 2 \mathrm{H}) . \mathrm{MS}$ $m / z=264$.

\subsubsection{Synthesis of 1,2-dibromo-4,5-bis(bromomethylbenzene) (8)}

A mixture of 7 (30.2 g, $0.11 \mathrm{~mol})$ dissolved in $100 \mathrm{~mL}$ of carbon tetrachloride, $42.7 \mathrm{~g}(0.24 \mathrm{~mol})$ of $\mathrm{N}$-bromosuccinimide (NBS) and $0.08 \mathrm{~g}$ of $2,2^{\prime}$-azobis(isobutyro)nitrile was heated to $80{ }^{\circ} \mathrm{C}$ and refluxed for $480 \mathrm{~min}$. After removing the carbon tetrachloride, the crude product was recrystallized from heptanes and dried under vacuum; yield $21 \%$. mp $84.7^{\circ} \mathrm{C}$, Found: $\mathrm{C}, 22.72 \%$; $\mathrm{H}, 1.15 \%$;. Calc for $\mathrm{C}_{10} \mathrm{H}_{10} \mathrm{Br}_{2}: \mathrm{C}, 22.78 \%$; H, 1.43\%. IR (KBr): $v_{\max } / \mathrm{cm}^{-1} 3000\left(v_{\mathrm{C}-\mathrm{H}}\right), 1650\left(v_{\mathrm{C}-\mathrm{C}}\right), 1460\left(v_{\mathrm{C}-\mathrm{C}}\right), 1200$ $\left(v_{\mathrm{C}-\mathrm{C}}\right), 950\left(\delta_{\mathrm{C}-\mathrm{H}}\right), 620\left(\delta_{\mathrm{C}-\mathrm{H}}\right) .{ }^{1} \mathrm{H}-\mathrm{NMR}\left(\mathrm{CDCl}_{3}\right): \delta$, ppm $4.43(\mathrm{~s}, 4 \mathrm{H}), 7.53(\mathrm{~s}, 2 \mathrm{H}) ; \mathrm{MS} \mathrm{m} / \mathrm{z}=422$.

\subsubsection{Synthesis of 1,2-dibromo-4,5-bis(hexoxymethyl)benzene (9)}

A piece of sodium was added to $120 \mathrm{~g}(1.18 \mathrm{~mol})$ of hexanol. After the added sodium dissolved, $5.00 \mathrm{~g}(0.13 \mathrm{~mol})$ of 8 was added. The temperature was gradually raised to $155{ }^{\circ} \mathrm{C}$, and then the mixture was stirred for $90 \mathrm{~min}$. The excess hexanol was removed by distillation and one hundred grams of water were added to the reaction mixture to dissolve the salt by-product. The resultant mixture was extracted with diethyl ether. The organic layer was washed with a small quantity of water and dried over calcium chloride. The diethyl ether was distilled off. The product $\mathbf{9}$ is a brown liquid; yield 88\%. IR (KBr): $v_{\max } / \mathrm{cm}^{-1} 2900\left(v_{\mathrm{C}-\mathrm{H}}\right), 1670\left(v_{\mathrm{C}-\mathrm{C}}\right), 1240\left(v_{\mathrm{C}-\mathrm{C}}\right), 1050\left(\delta_{\mathrm{C}-\mathrm{H}}\right), 630\left(\delta_{\mathrm{C}-\mathrm{H}}\right) .{ }^{1} \mathrm{H}-\mathrm{NMR}$ $\left(\mathrm{CDCl}_{3}\right)$ : $\delta$, ppm 0.89 (s, 6H), $1.28(\mathrm{~m}, 16 \mathrm{H}), 3.52$ (s, 4H), $4.45(\mathrm{~s}, 4 \mathrm{H}), 7.64(\mathrm{~s}, 2 \mathrm{H})$. 


\subsubsection{Synthesis of 1,2-dicyano-4,5-bis(hexoxymethyl)benzene (10)}

A mixture of $15.2 \mathrm{~g}$ (33.8 $\mathrm{mmol})$ of 1,2-dibromo-4,5-bis(hexoxymethyl) benzene (3), $13.6 \mathrm{~g}$ (96.6 mmol) of copper cyanide and $100 \mathrm{~cm}^{3}$ of DMF was refluxed for 300 minutes, then cooled, and poured into $170 \mathrm{~cm}^{3}$ of aqueous ammonia. The mixture was stirred for $10 \mathrm{~min}$, and was filtered. The bluish residue was washed with water and dried. The product was extracted with diethyl ether for 1,440 min using a Soxhlet apparatus and the solvent was evaporated; yield $66 \%$. mp $360.0^{\circ} \mathrm{C}$, Found: C, 80.58\%; H, 9.37\%; N, 8.26\%; Calc for $\mathrm{C}_{22} \mathrm{H}_{32} \mathrm{~N}_{2} \mathrm{O}_{2}$ : C, 81.43\%; H, 9.94\%; N, 8.63\%. IR (KBr): $v_{\max } / \mathrm{cm}^{-1} 3200\left(v_{\mathrm{C}-\mathrm{H}}\right), 2100\left(v_{\mathrm{C}-\mathrm{N}}\right), 1460\left(v_{\mathrm{C}-\mathrm{C}}\right), 1240\left(v_{\mathrm{C}-\mathrm{C}}\right), 1095\left(\delta_{\mathrm{C}-\mathrm{H}}\right), 60\left(\delta_{\mathrm{C}-\mathrm{H}}\right) .{ }^{1} \mathrm{H}-\mathrm{NMR}\left(\mathrm{CDCl}_{3}\right): \delta$, ppm 4.43 (s, 4H ), 7.53 (s, 2H). MS m/z = 357.

\subsubsection{Synthesis of 3-M}

Compounds 3-M were synthesized as follows: a mixture of $2.00 \mathrm{~g}(5.61 \mathrm{mmol})$ of 10, $11.8 \mathrm{mmol}$ of metal chloride, $0.1 \mathrm{~g}$ of DBU, and $20 \mathrm{~mL}$ of hexanol as solvent was refluxed for $600 \mathrm{~min}$ at $155^{\circ} \mathrm{C}$ and then filtered; 3-Fe (yield: 10\%) Found: C, 71.18\%; H, 8.66\%; N, 7.49\%. Calcd. for $\mathrm{C}_{88} \mathrm{H}_{128} \mathrm{~N}_{8} \mathrm{O}_{8} \mathrm{Fe}: \mathrm{C}, 71.22 \%$; H, 8.70\%; N, 7.56\%. IR (KBr): $v_{\max } / \mathrm{cm}^{-1} 3300\left(v_{\mathrm{C}-\mathrm{H}}\right), 2900\left(v_{\mathrm{C}-\mathrm{H}}\right), 1590$ $\left(v_{\mathrm{C}-\mathrm{O}}\right), 1150\left(v_{\mathrm{C}-\mathrm{C}}\right), 1090\left(\delta_{\mathrm{C}-\mathrm{H}}\right), 720\left(\delta_{\mathrm{C}-\mathrm{H}}\right) . \mathrm{UV}-V_{1}: \lambda_{\max }$ Py/nm: 665. 3-Co (yield: 10\%) Found: C, 71.18\%; H, 8.63\%; N, 7.43\%. Calcd. for $\mathrm{C}_{88} \mathrm{H}_{128} \mathrm{~N}_{8} \mathrm{O}_{8} \mathrm{Co}$ : C, 71.17\%; H, 8.68\%; N, 7.54\%. IR (KBr): $v_{\max } / \mathrm{cm}^{-1} 3300\left(v_{\mathrm{C}-\mathrm{H}}\right), 2900\left(v_{\mathrm{C}-\mathrm{H}}\right), 1590\left(v_{\mathrm{C}-\mathrm{O}}\right), 1150\left(v_{\mathrm{C}-\mathrm{C}}\right), 1090\left(\delta_{\mathrm{C}-\mathrm{H}}\right), 720\left(\delta_{\mathrm{C}-\mathrm{H}}\right) . \mathrm{UV}-\mathrm{Vis}: \lambda_{\max }$ Py/nm: 665. 3-Cu (yield: 10\%) Found: C, 71.32\%; H, 8.91\%; N, 7.18\%. Calcd. for $\mathrm{C}_{88} \mathrm{H}_{128} \mathrm{~N}_{8} \mathrm{O}_{8} \mathrm{Cu}: \mathrm{C}$, $70.95 \%$; H, 8.66\%; N, 7.52\%. IR (KBr): $v_{\max } / \mathrm{cm}^{-1} 3300\left(v_{\mathrm{C}-\mathrm{H}}\right), 2900\left(v_{\mathrm{C}-\mathrm{H}}\right), 1590\left(v_{\mathrm{C}-\mathrm{O}}\right), 1150\left(v_{\mathrm{C}-\mathrm{C}}\right)$, $1090\left(\delta_{\mathrm{C}-\mathrm{H}}\right), 720\left(\delta_{\mathrm{C}-\mathrm{H}}\right) . \mathrm{UV}-\mathrm{Vis}: \lambda_{\max }$ Py/nm: 665. 3-Zn (yield: 10\%) Found: C, 71.11\%; H, 8.53\%;

N, 7.50\%. Calcd. for $\mathrm{C}_{88} \mathrm{H}_{128} \mathrm{~N}_{8} \mathrm{O}_{8} \mathrm{Zn}$ : C, 70.87\%; H, 8.65\%; N, 7.51\%. IR (KBr): $v_{\max } / \mathrm{cm}^{-1} 3300$ $\left(v_{\mathrm{C}-\mathrm{H}}\right), 2900\left(v_{\mathrm{C}-\mathrm{H}}\right), 1590\left(v_{\mathrm{C}-\mathrm{O}}\right), 1150\left(v_{\mathrm{C}-\mathrm{C}}\right), 1090\left(\delta_{\mathrm{C}-\mathrm{H}}\right), 720\left(\delta_{\mathrm{C}-\mathrm{H}}\right) . \mathrm{UV}-\mathrm{Vis}: \lambda_{\max }$ Py/nm: 665.

\subsection{Synthesis of Anthraquinocyanines 4-M $(M=F e, C o, Z n)$}

Compounds 4 are a new type of phthalocyanine derivatives which were synthesized from a metal chloride, urea and 9,10-anthraquinone-2,3-dicarboxylic acid (13), which was synthesized from $o$ xylene and phthalic anhydride via o-(3,4-dimethybenzoyl)benzoic acid (11) and 2,3-dimethyl-9,10anthraquinone (12) (Scheme 4).

\subsubsection{Synthesis of o-(3,4-dimethybenzoyl)benzoic acid (11)}

Into a mixture of $16.3 \mathrm{~g}(0.11 \mathrm{~mol})$ of phthalic dianhydride and $14 \mathrm{~g}$ of anhydrous aluminium chloride, $10.7 \mathrm{~g}$ of $o$-xylene in $25 \mathrm{~mL}$ of chloroform was added. The reaction mixture was refluxed for $60 \mathrm{~min}$ and the liquor then poured into a mixture of $30 \mathrm{~g}$ ice and $20 \mathrm{~mL}$ concentrated $\mathrm{HCl}$, and then filtered. The product was recrystallized from diethyl ether; yield $81 \%$. mp $170.6{ }^{\circ} \mathrm{C}$. Found: C, 75.03\%; H, 5.49\%;. Calc for $\mathrm{C}_{16} \mathrm{H}_{14} \mathrm{O}_{3}$ : C, 75.57\%; H, $5.55 \%$. IR (KBr): $v_{\max } / \mathrm{cm}^{-1} 3450\left(v_{\mathrm{O}-\mathrm{H}}\right), 2950$ $\left(v_{\mathrm{C}-\mathrm{H}}\right), 1760\left(v_{\mathrm{C}-\mathrm{O}}\right), 1680\left(v_{\mathrm{C}-\mathrm{O}}\right), 1601\left(v_{\mathrm{C}-\mathrm{C}}\right), 1400\left(v_{\mathrm{C}-\mathrm{C}}\right), 1225\left(v_{\mathrm{C}-\mathrm{C}}\right), 1100\left(v_{\mathrm{C}-\mathrm{C}}\right), 900\left(\delta_{\mathrm{C}-\mathrm{H}}\right)$, $710\left(\delta_{\mathrm{C}-\mathrm{H}}\right) .{ }^{1} \mathrm{H}-\mathrm{NMR}\left(\mathrm{CDCl}_{3}\right): \delta, \operatorname{ppm} 2.27(\mathrm{~s}, 6 \mathrm{H}), 7.68(\mathrm{~m}, 7 \mathrm{H}) . \mathrm{MS} \mathrm{m} / \mathrm{z}=254$. 


\subsubsection{Synthesis of 2,3-dimethyl-9,10-anthraquinone (12)}

Eighteen $\mathrm{g}$ of $\mathbf{1 1}$ and $2 \mathrm{~mL}$ of concentrated sulfuric acid were heated to $150{ }^{\circ} \mathrm{C}$, then cooled and the crude product was recrystallized from benzene; yield $35 \%$. mp $212.5^{\circ} \mathrm{C}$. Found: $\mathrm{C}, 80.89 \% ; \mathrm{H}, 5.02 \%$; Calc for $\mathrm{C}_{16} \mathrm{H}_{12} \mathrm{O}_{3}: \mathrm{C}, 81.33 \%$; H, $5.12 \%$. IR (KBr): $v_{\max } / \mathrm{cm}^{-1} 2900\left(v_{\mathrm{C}-\mathrm{H}}\right), 1760\left(v_{\mathrm{C}-\mathrm{O}}\right), 1675\left(v_{\mathrm{C}-\mathrm{O}}\right)$, $1420\left(v_{\mathrm{C}-\mathrm{C}}\right), 1300\left(v_{\mathrm{C}-\mathrm{C}}\right), 780\left(\delta_{\mathrm{C}-\mathrm{H}}\right), 710\left(\delta_{\mathrm{C}-\mathrm{H}}\right) .{ }^{1} \mathrm{H}-\mathrm{NMR}\left(\mathrm{CHCl}_{3}\right): \delta, \mathrm{ppm} 2.22(\mathrm{~s}, 6 \mathrm{H}), 7.46(\mathrm{~m}, 7 \mathrm{H})$. MS $m / z=236$.

\subsubsection{Synthesis of 9,10-anthraquinone-2,3-dicarboxylic acid (13)}

A solution of $4 \mathrm{~g}$ of $12 \mathrm{in} 4.36 \mathrm{~mL}$ concentrated sulfuric acid was added to $160 \mathrm{~g}$ of water, and $12 \mathrm{~g}$ of potassium permanganate $\left(\mathrm{KMnO}_{4}\right)$ was added gradually to the solution. Reaction was allowed to continue at $90-95^{\circ} \mathrm{C}$ for 10 min with stirring; excess $\mathrm{KMnO}_{4}$ was then removed with oxalic acid. The crude product was filtered and washed with hot water. The product dissolved in hot dilute ammonia solution, unreacted 12 being filtered off. Product 13 was precipitated from the filtrate by addition of $\mathrm{HCl}$. The material was filtered, washed with hot water and dried; yield $66 \%$. mp $325.0{ }^{\circ} \mathrm{C}$. Found: $\mathrm{C}$, 64.26\%; H, 5.03\%;. Calc for $\mathrm{C}_{16} \mathrm{H}_{8} \mathrm{O}_{6}: \mathrm{C}, 64.87 \%$; H, $4.72 \%$. IR (KBr): $v_{\max } / \mathrm{cm}^{-1} 3300\left(v_{\mathrm{O}-\mathrm{H}}\right), 2900$ $\left(v_{\mathrm{C}-\mathrm{H}}\right), 1690\left(v_{\mathrm{C}-\mathrm{O}}\right), 1600\left(v_{\mathrm{C}-\mathrm{C}}\right), 1400\left(v_{\mathrm{C}-\mathrm{C}}\right), 1260\left(v_{\mathrm{C}-\mathrm{C}}\right), 980\left(\delta_{\mathrm{C}-\mathrm{H}}\right), 780\left(\delta_{\mathrm{C}-\mathrm{H}}\right) .{ }^{1} \mathrm{H}-\mathrm{NMR}\left(\mathrm{CDCl}_{3}\right): \delta$, ppm $7.27(\mathrm{~s}, 6 \mathrm{H})$.

\subsubsection{Synthesis of compounds 4-M}

Compounds 4 were synthesized by the following procedure: a mixture of $1.00 \mathrm{~g}(3.30 \mathrm{mmol})$ of 13, $2 \mathrm{~g}(34.0 \mathrm{mmol})$ of urea, $6.75 \mathrm{mmol}$ of metal chloride, and $0.1 \mathrm{~g}$ of DBU was heated to $210{ }^{\circ} \mathrm{C}$ until the reaction mixture was fused. The reaction product was washed with water and was dried; 4-Fe (20\%) Found: C, 70.60\%; H, 2.22\%; N, 10.29\%. Calcd. for $\mathrm{C}_{64} \mathrm{H}_{24} \mathrm{~N}_{8} \mathrm{O}_{8} \mathrm{Fe}: \mathrm{C}, 70.96 \% ; \mathrm{H}, 2.28 \% ; \mathrm{N}, 10.13 \%$. IR (KBr): $v_{\max } / \mathrm{cm}^{-1} 3300\left(v_{\mathrm{C}-\mathrm{H}}\right), 2900\left(v_{\mathrm{C}-\mathrm{H}}\right), 1690\left(v_{\mathrm{C}-\mathrm{O}}\right), 1470\left(v_{\mathrm{C}-\mathrm{C}}\right), 980\left(\delta_{\mathrm{C}-\mathrm{H}}\right), 780\left(\delta_{\mathrm{C}-\mathrm{H}}\right) . \mathrm{UV}-\mathrm{Vis}:$ $\lambda_{\max }$ Py/nm: 688. 4-Co (23\%) Found: C, 70.46\%; H, 2.22\%; N, 10.27\%. Calcd. for $\mathrm{C}_{64} \mathrm{H}_{24} \mathrm{~N}_{8} \mathrm{O}_{8} \mathrm{Co}$ : C, $70.17 \%$; H, 2.26\%; N, 10.30\%. IR (KBr): $v_{\max } / \mathrm{cm}^{-1} 3300\left(v_{\mathrm{C}-\mathrm{H}}\right), 2900\left(v_{\mathrm{C}-\mathrm{H}}\right), 1690\left(v_{\mathrm{C}-\mathrm{O}}\right), 1470\left(v_{\mathrm{C}-\mathrm{C}}\right)$, $980\left(\delta_{\mathrm{C}-\mathrm{H}}\right), 780\left(\delta_{\mathrm{C}-\mathrm{H}}\right)$. UV-Vis: $\lambda_{\max }$ Py/nm: 688. 4-Zn $(22 \%)$ Found: C, 69.84\%; H, 2.37\%; N, $10.48 \%$. Calcd. for $\mathrm{C}_{64} \mathrm{H}_{24} \mathrm{~N}_{8} \mathrm{O}_{8} \mathrm{Zn}$ : C, 69.98\%; H, 2.20\%; N, $10.20 \%$. IR (KBr): $v_{\max } / \mathrm{cm}^{-1} 3300\left(v_{\mathrm{C}-\mathrm{H}}\right)$, $2900\left(v_{\mathrm{C}-\mathrm{H}}\right), 1690\left(v_{\mathrm{C}-\mathrm{O}}\right), 1470\left(v_{\mathrm{C}-\mathrm{C}}\right), 980\left(\delta_{\mathrm{C}-\mathrm{H}}\right), 780\left(\delta_{\mathrm{C}-\mathrm{H}}\right) . \mathrm{UV}-\mathrm{Vis}: \lambda_{\max }$ Py/nm: 688.

\subsection{Synthesis of Alkylbenzopyridoporphyrazineporphyrazines 5}

In the synthesis of 5, a mixture of 3,6-didecylphthalonitrile and 3,4-pyridinecarbodinitrile was dissolved in pentanol $(7 \mathrm{~mL})$ and zinc chloride $(0.05 \mathrm{~g})$ was added (Scheme 5). Zinc 1,4-didecylbenzotris(3,4-pyrido)porphyrazine (5b), zinc bis(1,4-didecylbenzo)-3,4-pyridoporphyrazine (5c) and zinc tris(1,4-didecylbenzo)-3,4-pyridoporphyrazine (5d) were synthesized from mixtures of 3,6didecylphthalonitrile and 3,4-dicyanopyridine in $3(0.18 \mathrm{~g}, 0.30 \mathrm{mmol}): 1$ (0.02 $\mathrm{g}, 0.15 \mathrm{mmol})$, $1(0.12 \mathrm{~g}, 0.29 \mathrm{mmol}): 1(0.04 \mathrm{~g}, 0.29 \mathrm{mmol})$ and 1 (0.06 g, $0.15 \mathrm{mmol}): 3(0.06 \mathrm{~g}, 0.45 \mathrm{mmol})$ ratios, 
respectively. Zinc tetra-3,4-pyridoporphyrazine (5a) and zinc octadecylphthalocyanine (5e) were synthesized from 3,4-dicyanopyridine [28,54] and 3,6-didecylphthalonitrile [33, 59], respectively.

The mixtures were heated for $240 \mathrm{~min}$ in the presence of DBU as a catalyst. After cooling, the reaction mixture was dissolved in toluene $(50 \mathrm{~mL})$ and the solution filtered. The solvent was removed by evaporation. The products were separated and purified by TLC (eluent: toluene). 5a (29\%) Found: C, 57.81\%; H, 2.11\%; N, 28.90\%. Calcd. for $\mathrm{C}_{28} \mathrm{H}_{12} \mathrm{~N}_{12} \mathrm{Zn}$ : C, 57.79\%; H, 2.08\%; N, 28.89\%. IR $(\mathrm{KBr}): v_{\max } / \mathrm{cm}^{-1} 2960\left(v_{\mathrm{C}-\mathrm{H}}\right), 1500\left(v_{\mathrm{C}-\mathrm{C}}\right), 1470\left(v_{\mathrm{C}-\mathrm{C}}\right), 1450\left(v_{\mathrm{C}-\mathrm{C}}\right), 1210\left(\delta_{\mathrm{C}-\mathrm{H}}\right), 1090\left(\delta_{\mathrm{C}-\mathrm{H}}\right), 790$ $\left(\delta_{\mathrm{C}-\mathrm{H}}\right)$. UV-Vis: $\lambda_{\max }$ Py/nm: 675; 5b (65\%) Found: C, 68.31\%; H, 6.22\%; N, 17.90\%. Calcd. for $\mathrm{C}_{49} \mathrm{H}_{53} \mathrm{~N}_{11} \mathrm{Zn}$ : C, 68.32\%; H, 6.22\%; N, 17.89\%. IR (KBr): $v_{\max } / \mathrm{cm}^{-1} 2960\left(v_{\mathrm{C}-\mathrm{H}}\right), 1600\left(v_{\mathrm{C}-\mathrm{C}}\right), 1460$ $\left(v_{\mathrm{C}-\mathrm{C}}\right), 1440\left(v_{\mathrm{C}-\mathrm{C}}\right), 1210\left(\delta_{\mathrm{C}-\mathrm{H}}\right), 1080\left(\delta_{\mathrm{C}-\mathrm{H}}\right), 720\left(\delta_{\mathrm{C}-\mathrm{H}}\right) .{ }^{1} \mathrm{H}-\mathrm{NMR}\left(90 \mathrm{MHz}, \mathrm{CDCl}_{3}\right): \delta$, ppm 7.4 $(11.0 \mathrm{H}), 2.8(4.2 \mathrm{H}), 1.3(33.4 \mathrm{H}), 0.9(6.7 \mathrm{H}) . \mathrm{UV}-\mathrm{Vis}: \lambda_{\max }$ toluene/nm: 686. 5c $(84 \%)$ Found: C, $73.67 \%$; H, 8.30\%; N, 12.28\%. Calcd. for $\mathrm{C}_{70} \mathrm{H}_{94} \mathrm{~N}_{10} \mathrm{Zn}$ : C, 73.68\%; H, 8.30\%; N, 12.28\%. IR (KBr): $v_{\max } / \mathrm{cm}^{-1} 2970\left(v_{\mathrm{C}-\mathrm{H}}\right), 1600\left(v_{\mathrm{C}-\mathrm{C}}\right), 1500\left(v_{\mathrm{C}-\mathrm{C}}\right), 1470\left(v_{\mathrm{C}-\mathrm{C}}\right), 1450\left(v_{\mathrm{C}-\mathrm{C}}\right), 1210\left(\delta_{\mathrm{C}-\mathrm{H}}\right), 1090\left(\delta_{\mathrm{C}-\mathrm{H}}\right), 720$ $\left(\delta_{\mathrm{C}-\mathrm{H}}\right) .{ }^{1} \mathrm{H}-\mathrm{NMR}\left(90 \mathrm{MHz}, \mathrm{CDCl}_{3}\right): \delta$, ppm $7.4(10.0 \mathrm{H}), 2.8(8 \mathrm{H}), 1.3(63.8 \mathrm{H}), 0.9(12.3 \mathrm{H})$. UV-Vis: $\lambda_{\max }$ toluene/nm: 686. 5d (84\%) Found: C, 76.94\%; H, 9.57\%; N, 8.86\%. Calcd. for $\mathrm{C}_{91} \mathrm{H}_{135} \mathrm{~N}_{9} \mathrm{Zn}$ : C, 76.94\%; H, 9.58\%; N, 8.88\%. IR (KBr): $v_{\max } / \mathrm{cm}^{-1} 2970\left(v_{\mathrm{C}-\mathrm{H}}\right), 1600\left(v_{\mathrm{C}-\mathrm{C}}\right), 1500\left(v_{\mathrm{C}-\mathrm{C}}\right), 1470\left(v_{\mathrm{C}-\mathrm{C}}\right)$, $1210\left(\delta_{\mathrm{C}-\mathrm{H}}\right), 1100\left(\delta_{\mathrm{C}-\mathrm{H}}\right), 720\left(\delta_{\mathrm{C}-\mathrm{H}}\right) .{ }^{1} \mathrm{H}-\mathrm{NMR}\left(90 \mathrm{MHz}, \mathrm{CDCl}_{3}\right): \delta$, ppm $7.4(9.0 \mathrm{H}), 2.8(12.3 \mathrm{H}), 1.3$ $(95.9 \mathrm{H}), 0.9(18.8 \mathrm{H})$. UV-Vis: $\lambda_{\max }$ toluene/nm: 686. 5e $(96 \%)$ Found: C, 79.12\%; H, 10.41\%; N, 6.61\%. Calcd. for $\mathrm{C}_{112} \mathrm{H}_{176} \mathrm{~N}_{8} \mathrm{Zn}$ : C, 79.12\%; H, 10.43\%; N, 6.59\%. IR (KBr): $v_{\max } / \mathrm{cm}^{-1} 2970\left(v_{\mathrm{C}-\mathrm{H}}\right)$, $1600\left(v_{\mathrm{C}-\mathrm{C}}\right), 1500\left(v_{\mathrm{C}-\mathrm{C}}\right), 1470\left(v_{\mathrm{C}-\mathrm{C}}\right), 1210\left(\delta_{\mathrm{C}-\mathrm{H}}\right), 1100\left(\delta_{\mathrm{C}-\mathrm{H}}\right), 720\left(\delta_{\mathrm{C}-\mathrm{H}}\right) .{ }^{1} \mathrm{H}-\mathrm{NMR}\left(90 \mathrm{MHz}, \mathrm{CDCl}_{3}\right)$ : $\delta$, ppm $7.4(8.0 \mathrm{H}), 2.8(16.0 \mathrm{H}), 1.3(128.0 \mathrm{H}), 0.9(24.1 \mathrm{H})$. UV-Vis: $\lambda_{\max }$ toluene/nm: 703.

The regioisomers of $5 \mathrm{c}$ were separated by TLC (Merk Silica gel $60 \mathrm{~F}_{254}$ on aluminium sheet, eluent: toluene - Py, 7:3) into four green- to blue-colored fractions. These fractions were numbered from 1, 2, 3 and 4 , according to their $\mathrm{R}_{\mathrm{f}}$ values of $0.95,0.91,0.75$ and 0.65 , respectively. Each fraction was recovered by scraping from the TLC plate, dissolved in pyridine, the solution filtered, and the solvent removed. Fraction 1: ${ }^{1} \mathrm{H}-\mathrm{NMR}$ (benzene- $\mathrm{d}_{6}$ ); $\delta$ ppm $0.93(\mathrm{t}, 12 \mathrm{H}), 1.21-1.88(\mathrm{~m}, 48 \mathrm{H}), 1.88-2.23(\mathrm{~m}$, $8 \mathrm{H}), 2.29-2.69(\mathrm{~m}, 8 \mathrm{H}), 4.13(\mathrm{t}, 4 \mathrm{H}), 4.32(\mathrm{t}, 4 \mathrm{H}), 7.35(\mathrm{~d}, 2 \mathrm{H}), 7.49(\mathrm{~d}, 2 \mathrm{H}), 8.30(\mathrm{~m}, 6 \mathrm{H})$. Fraction 2: ${ }^{1} \mathrm{H}-\mathrm{NMR}$ (benzene- $\mathrm{d}_{6}$ ); $\delta$ ppm $0.92(\mathrm{t}, 12 \mathrm{H}), 1.24-1.80(\mathrm{~m}, 48 \mathrm{H}), 1.82-2.29(\mathrm{~m}, 8 \mathrm{H}), 2.32-2.62(\mathrm{~m}$, $8 \mathrm{H}), 4.12(\mathrm{t}, 4 \mathrm{H}), 4.30(\mathrm{t}, 4 \mathrm{H}), 7.36(\mathrm{~d}, 2 \mathrm{H}), 7.49(\mathrm{~d}, 2 \mathrm{H}), 8.31(\mathrm{~m}, 6 \mathrm{H})$. Fraction 3: ${ }^{1} \mathrm{H}-\mathrm{NMR}$ (benzene- $\mathrm{d}_{6}$ ); $\delta$ ppm $0.92(\mathrm{t}, 12 \mathrm{H}), 1.16-1.95(\mathrm{~m}, 48 \mathrm{H}), 1.95-2.20(\mathrm{~m}, 4 \mathrm{H}), 2.20-2.36(\mathrm{~m}, 4 \mathrm{H}), 2.36-$ $2.70(\mathrm{~m}, 8 \mathrm{H}), 3.99(\mathrm{t}, 4 \mathrm{H}), 4.23(\mathrm{t}, 4 \mathrm{H}), 7.36(\mathrm{~d}, 2 \mathrm{H}), 7.49(\mathrm{~d}, 2 \mathrm{H}), 8.30(\mathrm{~m}, 6 \mathrm{H})$. Fraction 4: ${ }^{1} \mathrm{H}-\mathrm{NMR}$ (benzene- $\left.\mathrm{d}_{6}\right) ; \delta$ ppm $0.92(\mathrm{t}, 12 \mathrm{H}), 1.27-1.83(\mathrm{~m}, 48 \mathrm{H}), 1.83-2.26(\mathrm{~m}, 8 \mathrm{H}), 2.30-2.68(\mathrm{~m}, 8 \mathrm{H}), 4.07(\mathrm{t}$, $4 \mathrm{H}), 4.29(\mathrm{t}, 4 \mathrm{H}), 7.35(\mathrm{~d}, 2 \mathrm{H}), 7.48(\mathrm{~d}, 2 \mathrm{H}), 8.31(\mathrm{~m}, 6 \mathrm{H})$.

Quaternization of $5 \mathrm{c}$ was performed as follows: zinc $5 \mathrm{c}(0.17 \mathrm{~g}, 0.15 \mathrm{mmol})$ was reacted with quaternizing agents such as MCAA $(0.57 \mathrm{~g}, 6 \mathrm{mmol})$, DES $(0.1 \mathrm{~g}, 0.6 \mathrm{mmol})$ and DMS (0.2 g, $1.5 \mathrm{mmol}$ ), respectively, in $\mathrm{DMF}$ as solvent at $140^{\circ} \mathrm{C}$ for $120 \mathrm{~min}$. The reaction mixture was dissolved in acetone $(20 \mathrm{~mL})$, cooled to room temperature and the solution filtered. The solvent was removed. The products were purified by TLC (eluent: THF-toluene, 8:2). Each product was recovered by scraping from the TLC plate, dissolving in Py, filtering the solution, and removal of the solvent. 5c with MCAA: dark blue solid (32 mg; yield 23\%). ${ }^{1} \mathrm{H}-\mathrm{NMR}\left(\mathrm{DMSO}-\mathrm{d}_{6}\right) ; \delta$ ppm $0.85\left(\mathrm{~m}, 12 \mathrm{H}, \mathrm{CH}_{3}\right)$, 1.19-1.71 (m, 48H, $\left.\gamma-\mathrm{CH}_{2}\right), 1.79-2.12\left(\mathrm{~m}, 8 \mathrm{H}, \beta-\mathrm{CH}_{2}\right), 2.27-2.68\left(\mathrm{~m}, 8 \mathrm{H}, \beta-\mathrm{CH}_{2}\right), 4.15(\mathrm{~m}, 4 \mathrm{H}, \alpha-$ $\mathrm{CH}_{2}$ ), 4.39 (m, 4H, $\left.\alpha-\mathrm{CH}_{2}\right), 6.19$ (s, 2H, $\mathrm{CH}_{2}$ ), 7.37 (m, 4H, arm), 8.32 (m, 6H, Py). IR (KBr): 
$v_{\text {max }} / \mathrm{cm}^{-1} 3050\left(v_{\mathrm{C}-\mathrm{H}}\right), 2980\left(v_{\mathrm{C}-\mathrm{H}}\right), 1730\left(v_{\mathrm{C}-\mathrm{O}}\right), 1620\left(v_{\mathrm{C}-\mathrm{C}}\right), 1400\left(v_{\mathrm{C}-\mathrm{C}}\right), 1210\left(\delta_{\mathrm{C}-\mathrm{H}}\right), 1080\left(\delta_{\mathrm{C}-\mathrm{H}}\right), 790$ $\left(\delta_{\mathrm{C}-\mathrm{H}}\right), 690\left(\delta_{\mathrm{C}-\mathrm{H}}\right)$. UV-Vis $\left(\lambda_{\max }\right.$ toluene $\left./ \mathrm{nm}\right)$ 686: $\left(\lambda_{\max } \mathrm{Py} / \mathrm{nm}\right)$ 690: $\left(\lambda_{\max }\right.$ Water $\left./ \mathrm{nm}\right)$ 681; Found: C, 45.02\%; H, 2.49\%; N, 17.48\%. Calcd. for $\mathrm{C}_{74} \mathrm{H}_{100} \mathrm{~N}_{10} \mathrm{O}_{4} \mathrm{Zn}$ : C, 45.05\%; H, 2.52\%; N.17.50\%. 5c with DES: blue solid (37 mg, yield 17\%). ${ }^{1} \mathrm{H}-\mathrm{NMR}\left(\mathrm{DMSO}_{\mathrm{d}}\right) \mathrm{\delta}$, ppm $0.86\left(\mathrm{~m}, 12 \mathrm{H}, \mathrm{CH}_{3}\right), 1.02-1.70$ (m, $\left.48 \mathrm{H}, \gamma-\mathrm{CH}_{2}\right), 1.88-2.11\left(\mathrm{~m}, 8 \mathrm{H}, \beta-\mathrm{CH}_{2}\right), 2.30-2.68\left(\mathrm{~m}, 8 \mathrm{H}, \beta-\mathrm{CH}_{3}\right), 4.11\left(\mathrm{~m}, 4 \mathrm{H}, \alpha-\mathrm{CH}_{2}\right), 4.25(\mathrm{~m}, 4 \mathrm{H}$, $\left.\alpha-\mathrm{CH}_{2}\right), 7.38\left(\mathrm{~m}, 4 \mathrm{H}\right.$, arom), $8.18(\mathrm{~m}, 4 \mathrm{H}, \mathrm{Py}) . \mathrm{IR}(\mathrm{KBr}) v_{\max } / \mathrm{cm}^{-1} 3050\left(v_{\mathrm{C}-\mathrm{H}}\right), 2960\left(v_{\mathrm{C}-\mathrm{H}}\right)$, $1500\left(v_{\mathrm{C}-\mathrm{C}}\right), 1450\left(v_{\mathrm{C}-\mathrm{C}}\right), 1400\left(v_{\mathrm{C}-\mathrm{C}}\right), 1340\left(v_{\mathrm{S}-\mathrm{O}}\right), 1180\left(v_{\mathrm{S}-\mathrm{O}}\right), 1250\left(\delta_{\mathrm{C}-\mathrm{H}}\right), 920\left(\delta_{\mathrm{C}-\mathrm{H}}\right), 760\left(\delta_{\mathrm{C}-\mathrm{H}}\right), 590$ $\left(\delta_{\mathrm{C}-\mathrm{S}}\right)$. UV-Vis $\left(\lambda_{\max }\right.$ toluene/nm) 687: $\left(\lambda_{\max } \mathrm{Py} / \mathrm{nm}\right)$ 731: $\left(\lambda_{\max }\right.$ water/nm) 679 . Found: C,37.10\%; H, 1.78\%; N. 18.49\%. Calcd. for $\mathrm{C}_{70} \mathrm{H}_{98} \mathrm{~N}_{10} \mathrm{~S}_{2} \mathrm{O}_{6} \mathrm{Zn}$ : C, 37.11\%; H, 1.78\%; N, 18.54\%. 5c with DMS: dark blue solid (53 mg, yield 28\%). ${ }^{1} \mathrm{H}-\mathrm{NMR}$ (DMSO-d $\left.\mathrm{d}_{6}\right): \delta \mathrm{ppm} 0.88\left(\mathrm{~m}, 12 \mathrm{H}, \mathrm{CH}_{3}\right), 1.14-1.72(\mathrm{~m}$, $\left.48 \mathrm{H}, \gamma-\mathrm{CH}_{2}\right), 1.82-2.17\left(\mathrm{~m}, 8 \mathrm{H}, \beta-\mathrm{CH}_{2}\right), 2.29-2.62\left(\mathrm{~m}, 8 \mathrm{H}, \beta-\mathrm{CH}_{2}\right), 4.06\left(\mathrm{~s}, 6 \mathrm{H}, \mathrm{CH}_{3}\right), 4.27(\mathrm{~m}, 4 \mathrm{H}, \alpha-$ $\mathrm{CH}_{2}$ ), 4.51 (m, 4H, $\left.\alpha-\mathrm{CH}_{2}\right), 7.34$ (m, 4H, arom), 8.23 (m, 6H, Py); IR (KBr): $v_{\max } / \mathrm{cm}^{-1} 3060\left(v_{\mathrm{C}-\mathrm{H}}\right)$, $2980\left(v_{\mathrm{C}-\mathrm{H}}\right), 1500\left(v_{\mathrm{C}-\mathrm{C}}\right), 1450\left(v_{\mathrm{C}-\mathrm{C}}\right), 1400\left(v_{\mathrm{C}-\mathrm{C}}\right), 1250\left(\delta_{\mathrm{C}-\mathrm{H}}\right), 1100\left(\delta_{\mathrm{C}-\mathrm{H}}\right), 950\left(\delta_{\mathrm{C}-\mathrm{H}}\right), 830\left(\delta_{\mathrm{C}-\mathrm{H}}\right), 660$ $\left(\delta_{\mathrm{C}-\mathrm{H}}\right)$. UV-Vis $\left(\lambda_{\max }\right.$ toluene/nm) 739: $\left(\lambda_{\max } \mathrm{Py} / \mathrm{nm}\right)$ 739: $\left(\lambda_{\max }\right.$ water/nm) 684. Found: C, 49.03\%; H, $3.08 \%$; N, 21.40\%. Calcd. for $\mathrm{C}_{72} \mathrm{H}_{100} \mathrm{~N}_{10} \mathrm{Zn}$ : C, 49.03\%; H, 3.09\%; N, 21.43\%.

Quaternized regioisomers of 5c: Regioisomers of 5c $(0.4 \mathrm{mg}, 0.35 \mu \mathrm{mol})$ were reacted with a quaternizing agent such as DMS $(0.5 \mathrm{mg}, 3.5 \mu \mathrm{mol})$ in DMF as solvent at $140{ }^{\circ} \mathrm{C}$ for $120 \mathrm{~min}$. The products were purified with TLC (eluent: THF-toluene, 8: 2). Each product was recovered by scraping from the TLC plate, dissolving in pyridine, filtering the solution and removal of the solvent. Fraction 1 with DMS: dark blue solid (0.053 mg, yield $13 \%) .{ }^{1} \mathrm{H}-\mathrm{NMR}$ (DMSO-d $\left.\mathrm{d}_{6}\right): \delta \mathrm{ppm} 0.86\left(\mathrm{t}, 12 \mathrm{H}, \mathrm{CH}_{3}\right)$, 1.15-1.70 (m, 48H, $\left.\gamma-\mathrm{CH}_{2}\right), 1.82-2.12\left(\mathrm{~m}, 8 \mathrm{H}, \beta-\mathrm{CH}_{2}\right), 2.19-2.49\left(\mathrm{~m}, 8 \mathrm{H}, \beta-\mathrm{CH}_{2}\right), 3.67\left(\mathrm{~s}, 6 \mathrm{H}, \mathrm{CH}_{3}\right)$, $3.92\left(\mathrm{t}, 4 \mathrm{H}, \alpha-\mathrm{CH}_{2}\right), 4.19\left(\mathrm{t}, 4 \mathrm{H}, \alpha-\mathrm{CH}_{2}\right), 7.37$ (m, 4H, arom), $\left.8.20(\mathrm{~m}, 6 \mathrm{H}, \mathrm{Py}) ; \mathrm{IR}(\mathrm{KBr}): v_{\max } / \mathrm{cm}^{-1}\right)$ $3070\left(v_{\mathrm{C}-\mathrm{H}}\right), 2980\left(v_{\mathrm{C}-\mathrm{H}}\right), 1500\left(v_{\mathrm{C}-\mathrm{C}}\right), 1400\left(v_{\mathrm{C}-\mathrm{C}}\right), 1250\left(\delta_{\mathrm{C}-\mathrm{H}}\right), 1100\left(\delta_{\mathrm{C}-\mathrm{H}}\right), 950\left(\delta_{\mathrm{C}-\mathrm{H}}\right), 820\left(\delta_{\mathrm{C}-\mathrm{H}}\right), 660$ $\left(\delta_{\mathrm{C}-\mathrm{H}}\right)$; UV-Vis $\left(\lambda_{\max }\right.$ toluene/nm) 680: $\left(\lambda_{\max } \mathrm{Py} / \mathrm{nm}\right)$ 703: $\left(\lambda_{\max }\right.$ water/nm) 690; Fluorescence $\left(\mathrm{F}_{\max }\right.$ Py/nm) 687: ( $\mathrm{F}_{\max }$ water/nm) 695. Found: C, 49.00\%; H, 3.01\%; N, 21.33\%. Calcd. for $\mathrm{C}_{72} \mathrm{H}_{100} \mathrm{~N}_{10} \mathrm{Zn}$ : C, 49.03\%; H, 3.09\%; N, 21.43\%. Fraction 2 with DMS: dark blue solid (0.065 mg, yield $15 \%)$. ${ }^{1} \mathrm{H}-$ NMR (DMSO-d $)_{6}$ : $\delta$ ppm $0.87\left(\mathrm{t}, 12 \mathrm{H}, \mathrm{CH}_{3}\right), 1.16-1.73\left(\mathrm{~m}, 48 \mathrm{H}, \gamma-\mathrm{CH}_{2}\right), 1.73-2.10\left(\mathrm{~m}, 8 \mathrm{H}, \beta-\mathrm{CH}_{2}\right)$, 2.10-2.55 (m, 8H, $\left.\beta-\mathrm{CH}_{2}\right), 3.90\left(\mathrm{~s}, 6 \mathrm{H}, \mathrm{CH}_{3}\right), 3.99\left(\mathrm{t}, 4 \mathrm{H}, \alpha-\mathrm{CH}_{2}\right), 4.17\left(\mathrm{t}, 4 \mathrm{H}, \alpha-\mathrm{CH}_{2}\right), 7.23(\mathrm{~m}, 4 \mathrm{H}$, arom), 8.25 (m, 6H, Py). IR (KBr): $v_{\max } / \mathrm{cm}^{-1} 3070\left(v_{\mathrm{C}-\mathrm{H}}\right), 2980\left(v_{\mathrm{C}-\mathrm{H}}\right), 1500\left(v_{\mathrm{C}-\mathrm{C}}\right), 1400\left(v_{\mathrm{C}-\mathrm{C}}\right), 1250$ $\left(\delta_{\mathrm{C}-\mathrm{H}}\right), 1100\left(\delta_{\mathrm{C}-\mathrm{H}}\right), 980\left(\delta_{\mathrm{C}-\mathrm{H}}\right), 830\left(\delta_{\mathrm{C}-\mathrm{H}}\right), 660\left(\delta_{\mathrm{C}-\mathrm{H}}\right)$; UV-Vis $\left(\lambda_{\max }\right.$ toluene/nm) 689: $\left(\lambda_{\max }\right.$ Py $\left./ \mathrm{nm}\right)$ 675: $\left(\lambda_{\max }\right.$ water/nm) 686; Fluorescence $\left(\mathrm{F}_{\max } \mathrm{Py} / \mathrm{nm}\right)$ 684: $\left(\mathrm{F}_{\max }\right.$ water/nm) 690; Found: C, 48.99\%; H, 2.98\%; N, 21.22\%. Calcd. for $\mathrm{C}_{72} \mathrm{H}_{100} \mathrm{~N}_{10} \mathrm{Zn}$ : C, 49.03\%; H, 3.09\%; N, 21.43\%. Fraction 3 with DMS: dark blue solid (0.055 mg, yield $11 \%$ ). ${ }^{1} \mathrm{H}-\mathrm{NMR}\left(\mathrm{DMSO}-\mathrm{d}_{6}\right): \delta$ ppm $0.85\left(\mathrm{~m}, 12 \mathrm{H}, \mathrm{CH}_{3}\right), 1.09$ $1.63\left(\mathrm{~m}, 48 \mathrm{H}, \gamma-\mathrm{CH}_{2}\right), 1.70-2.11\left(\mathrm{~m}, 8 \mathrm{H}, \beta-\mathrm{CH}_{2}\right), 2.11-2.42\left(\mathrm{~m}, 8 \mathrm{H}, \beta-\mathrm{CH}_{2}\right), 3.86\left(\mathrm{~s}, 6 \mathrm{H}, \mathrm{CH}_{3}\right), 3.97(\mathrm{t}$, $\left.4 \mathrm{H}, \alpha-\mathrm{CH}_{2}\right), 4.21\left(\mathrm{t}, 4 \mathrm{H}, \alpha-\mathrm{CH}_{2}\right), 7.23-7.33$ (m, 4H, arom), 8.21 (m, 6H, Py). IR (KBr): $\lambda_{\max } / \mathrm{cm}^{-1} 3080$ $\left(v_{\mathrm{C}-\mathrm{H}}\right), 2970\left(v_{\mathrm{C}-\mathrm{H}}\right), 1500\left(v_{\mathrm{C}-\mathrm{C}}\right), 1400\left(v_{\mathrm{C}-\mathrm{C}}\right), 1250\left(\delta_{\mathrm{C}-\mathrm{H}}\right), 1100\left(\delta_{\mathrm{C}-\mathrm{H}}\right), 950\left(\delta_{\mathrm{C}-\mathrm{H}}\right), 830\left(\delta_{\mathrm{C}-\mathrm{H}}\right), 660\left(\delta_{\mathrm{C}-}\right.$ H). UV-Vis $\left(\lambda_{\max }\right.$ toluene/nm) 681: $\left(\lambda_{\max } \mathrm{Py} / \mathrm{nm}\right)$ 689: $\left(\lambda_{\max }\right.$ water/nm) 689; Fluorescence $\left(\mathrm{F}_{\max } \mathrm{Py} / \mathrm{nm}\right)$ 690: ( $\mathrm{F}_{\max }$ water / nm) 698; Found: C, 49.03\%; H, 3.03\%; N, 21.40\%. Calcd. for $\mathrm{C}_{72} \mathrm{H}_{100} \mathrm{~N}_{10} \mathrm{Zn}$ : C, 49.03\%; H, 3.09\%; N, 21.43\%. Fraction 4 with DMS: dark blue solid (0.078 mg, yield $19 \%) .{ }^{1} \mathrm{H}-$ NMR (DMSO-d $\left.{ }_{6}\right): \delta$ ppm $0.87\left(\mathrm{t}, 12 \mathrm{H}, \mathrm{CH}_{3}\right), 1.20-1.63\left(\mathrm{~m}, 48 \mathrm{H}, \gamma-\mathrm{CH}_{2}\right), 1.71-2.17\left(\mathrm{~m}, 8 \mathrm{H}, \beta-\mathrm{CH}_{2}\right)$, 2.17-2.47 (m, 8H, $\left.\beta-\mathrm{CH}_{2}\right), 3.85\left(\mathrm{~s}, 6 \mathrm{H}, \mathrm{CH}_{3}\right), 4.09\left(\mathrm{t}, 4 \mathrm{H}, \alpha-\mathrm{CH}_{2}\right), 4.27\left(\mathrm{t}, 4 \mathrm{H}, \alpha-\mathrm{CH}_{2}\right), 7.21-7.36(\mathrm{~m}$, 4H, arom), 8.22 (m, 6H, Py). IR (KBr): $\lambda_{\max } / \mathrm{cm}^{-1} 3070\left(v_{\mathrm{C}-\mathrm{H}}\right), 2980\left(v_{\mathrm{C}-\mathrm{H}}\right), 1500\left(v_{\mathrm{C}-\mathrm{C}}\right), 1400\left(v_{\mathrm{C}-\mathrm{C}}\right)$, 
$1250\left(\delta_{\mathrm{C}-\mathrm{H}}\right), 1100\left(\delta_{\mathrm{C}-\mathrm{H}}\right), 950\left(\delta_{\mathrm{C}-\mathrm{H}}\right), 830\left(\delta_{\mathrm{C}-\mathrm{H}}\right), 660\left(\delta_{\mathrm{C}-\mathrm{H}}\right)$; UV-Vis $\left(\lambda_{\max }\right.$ toluene $\left./ \mathrm{nm}\right) 677:\left(\lambda_{\max }\right.$ Py/nm) 730: $\left(\lambda_{\max }\right.$ water $\left./ \mathrm{nm}\right)$ 673; Fluorescence $\left(\mathrm{F}_{\max } \mathrm{Py} / \mathrm{nm}\right)$ 686: $\left(\mathrm{F}_{\max }\right.$ water $\left./ \mathrm{nm}\right)$ 687; Found: C.49.02: H. 3.08: N. 21.43. Calcd. for $\mathrm{C}_{72} \mathrm{H}_{100} \mathrm{~N}_{10} \mathrm{Zn:}$ C. 49.03: H. 3.09: N.21.43.

\subsection{Synthesis of subphthalocyanine derivatives $\mathbf{6}$}

Compound 6a was synthesized from 1,2-dicyanobenzene. Compound $\mathbf{6 c}$ was synthesized from 1,2dicyano-3,4,5,6-tetrafluorobenzene. Compounds 6d-g were synthesized from the precursors, 1,2dicyano-3,6-bis(thiobutyl)-4,5-difluorobenzene (14a) [36], 1,2-dicyano-3,4,5,6-tetrakis(thiobutyl)benzene (14b) [36], 1,2-dicyano-3,6-bis(thiophenyl)-4,5-difluorobenzene (14c) [36] and 1,2-dicyano3,4,5,6-tetrakis(thiophenyl)benzene (14d) [36], respectively.

Compound 6a: A solution of boron trichloride $(20.5 \mathrm{~mL}, 0.02 \mathrm{~mol}, 1 \mathrm{M}$ in hexane) was added into a mixture of 1,2-benzenedicarbonitrile $(5.0 \mathrm{~g}, 0.04 \mathrm{~mol})$ and 1-chloronaphtahalene $(12 \mathrm{~mL})$ under an argon atmosphere at $-3^{\circ} \mathrm{C}$. After addition, the reaction mixture was heated to $120{ }^{\circ} \mathrm{C}$ with stirring. Hexane was distilled off. It was heated to $250^{\circ} \mathrm{C}$ for 10 minutes and cooled to room temperature. The product was extracted with petroleum ether for $1440 \mathrm{~min}$ and then toluene for $120 \mathrm{~min}$ on a Soxhlet extractor. The obtained product was recrystallized from ethanol (Scheme 6).

SubPC derivatives $\mathbf{6 b}-\mathbf{g}$ were synthesized in accordance with above-mentioned SubPC synthetic method. 6a (71\%) Found: C, 66.88\%; H, 2.81\%; N, 19.50\%. Calcd. for $\mathrm{C}_{24} \mathrm{H}_{12} \mathrm{~N}_{6} \mathrm{BCl}$ : C, 66.88\%; H, $2.81 \%$; N, 19.59\%. IR (KBr): $v_{\max } / \mathrm{cm}^{-1} 3200\left(v_{\mathrm{C}-\mathrm{H}}\right), 3070\left(v_{\mathrm{C}-\mathrm{H}}\right), 2370\left(v_{\mathrm{C}-\mathrm{N}}\right), 1611\left(v_{\mathrm{C}-\mathrm{C}}\right), 1452\left(v_{\mathrm{C}-\mathrm{C}}\right)$, $1304\left(v_{\mathrm{C}-\mathrm{H}}\right), 1130\left(\delta_{\mathrm{C}-\mathrm{H}}\right), 950\left(\delta_{\mathrm{C}-\mathrm{S}}\right) .{ }^{1} \mathrm{H}-\mathrm{NMR}\left(\mathrm{CDCl}_{3}\right): \delta$, ppm $7.21(\mathrm{~s}, 12 \mathrm{H}) . \mathrm{MS} \mathrm{m} / \mathrm{z}=431$. UV-Vis: $\lambda_{\max }$ (toluene)/nm: 564. 6b (39\%) Found: C, 72.18\%; H, 6.06\%; N, 14.01\%. Calcd. for $\mathrm{C}_{36} \mathrm{H}_{36} \mathrm{~N}_{6} \mathrm{BCl}$ : C, 72.18\%; H, 6.06\%; N, 14.01\%. IR (KBr): $v_{\max } / \mathrm{cm}^{-1} 2980\left(v_{\mathrm{C}-\mathrm{H}}\right), 1720\left(v_{\mathrm{C}-\mathrm{C}}\right), 1620\left(v_{\mathrm{C}-\mathrm{C}}\right), 1450\left(v_{\mathrm{C}-}\right.$ $\mathrm{H}), 1400\left(v_{\mathrm{C}-\mathrm{H}}\right), 1360\left(\delta_{\mathrm{C}-\mathrm{H}}\right), 1280\left(\delta_{\mathrm{C}-\mathrm{H}}\right), 1190(\delta \mathrm{C}-\mathrm{H}), 760\left(\delta_{\mathrm{C}-\mathrm{H}}\right) .{ }^{1} \mathrm{H}-\mathrm{NMR}\left(\mathrm{CDCl}_{3}\right): \delta, \mathrm{ppm} 7.80(\mathrm{~s}$, $3 \mathrm{H}), 7.49(\mathrm{~s}, 3 \mathrm{H}), 7.32(\mathrm{~s}, 3 \mathrm{H}), 1.35(\mathrm{~s}, 9 \mathrm{H}) . \mathrm{MS} \mathrm{m} / \mathrm{z}=599 . \mathrm{UV}-\mathrm{Vis}: \lambda_{\max }$ toluene/nm: 566. 6c $(26 \%)$ Found: C, 50.39\%; N, 14.70\%. Calcd. for $\mathrm{C}_{24} \mathrm{~N}_{6} \mathrm{BClF}_{12}$ : C, 50.39\%; H, 0.00\%; N, 14.70\%. IR (KBr): $v_{\max } / \mathrm{cm}^{-1} 1490\left(v_{\mathrm{C}-\mathrm{H}}\right), 1450\left(v_{\mathrm{C}-\mathrm{N}}\right), 1270\left(v_{\mathrm{C}-\mathrm{F}}\right), 1220\left(v_{\mathrm{C}-\mathrm{F}}\right), 1120\left(v_{\mathrm{C}-\mathrm{H}}\right), 960\left(\delta_{\mathrm{C}-\mathrm{H}}\right), 800\left(\delta_{\mathrm{C}-\mathrm{H}}\right), 760$ $\left(\delta_{\mathrm{C}-\mathrm{S}}\right)$. MS $\mathrm{m} / \mathrm{z}=647$. UV-Vis: $\lambda_{\max }$ toluene/nm: $572.6 \mathrm{~d}(8 \%)$ Found: $\mathrm{C}, 53.99 \%$; H, 5.10\%; N, 7.84\%. Calcd. for $\mathrm{C}_{48} \mathrm{H}_{54} \mathrm{~N}_{6} \mathrm{BClF}_{6} \mathrm{~S}_{6}: \mathrm{C}, 53.99 \% ; \mathrm{H}, 5.10 \%$; N, 7.87\%. IR (KBr): $v_{\max } / \mathrm{cm}^{-1} 2980\left(v_{\mathrm{C}-\mathrm{H}}\right), 2150$ $\left(v_{\mathrm{C}-\mathrm{N}}\right), 1600\left(v_{\mathrm{C}-\mathrm{C}}\right), 1500\left(v_{\mathrm{C}-\mathrm{C}}\right), 1450\left(v_{\mathrm{C}-\mathrm{C}}\right), 1150\left(\delta_{\mathrm{C}-\mathrm{H}}\right), 850\left(\delta_{\mathrm{C}-\mathrm{H}}\right) .{ }^{1} \mathrm{H}-\mathrm{NMR}\left(\mathrm{CDCl}_{3}\right): \delta, \mathrm{ppm} 3.15(\mathrm{t}$, 12H), $1.51(\mathrm{~m}, 24 \mathrm{H}), 0.90(\mathrm{t}, 18 \mathrm{H}) . \mathrm{MS} \mathrm{m} / \mathrm{z}=1068$. UV-Vis: $\lambda_{\max }$ (toluene)/nm: $596.6 \mathrm{6e}(5 \%)$ Found: C, 60.69\%; H, 2.55\%; N, 7.08\%. Calcd. for $\mathrm{C}_{60} \mathrm{H}_{30} \mathrm{~N}_{6} \mathrm{BClF}_{6} \mathrm{~S}_{6}: \mathrm{C}, 60.66 \%$; H, 2.55\%; N, 7.08\%. IR $(\mathrm{KBr}): v_{\max } / \mathrm{cm}^{-1} 3050\left(v_{\mathrm{C}-\mathrm{H}}\right), 2250\left(v_{\mathrm{C}-\mathrm{N}}\right), 1580\left(v_{\mathrm{C}-\mathrm{C}}\right), 1450\left(v_{\mathrm{C}-\mathrm{C}}\right), 1250\left(v_{\mathrm{C}-\mathrm{F}}\right), 1090\left(\delta_{\mathrm{C}-\mathrm{H}}\right), 670\left(\delta_{\mathrm{C}-\mathrm{S}}\right)$. ${ }^{1} \mathrm{H}-\mathrm{NMR}\left(\mathrm{CDCl}_{3}\right): \delta$, ppm $7.26(\mathrm{~m}, 30 \mathrm{H}) . \mathrm{MS} \mathrm{m} / \mathrm{z}=1188$. UV-Vis: $\lambda_{\max }$ toluene/nm: $621.6 \mathrm{6f}(17 \%)$ Found: C, 58.07\%; H, 7.31\%; N, 5.65\%. Calcd. for $\mathrm{C}_{72} \mathrm{H}_{108} \mathrm{~N}_{6} \mathrm{BClS}_{12}$ : C, 58.07\%; H, 7.31\%; N, $5.65 \%$. IR (KBr): $v_{\max } / \mathrm{cm}^{-1} 2980\left(v_{\mathrm{C}-\mathrm{H}}\right), 2125\left(v_{\mathrm{C}-\mathrm{N}}\right), 1580\left(v_{\mathrm{C}-\mathrm{C}}\right), 1500\left(v_{\mathrm{C}-\mathrm{C}}\right), 1460\left(v_{\mathrm{C}-\mathrm{C}}\right), 1000\left(v_{\mathrm{C}-\mathrm{H}}\right)$, $800\left(\delta_{\mathrm{C}-\mathrm{H}}\right) .{ }^{1} \mathrm{H}-\mathrm{NMR}\left(\mathrm{CDCl}_{3}\right): \delta$, ppm $3.16(\mathrm{t}, 24 \mathrm{H}), 1.50(\mathrm{~m}, 48 \mathrm{H}), 0.91(\mathrm{t}, 36 \mathrm{H}) . \mathrm{UV}-\mathrm{Vis}: \lambda_{\max }$ toluene/nm: 612. 6g (13\%) Found: C, 66.67\%; H, 3.50\%; N, 4.86\%. Calcd. for $\mathrm{C}_{96} \mathrm{H}_{60} \mathrm{~N}_{6} \mathrm{BClS}_{12}$ : C, 66.67\%; H, 3.50\%; N, 4.86\%. IR (KBr): $v_{\max } / \mathrm{cm}^{-1} 3080\left(v_{\mathrm{C}-\mathrm{H}}\right), 2190\left(v_{\mathrm{C}-\mathrm{N}}\right), 1600\left(v_{\mathrm{C}-\mathrm{C}}\right), 1500\left(v_{\mathrm{C}-\mathrm{C}}\right)$, $1460\left(v_{\mathrm{C}-\mathrm{C}}\right), 1000\left(\delta_{\mathrm{C}-\mathrm{H}}\right), 800\left(\delta_{\mathrm{C}-\mathrm{H}}\right) .{ }^{1} \mathrm{H}-\mathrm{NMR}\left(\mathrm{CDCl}_{3}\right): \delta$, ppm $7.26(\mathrm{~m}, 60 \mathrm{H})$. UV-Vis: $\lambda_{\max }$ (toluene)/nm: 634 . 


\subsection{Synthesis of octakis(thiophenyl)phthalocyanines $\mathbf{1 5}$}

The target compounds $\mathbf{1 5}$ were synthesized in three steps via intermediates $\mathbf{1 6}$ and 17a-c. Intermediate 16 was synthesized by the following procedure: 2,3-dicyanohydroquinone (4.80 $\mathrm{g}$, $30 \mathrm{mmol})$ in dichloromethane $(100 \mathrm{~mL})$ and Py $(5.93 \mathrm{~g}, 75 \mathrm{mmol})$ was treated with trifluoromethanesulfonic anhydride $(21.16 \mathrm{~g}, 75 \mathrm{mmol})$ under nitrogen at $-78{ }^{\circ} \mathrm{C}$. After the reaction, the mixture was allowed to warm slowly to room temperature; stirring was continued for $1,440 \mathrm{~min}$. The mixture was poured into water $(600 \mathrm{~mL})$ and the organic layer was extracted using dichloromethane $(5 \times 100 \mathrm{~mL})$. The extract was washed in turn with water, $2 \%$-hydrochloric acid, water, brine and water, and dried on magnesium sulfate $\left(\mathrm{MgSO}_{4}\right)$. The filtrate and the solvent evaporated. The crude product was recrystallized from dichloromethane to afford $16(6.35 \mathrm{~g}, 50 \%)$ as colorless needles. Found: C, 28.32\%; H, 0.48\%; N, 6.59\%. Calcd. for $\mathrm{C}_{10} \mathrm{H}_{2} \mathrm{~F}_{6} \mathrm{~N}_{2} \mathrm{~S}_{2} \mathrm{O}_{6}: \mathrm{C}, 28.31 \%$; $\mathrm{H}$, 0.48\%; F, 26.87\%; N, 6.60\%; O, 22.63\%; S, 15.12\%. IR (KBr): cm-1 $3115(\mathrm{vC}-\mathrm{H}), 2550(v \mathrm{C}-\mathrm{N})$, 1601 (vC-C), 1472 (vC-C), 1439 (vC-C), $1134(v S=O) .{ }^{1} \mathrm{H}-\mathrm{NMR}(400 \mathrm{MHz}$, DMSO-d 6 ): $\delta$, ppm 8.44 (s, 2H).

Intermediates 17a-c were synthesized as follows: to a mixture of $\mathbf{1 6}(0.85 \mathrm{~g}, 2 \mathrm{mmol})$, potassium carbonate $(1.16 \mathrm{~g})$ and DMSO $(15 \mathrm{~mL})$, thiophenols such as $p$-toluenethiol, 4-methoxybenzenethiol and tert-butylthiophenol $(4 \mathrm{mmol})$ were added; the mixture was reacted at room temperature for 1,440 $\mathrm{min}$ in nitrogen atmosphere. The reaction products were poured into water $(300 \mathrm{~mL})$, and the organic layer extracted using dichloromethane $(5 \times 100 \mathrm{~mL})$, and dried on $\mathrm{MgSO}_{4}$. The filtrate and the solvent evaporated. The crude product was washed with methanol $\left(3 \times 50 \mathrm{~cm}^{3}\right)$ and recrystallized from toluene to afford 17 as a yellow solid. 3,6-bis(thiophenylmethyl)phthalonitrile (2a) $(0.27 \mathrm{~g}, 35 \%)$ Found: C, 70.90\%; H, 4.30\%; N, 7.50\%. Calcd. for $\mathrm{C}_{22} \mathrm{H}_{16} \mathrm{~N}_{2} \mathrm{~S}_{2}$ : C, 70.93\%; H, 4.33\%; N, 7.52\%; S, 17.22. IR (KBr): $\mathrm{cm}^{-1} 3050\left(v_{\mathrm{C}-\mathrm{H}}\right), 2970\left(v_{\mathrm{C}-\mathrm{H}}\right), 2218\left(v_{\mathrm{C}-\mathrm{N}}\right), 1600\left(v_{\mathrm{C}-\mathrm{C}}\right), 1535\left(v_{\mathrm{C}-\mathrm{C}}\right), 1490\left(v_{\mathrm{C}-\mathrm{C}}\right), 1435$ $\left(v_{\mathrm{C}-\mathrm{C}}\right), 1210,809\left(\delta_{\mathrm{C}-\mathrm{H}}\right) .{ }^{1} \mathrm{H}-\mathrm{NMR}\left(\mathrm{DMSO}-d_{6}\right): \delta$, ppm $7.54(\mathrm{~d}, 4 \mathrm{H}), 7.46(\mathrm{~d}, 4 \mathrm{H}), 7.35(\mathrm{~s} 2 \mathrm{H}), 2.66(\mathrm{tt}$, 6H); 3,6-bis(thiophenylmethoxy)phthalonitrile (2b) (0.28 g, 34\%) Found: C, 65.30\%; H, 4.00\%; N, 6.93\%. Calcd. for $\mathrm{C}_{22} \mathrm{H}_{16} \mathrm{~N}_{2} \mathrm{~S}_{2} \mathrm{O}_{2}$ : C, 65.32\%; H, 3.99\%; N, 6.93\%; S, 15.82\%; O, 7.91\%. IR (KBr): $\mathrm{cm}^{-1} 3050\left(v_{\mathrm{C}-\mathrm{H}}\right), 2970\left(v_{\mathrm{C}-\mathrm{H}}\right), 2216\left(v_{\mathrm{C}-\mathrm{N}}\right), 1600\left(v_{\mathrm{C}-\mathrm{C}}\right), 1540\left(v_{\mathrm{C}-\mathrm{C}}\right), 1487\left(v_{\mathrm{C}-\mathrm{C}}\right), 1430\left(v_{\mathrm{C}-\mathrm{C}}\right), 1210$, $810\left(\delta_{\mathrm{C}-\mathrm{H}}\right) .{ }^{1} \mathrm{H}-\mathrm{NMR}\left(\mathrm{DMSO}-d_{6}\right): \delta$, ppm $7.49(\mathrm{~d}, 4 \mathrm{H}), 7.06(\mathrm{~d}, 4 \mathrm{H}), 7.04(\mathrm{~s} 2 \mathrm{H}), 3.79(\mathrm{~s}, 6 \mathrm{H}) ; 3,6-$ bis(thiophenyl tert-butyl)phthalonitrile (2c) $(0.38 \mathrm{~g}, 42 \%)$ Found: C, 73.65\%; H, 6.18\%; N, 6.11\%. Calcd. for $\mathrm{C}_{28} \mathrm{H}_{28} \mathrm{~N}_{2} \mathrm{~S}_{2}$ : C, 73.64\%; H, 6.18\%; N, 6.13\%; S, 14.04\%. IR (KBr): $\mathrm{cm}^{-1} 3040\left(v_{\mathrm{C}-\mathrm{H}}\right), 2960$ $\left(v_{\mathrm{C}-\mathrm{H}}\right), 2210\left(v_{\mathrm{C}-\mathrm{N}}\right), 1600\left(v_{\mathrm{C}-\mathrm{C}}\right), 1500\left(v_{\mathrm{C}-\mathrm{C}}\right), 1460\left(v_{\mathrm{C}-\mathrm{C}}\right), 1210,808\left(\delta_{\mathrm{C}-\mathrm{H}}\right) .{ }^{1} \mathrm{H}-\mathrm{NMR}\left(\mathrm{DMSO}-d_{6}\right): \delta$, ppm 7.50 (d, 4H), 7.46 (d, 4H), $7.26(\mathrm{~s}, 2 \mathrm{H}), 1.28$ (s, 18H).

The target compounds 15 were synthesized following procedure; A solution of 17 (0.25 mmol), the appropriate metal chloride or metal acetate $(0.065 \mathrm{mmol})$, DBU $(0.2 \mathrm{~mL})$ as a catalyst and 1-pentanol $(10 \mathrm{~mL})$ was refluxed for $420 \mathrm{~min}$. After cooling to room temperature, the reaction products were poured into methanol to form a precipitate, which was washed with water and methanol, and chromatographed on silica gel with toluene as eluent. The 1,4,8,11,15,18,22,25-octakis(thiophenylmethyl)phthalocyanines (15a); 15a-Cu (0.02 g, 18\%) Found: C, 67.98\%; H, 4.51\%; N, 7.01\%. Calcd. for $\mathrm{C}_{88} \mathrm{H}_{65} \mathrm{~N}_{8} \mathrm{~S}_{8} \mathrm{Cu}: \mathrm{C}, 67.99 \% ; \mathrm{H}, 4.21 \% ; \mathrm{N}, 7.21 \% ; \mathrm{S}, 16.50 \% ; \mathrm{Cu}, 4.09 \%$. MS (FAB): $\mathrm{m} / \mathrm{z}$ found 1554, Calcd. 1554.59: 15a-Co (0.02 g, 24\%) Found: C, 68.10\%; H, 4.20\%; N, 7.25\%. Calcd. for $\mathrm{C}_{88} \mathrm{H}_{65} \mathrm{~N}_{8} \mathrm{~S}_{8} \mathrm{Co}$ : C, 68.19\%; H, 4.23\%; N, 7.23\%; S, 16.55\%; Co, 3.80\%. MS (FAB): $\mathrm{m} / \mathrm{z}$ found 1550, 
Calcd. 1549.97: 15a-Ni (0.03 g, 28\%) Found: C, 68.18\%; H, 4.20\%; N, 7.13\%. Calcd. for $\mathrm{C}_{88} \mathrm{H}_{65} \mathrm{~N}_{8} \mathrm{~S}_{8} \mathrm{Ni}$ : C, 68.20\%; H, 4.23\%; N, 7.23\%; S, 16.55\%; Ni, 3.79\%. MS (FAB): $\mathrm{m} / \mathrm{z}$ found 1550 , Calcd. 1549.73: 15a-Zn (0.02 g, 24\%) Found: C, 67.87\%; H, 4.23\%; N, 7.11\%. Calcd. for $\mathrm{C}_{88} \mathrm{H}_{65} \mathrm{~N}_{8} \mathrm{~S}_{8} \mathrm{Zn}: \mathrm{C}, 67.91 \%$; H, 4.21\%; N, 7.20\%; S, 16.48\%; Zn, 4.20\%. MS (FAB): $\mathrm{m} / \mathrm{z}$ found 1556, Calcd. 1556.43: 15a-Pb (0.04 g, 34\%) Found: C, 62.29\%; H, 3.88\%; N, 6.40\%. Calcd. for $\mathrm{C}_{88} \mathrm{H}_{65} \mathrm{~N}_{8} \mathrm{~S}_{8} \mathrm{~Pb}$ : C, 62.24\%; H, 3.86\%; N, 6.60\%, S, 15.11\%; Pb, 12.19\%. MS (FAB): $\mathrm{m} / \mathrm{z}$ found 1699, Calcd. 1698.24: 15a-H $\mathrm{H}_{2}\left(0.04\right.$ g, 19\%) Found: C, 70.85\%; H, 4.66\%; N, 7.51\%. Calcd. for $\mathrm{C}_{88} \mathrm{H}_{66} \mathrm{~N}_{8} \mathrm{~S}_{8}$ : $\mathrm{C}, 70.84 \%$; H, 4.46\%; N, 7.51\%, S, 17.1\%. MS (FAB): $\mathrm{m} / \mathrm{z}$ found 1492, Calcd. 1492.04; 1,4,8,11,15,18,22,25-octakis(thiophenylmethoxy)phthalocyanines $\quad(\mathbf{1 5 b}) ; \quad \mathbf{1 5 b}-\mathbf{C u} \quad(0.03 \mathrm{~g}, \quad 27 \%)$ Found: C, 62.88\%; H, 3.91\%; N, 6.65\%. Calcd. for $\mathrm{C}_{88} \mathrm{H}_{65} \mathrm{~N}_{8} \mathrm{~S}_{8} \mathrm{O}_{8} \mathrm{Cu}: \mathrm{C}, 62.82 \% ; \mathrm{H}, 3.89 \%$; , 6.66\%; S, 15.25\%; O, 7.61\%; Cu, 3.77\%. MS (FAB): $\mathrm{m} / \mathrm{z}$ found 1682, Calcd. 1682.58: 15b-Co (0.02g, 21\%) Found: C, 63.00\%; H, 3.89\%; N, 6.59\%. Calcd. for $\mathrm{C}_{88} \mathrm{H}_{65} \mathrm{~N}_{8} \mathrm{~S}_{8} \mathrm{O}_{8} \mathrm{Co}$ : C, 62.99\%; H, 3.90\%; N, 6.68\%; S, 15.29\%; O, 7.63\%; Co, 3.51\%. MS (FAB): $\mathrm{m} / \mathrm{z}$ found 1678, Calcd. 1677.97: 15b-Ni (0.03 g, 25\%) Found: C, 63.01\%; H, 3.92\%; N, 6.67\%. Calcd. for $\mathrm{C}_{88} \mathrm{H}_{65} \mathrm{~N}_{8} \mathrm{~S}_{8} \mathrm{O}_{8} \mathrm{Ni}: \mathrm{C}, 63.01 \%$; H, 3.92\%; N, 6.67\%; S, 15.29\%; O, 7.63\%; Ni, 3.49\%. MS (FAB): $\mathrm{m} / \mathrm{z}$ found 1678, Calcd. 1677.73: 15b-Zn (0.03 g, $29 \%$ ) Found: C, 62.75\%; H, 3.95\%; N, 6.65\%. Calcd. for $\mathrm{C}_{88} \mathrm{H}_{65} \mathrm{~N}_{8} \mathrm{~S}_{8} \mathrm{O}_{8} \mathrm{Zn}: \mathrm{C}, 62.75 \% ; \mathrm{H}, 3.89 \%$; N, 6.65\%; S, 15.23\%; O, 7.60\%; Zn, 3.88\%. MS (FAB): m/z found 1684, Calcd. 1684.42: 15b-Pb (0.04 g, 35\%) Found: C, 57.88\%; H, 3.59\%; N, 6.15\%. Calcd. for $\mathrm{C}_{88} \mathrm{H}_{65} \mathrm{~N}_{8} \mathrm{~S}_{8} \mathrm{O}_{8} \mathrm{~Pb}: \mathrm{C}, 57.88 \%$; $\mathrm{H}$, $3.59 \%$; N, 6.14\%; S, 14.05\%; O, 7.01\%; Pb, 11.33\%. MS (FAB): $\mathrm{m} / \mathrm{z}$ found 1827, Calcd. 1826.23: 15b-H $\mathrm{H}_{2}\left(0.02\right.$ g, 8\%) Found: C, 65.24\%; H, 4.11\%; N, 6.93\%. Calcd. for $\mathrm{C}_{88} \mathrm{H}_{66} \mathrm{~N}_{8} \mathrm{O}_{8} \mathrm{~S}_{8}: \mathrm{C}, 65.24 \%$; $\mathrm{H}$, $4.11 \%$; N, 6.92\%, O, 7.90, S, 15.18\%. MS (FAB): $\mathrm{m} / \mathrm{z}$ found 1620, Calcd. 1620.03; 1,4,8,11,15,18,22,25-octakis-(thiophenyl tert-butyl)phthalocyanines (15c); 15c-Cu (0.02 g, 20\%) Found: C, 71.13\%; H, 6.05\%; N, 5.87\%. Calcd. for $\mathrm{C}_{112} \mathrm{H}_{113} \mathrm{~N}_{8} \mathrm{~S}_{8} \mathrm{Cu}$ : C, 61.13\%; H, 6.02\%; N, 5.92\%; S, 13.56\%; Cu, 3.37\%. MS (FAB): m/z found 1891, Calcd. 1891.22: 15c-Co (0.02 g, 21\%) Found: C, $71.24 \% ; \mathrm{H}, 6.04 \%$; N, 5.93\%. Calcd. for $\mathrm{C}_{112} \mathrm{H}_{113} \mathrm{~N}_{8} \mathrm{~S}_{8} \mathrm{Co}: \mathrm{C}, 71.30 \% ; \mathrm{H}, 6.04 \% ; \mathrm{N}, 5.94 \%$; $\mathrm{S}$, 13.60\%, Co, 3.12\%. MS (FAB): $\mathrm{m} / \mathrm{z}$ found 1886, Calcd. 1886.61: 15c-Ni (0.03 g, 23\%) Found: C, $71.31 \%$; H, 6.04\%; N, 5.89\%. Calcd. for $\mathrm{C}_{112} \mathrm{H}_{113} \mathrm{~N}_{8} \mathrm{~S}_{8} \mathrm{Ni}$ : C, 71.31\%; H, 6.04\%; N, 5.94\%; S, 13.60\%; Ni, 3.11\%. MS (FAB): $\mathrm{m} / \mathrm{z}$ found 1886, Calcd. 1886.37: 15c-Zn (0.03 g, 28\%) Found: C, 71.00\%; H, 6.01\%; N, 5.92\%. Calcd. for $\mathrm{C}_{112} \mathrm{H}_{113} \mathrm{~N}_{8} \mathrm{~S}_{8} \mathrm{Zn}$ : C, 71.06\%; H, 6.02\%; N, 5.92\%; S, 13.55\%; Zn, 3.45\%. MS (FAB): $\mathrm{m} / \mathrm{z}$ found 1893, Calcd. 1803.07: 15c-Pb (0.04 g, 34\%) Found: C, 66.12\%; H, 5.63\%; N, 5.53\%. Calcd. for $\mathrm{C}_{112} \mathrm{H}_{113} \mathrm{~N}_{8} \mathrm{~S}_{8} \mathrm{~Pb}$ : C, 66.11\%; H, 5.60\%; N, 5.51\%; S, 12.61\%; Pb, 10.17\%. MS (FAB): $\mathrm{m} / \mathrm{z}$ found 2035, Calcd. 2034.88: 15c-H $(0.02 \mathrm{~g}, 9 \%)$ Found: C, 73.55\%; H, 6.26\%; N, 6.13\%. Calcd. for $\mathrm{C}_{112} \mathrm{H}_{114} \mathrm{~N}_{8} \mathrm{~S}_{8}$ : C, 73.56\%; H, 6.28\%; N, 6.13\%, S, 14.03\%. MS (FAB): $\mathrm{m} / \mathrm{z}$ found 1829 , Calcd. 1828.68.

\subsection{Electrochemical measurements}

CV of metal octakis(hexoxymethyl)phthalocyanines and metal anthraquinocyanine were carried out with a BAS CV-50W voltammetric analyzer at room temperature in DMSO containing a $0.10 \mathrm{~mol} \cdot \mathrm{L}^{-1}$ solution of TBAP in a stream of nitrogen. CVs were recorded by scanning the potential at the rate of $50 \mathrm{mV} \mathrm{s}^{-1}$. The working and counter electrodes were platinum wires and the reference electrode was a $\mathrm{Ag} / \mathrm{AgCl}$ saturated sodium chloride electrode. The chronoamperometry was measured following an 
applied voltage pulse from -1200 to $0 \mathrm{mV}$ vs. $\mathrm{Ag} / \mathrm{AgCl}$ and from 0 to $+1600 \mathrm{mV}$ vs. $\mathrm{Ag} / \mathrm{AgCl}$, and the reversible pulse.

\subsection{Laser- flash photolysis}

Laser flash photolysis in film was performed using a total reflection sapphire cell $(10 \cdot 30 \mathrm{~mm}$, $1 \mathrm{~mm}$ thick, and both of the short side were cut at a 45 degree angle), which was spin-coated with a $1.2 \mu \mathrm{m}$ thick photopolymer film. An excitation light pulse (20 ms, $355 \mathrm{~nm}$ and $10 \mathrm{~mJ}$ per pulse) from a YAG laser was expanded and exposed over the entire sample cell. A monitoring light from a xenon lamp passed through the multireflection cell which was connected to the head of an optical fiber attached to a monochrometer equipped with a photomultiplier or to a spectral multichannel analyzer system. The films were prepared as follows: a $10 \mathrm{wt} \%$ PMMA solution was made up in cyclohexanone, and allylbenzopyridoporphyrazines were added to this solution by dissolving to a thickness of $1.2 \mu \mathrm{m}$ thick by spin-coating a solution onto a sapphire cell. After that the films were covered with a PVA solution.

\section{Conclusions}

M-PCs 1, 2, 3, and a new type of phthalocyanine derivative, 4 have been synthesized. Then, the cyclotetramerization products from a 1:1 mol mixture of 3,6-didecylphthalonitrile and 3,4dicynopyridine, zinc bis(1,4-didecylbenzo)bis(3,4-pyrido)porphyrazines, 5 were synthesized. The cyclotetramerization products have position isomers. The isomers of 5c was separated into fore fractions. Moreover, metal phthalocyanine analogous, SubPCs and its derivatives which possessed substituents such as thiobutyl and thiophenyl were synthesized.

Electrochemical measurements were performed above mentioned phthalocyanine derivatives and analogous in order to examine their electron transfer abilities and electrochemical mechanism in an organic solvent.

Photochemical properties such as the triplet state lifetime were measured using laser-flash photolysis. The triplet state of zinc non-peripheral substituted alkylbenzopyridoporphyrazines, 5c and position isomers were measured, using laser-flash photolysis in a PMMA film. In generally, the triplet lifetime increased as the number of Py groups in the molecule increased. However, the lowest symmetric isomer having two Py rings in the molecule showed the longest triplet state lifetime. The compound was suitable for use as a photosensitizer in photodynamic cancer therapy.

Thiobutyl and thiophenyl substituted subPC derivatives 6 were measured sensitization properties. Sensitization properties of 6 with 2,4,6-tris(trichloromethyl)-1,3,5-triazine as radical generation reaction in a PMMA film have been investigated by laser-flash photolysis.

Phthalocyanines having $S$-aryl groups at non-peripheral position, i.e., 1,4,8,11,15,18,22,25octakis(thio-phenylmethyl)phthalocyane compounds 15 can be synthesized. Their strong Q band absorption peaks appear around $800 \mathrm{~nm}$. The synthesized phthalocyanines have high solubility in organic solvents, high heat resistance without discotic liquid crystal behavior, no absorptions in the visible region, and a simple structure without any regioisomers. 


\section{Acknowledgements}

We thank Dr. Toshiyuki Urano (Science and Technology Research Center, Mitsubishi Chemical Corporation), Professor Dr. Michael J. Cook (University of East Anglia) and Emeritus professor Dr. Ryo Hirohashi (Chiba University) for their interest and helpful advice. We are grateful to our graduate students Mr. Taku Kato (Electronic Materials Research Laboratories, Nissan Chemical Industries), Mr. Masayoshi Kawaguchi, Ms. Tomomi Kawaguchi, Mr. Masaki Watanabe (U-Tech Corporation, Innovation Technology department), Ms. Seiko Kanazawa (Information \& Communication Division, Toppan Printing Co. Ltd) and Mr. Hisashi Soga.

\section{References}

1. Sakamoto, K.; Okumura, E.; Hirohashi, R. Phthalocyanine as Functional Dyes. IPC: Tokyo, Japan, 2004.

2. de la Torre, G.; Vazquez, P.; Torres, T. Role of structural factors in the nonlinear optical properties of phthalocyanines and related componds. Chem. Rev. 2004, 104, 3723-3750.

3. Cid, J.-J.; Yum, J.-H.; Jang, S.-R.; Nazeeruddin, M.K.; Martinez- Ferrero, E.; Palomares, E.; Ko, J.; Graetzel, M.; Torres, T. Molecular cosensitization for efficient panchromatic dye-sensitized solar cells. Angew. Chem. Int. Ed. 2007, 46, 8358-8362.

4. Kadish, K.M.; Smith, K.M.; Guilard, R. The Porphyrin Handbook; Academic Press: San Diego, CA, USA, 2003; Volumes 15-20.

5. Pinzon, J.R.; Plonska-Brzezinska, M.E.; Cadona, C.M.; Athans, A.J.; Gayathri, S.S.; Guldi, D.M.; Herranz, M.A.; Martin, N.; Torres, T.; Echegoyen, L. Sc3N@C80-ferrocene electrondonor/acceptor conjugates as promising materials for photovoltalic applications. Angew. Chem. Int. Ed. 2008, 47, 4173-4176.

6. Campidelli, S.; Ballesteros, B.; Filoramo, A.; Diaz, D.; de la Torre, G.; Torres, T.; Rahman, G.M.A.; Aminur, E.C.; Kiessling, D.; Werner, F.; Sgobba, V.; Guldi, D.M., Cioffi, C.; Prato, M.; Bourgoin, J-P. Facile decoration of functionalized single-wall carbon nanotubes with phthalocyanines via "Click Chemistry". J. Am. Chem. Soc. 2008, 130, 11503-11509.

7. Dougherty, T.J. Photodynamic Therapy. Phtotochem. Phthobiol. 1993, 58, 895.

8. Moan, J. Properties for optimal PDT sensitizers. J. Photochem. Photobiol. B Biol. 1990, 5, 521-524.

9. Cook, M.J.; Chambrier, I.; Cracknell, S.J.; Mayes D.A.; Russell, D.A. Octa-alkyl zinc phthalocyanines: Potential photosensitizers dor use in the photodynamic therapy of cancer. Phtotochem. Photobiol.1995, 62, 542-545.

10. Linstead, R.P.; Noble, E.G.; Wright, J.M. Phthalocyanines IX. Derivatives of thiophene thionaphthene, pyridine and pyrazine, and a note on the nomencleature. J. Chem. Soc. 1937, 911-921.

11. Yokote, M.; Shibamiya, F; Shoji, S. Copper tetra-3,4-pyridinoporphyrazine from pyridine-3,4dicarboxylic acid. J. Chem. Soc. Jpn. Ind. Chem Sec. 1964, 67, 166-168. 
12. Yokote, M.; Shibamiya, F; Hayakawa, H. Aza compounds XXIX. J. Synth. Org. Chem. Jpn. 1965, 23, 151-155.

13. de la Torre, G.; Claessens, C.G.; Torres, T. Phthalocyanines: Old dyes, new materials. Putting color in nanothechnology. Chem. Commun. 2007, 2000-2015.

14. Tokita, S.; Kojima, M.; Kai, N.; Kuroki, K., Nishi, H.; Tomoda, H.; Saitoh, S.; Shiraishi, S. Synthesis and properties of 2,3,9,10,16,17,23,24-octaalkyl tetrpyrazinoporphyrazine. J. Chem. Soc. Jpn.1990, 219-224.

15. Yokote, M.; Shibamiya, F. Cu Bz-azaphthalocyanines. J. Chem. Soc. Jpn. Ind. Chem. Sec.1959, 62, 224-227.

16. Sakamoto, K.; Ohno, E. Synthesis of soluble metal phthalocyanine derivatives and their electron transfer prpperties. J. Soc. Dyers Colour. 1996, 112, 368-374.

17. Ohno, E.; Sakamoto, K. Synthesis of metal anthaquinocyqnine and its cyclic voltamograpy. $J$. Chem. Soc. Jpn. 1995, 730-735.

18. Pawlowski, G.; Hanack, M. Synthesis and properties of a new kind of one-dimentional conduction Part 4. A convenient synthesis of octasubstituted phthalocyanines. Synthesis 1980, 287-289.

19. McKeown, N.B.; Chambrier, I.; Cook, M.J. Synthesis and Characterization of some 1,4,8,11,15,18,22,25-Octa-alkyl and 1,4,8,11,15,18-Hexa-alkyl-22,25-bis(carboxypropyl)phthalocyanines. J. Chem. Soc. Perkin Trans. 1 1990, 1169-1170.

20. Chambrier, I.; Cook, M.J.; Cracknell, S.J.; McMurdo, J. Synthesis and characterization of some non-uniformly substituted mesogenic phthalocyanines. J. Mater. Chem. 1993, 3, 841-849.

21. Sakamoto, K. Studies on phthalocyanine type compounds (Part 12). Solvent treatment of cobalt phthalocyanine and its pyridine adduct. J. Jpn. Soc. Colour Mater. 1995, 68, 67-74.

22. Weber, J.H.; Busch, D.H. Complexes derived from strong field ligands. XiX Magnetic properties of transition metal derivatives of 4,4',4', 4','-tetrasulfophthalocyanines. Inorg. Chem. 1965, 4, 469-471.

23. Claessens, C.G.; Gonzalez-Rodriguez, D.; Torre, T. Subphthalocyanines: Singular nonplanar aromatic compounds-Synthesis, reactivity, and physical properties. Chem. Rev. 2002, 102, 835-853.

24. Boston, D.R.; Bailar, J.C. Phthalocyanine derivatives from 1,2,4,5-tetracyanobenzene or pyromeliyic dianhydride and metal salt. Inorg. Chem. 1972, 11, 1578-1583.

25. Moeno, S.; Nykong, T. The photophysical studies of a mixure of CdTequantum dots and negativelycharged zinc phthalocyanines. Polyhedron 2008, 27, 1953-1958.

26. Ohno, E.; Sakamoto, K. Development of metal phthalocyanine derivatives fixed redox resin. $J$. Jpn. Soc. Colour Mater. 1998, 71, 83-90.

27. Hanack,M.; Beck, A.; Lehmann, H. Syntheses of liquid crystalline phthalocyanines. Synthesis 1987, 703-705.

28. Sakamoto, K.; Ohno, E. Synthesis of cobalt phthalocyanine derivatives and their cyclic voltammograms. Dye. Pigment. 1997, 35, 375-386.

29. Freyer, W. Electornic spectra of tetra[2,3-(9,10-antraquino)]tetraazaporphyrin and related compounds. Zeitschrift Chem. 1986, 26, 216-217. 
30. Markovitsi, D.; Lecuyer, I.; Simon, J. One-dimentional triplet energymigration in columnar liquid crystals of octasubstituted phthalocyanines. J. Phys. Chem.1991, 95, 3620-3626.

31. Tokita, S.; Matsuoka, M.; Kogo, Y.; Kihara, H. Kinouseishikiso no Bunshisekkei [In Japanese]; Maruzen: Tokyo, Japan, 1989.

32. Sakamoto, K.; Ohno, E. Synthesis and electron transfer property of phthalocyanine derivatives. Prog. Org. Coat. 1997, 31, 139-145.

33. Sakamoto, K.; Kato, T.; Cook, M.J. Position isomer separation of non-peripheral substituted zinc di-benzo-di(3,4-pyrido)porphyrazines. J. Porphyrin Phthalocyanine 2001, 5, 742-750.

34. Sakamoto, K.; Ohno-Okumura, E.; Kato, T.; Watanabe, M.; Cook, M.J. Investigation of zinc bis(1,4-didecylbenzo)-bis(2,3-pyrido)porphyrazines as an efficient photosensitizer by cyclic voltammetry. Dye. Pigment. 2008, 78, 213-218.

35. Rollmann, L.D.; Iwamoto, R.T. Electrochemistry, electron paramagnetic reonance, and visible spectra of cobalt, nickel and metal-free phthalocyanines in dimethyl sulfoxide. J. Am. Chem. Soc. 1968, 90, 1455-1463.

36. Ohno-Okumura, E.; Sakamot, K.; Kato, T.; Hatano, T.; Fukui, K.; Karatsu, T.; Kitamura, A.; Urano, T. Synthesis of subphthalocyanine derivatives and their characterization. Dye. Pigment. 2002, 53, 57-65.

37. Burnham, P.M.; Cook, M.J.; Gerrard, L.A.; Henney, M.J; Hughes D.1. Structural characterization of a red phthalocyanine. Chem. Commmun. 2003, 2064-2065.

38. Sakamoto, K.; Ohno-Okumura, E.; Kato, T.; Soga, H. Synthesis on near infrared absorbed metal phthalocyanine with S-aryl groups at non-peripheral positions. J. Porphyrins Phthalocyanines 2009, in press.

39. Kobayashi, N.; Fukuda, T.; Ueno, K.; Ogino, H. Extremely non-planer phthalocyanines with saddle or helical conformation: synthesis and structural characterization. J. Am. Chem. Soc. 2001, 123, 10740-10741.

40. Lever, A.B.P.; Licoccis, S.; Magrell, K.; Ramanamy, B.S. Mapping of the energy levels of metallophthalocyanines via electronic spectroscopy, electrochemistry and photochemistry. Adv. Chem. Ser.1982, 210, 237-252.

41. Kasuga, K.; Tsutsui, M., Some new developments in the chemistry of metallophthalocyanines. Coord. Chem. Rev.1980, 32, 67-96.

42. Clack, D.W.; Hush, N.S.; Wolsey, I.S. Reduction potentials of some metal phthalocyanines. Inorg, Chem. Acta 1976, 129-132.

43. Orihara,Y.; Nishikawa, M.; Ohno, H.; Tsuchida, E.; Matsuda, H. Effect of substituents on the oxidation potential of phthalocyanines and electrocrystallization. Bull. Chem. Soc. Jpn.1987, 60, 3731-3738.

44. Kadish, K.M.; Moninot, G.; Hu, Y.; Dubois, D.; Ibnlfassi, A.; Barbe, J-M.; Guilard, R. Doubledecker actinide porphyrins and phthalocyanines. Synthesis and heteroleptic complexes. J. Am. Chem. Soc. 1993, 115, 8153-8166.

45. Nicholson, R.S.; Shain, I. Theory of stationaryelectrode polarography. Single scan and cyclic method applied to reversible, irreversible and kinetic system. Anal.Chem. 1964, 36, 706-723. 
46. Lexa, D.; Reix, M. Redox behavior of metallic complexes of various tetrapyrrolic rings. Halfwave potentials of the complex. J. Chem. Phys. Phys-Chim. Biol. 1974, 71, 511-513.

47. Wolberg, A.; Manassen, J. Electrochemical and electron paramagnetic resonance studies of metallophthalocyanines and their electrochemical oxidation products. J. Am. Chem. Soc. 1970, 92, 2982-2991.

48. Giraudeau, A.; Fan, F.-R.F.; Bard, A.J. Semiconductor electrode 30. Spectral sensitization of the semiconductors titanium oxide $\left(\mathrm{n}-\mathrm{TiO}_{2}\right)$ and tungsten oxide $\left(\mathrm{n}-\mathrm{WO}_{3}\right)$ with metal phthalocyanines. J. Am. Chem. Soc.1980, 102, 5137-5142.

49. Shirai, A.; Kobayshi, N. Phthalocyanine Chemistry and Function; IPC: Tokyo, Japan, 1997.

50. Sakamoto, K.; Ohno E. Electrochemical characterization of soluble cobalt phthalocyanine derivatives. Dye. Pigment. 1998, 37, 291-306.

51. Sakamoto, K.; Ohno-Okumura, E. Synthesis of octasubstituted cobalt phthalocyanines and their redox properties. J. Porphyrins Phthalocyanines 1999, 3, 634-642.

52. Ohno, E.; Sakamoto, K. Electron transfer mechanism of metal anthraquinocyanine. J. Chem. Soc. Jpn.1997, 58-67.

53. Sakamoto, K.; Ohno-Okumura, E. Electrochemical characteristics of anthraquinocyanine and phthalocyanine derivatives. J. Jpn. Soc. Colour Mater. 1999, 72, 2-10.

54. Ohno-Okumura, E.; Sakamoto, K. Synthesis of metal octakis(alkoxymethyl)phthalocyanines and their redox behavior. J. Jpn. Soc. Colour Mater. 1999, 72, 345-354.

55. Lezonoff, C.C.; Lever, A.B.P. Phthalocyanines Properties and Applications; Wiley-VCH: New York, NY, USA, 1989-1993; Volumes 1-4.

56. Wopschall, R.H.; Shain, I. Effects of adsorption of electroactive species in stationary electrode polarography. Anal. Chem. 1967, 39, 1514-1527.

57. Urano, T.; Nguyen, K.O.; Nagasaka, H.; Tsuchiya, M; Shimizu, S.; Itoh, H.; Senda, Y. Laser flash photolysis in high speed photopolymer coating layers. Bull. Chem. Soc. Jpn. 1994, 67, 1074-1077.

58. Urano, T.; Ohno-Okumura, E.; Sakamoto K.; Itoh, H., Yamaoka, T. Dye sensitization mechanisms in photopolymer layer for laser-printing plate. J. Photopolym. Sci. Tech. 1999, 12, 747-758.

59. Sakamoto, K.; Kato, T.; Kawaguchi, T.; Ohno-Okumura, E.; Urano, T.; Yamaoka, T.; Suzuki, S.; Cook, M.J. Photosensitizer efficacy of non-periperal substituted alkylbenzoporphyrazines for photodynamic therapy of cancer. J. Photochem. Photobiol. A Chem. 2002, 153, 245-252.

60. Darwent, J.R.; Douglas, P.; Harriman, A.; Porter, G.; Richoux, M.C. Metal phthalocyanines and porphyrins for reduction of water to hydrogen. Coord. Chem. Rev. 1982, 44, 83-126.

61. Ozoemen, K.; Kuznetsova, N.; Nyokong, T. Photosensitized transformation of 4-chlorophenol in the presence of aggregated and non-agregated metallophthalocyanines. J. Photochem. Photobiol. A Chem. 2001, 139, 217-222.

62. Murphy, S.T.; Konda, K.; Foote, C.S. Singlet-Oxygen-Sensitized delayed Fluorescence: Direct ditection of triplet phthalocyanines as an intermediate. J. Am. Chem. Soc. 1999, 121, 3751-3755. 
63. Gerdes, R.; Wohrle, D.; Spiller, W.; Schmeider, G.; Schulz-Ekloff, G. Photo-oxidation of phenol and monochlorophenols in oxygen-saturated solutions by different photosensitizers. $J$. Photochem. Photobiol. A Chem. 1997, 111, 65-74.

64. Lang, K.; Wagnerova, D.M.; Brodilova, J. The role of excited states in the photosensitized oxidation of substrates with dioxygen. J. Photochem. Photobiol. A Chem. 1993, 72, 9-14.

65. Iliev, V.; Alexiev, V.; Bilyarska, L. Effect of metal phthalocyanine complex aggregation on the catalytic and photocatalytic oxidation of sulfer containing compounds. J. Mol. Catal. A Chem. 1999, 137, 15-22.

66. Lukyanets, E.A. Phthalocyanines as photosensitizers in the photodynamic therapy of cancer. $J$. Porphyrins Phthalocyanines 1999, 3, 424-432.

67. Kaliya, O.L.; Lukyanets, E.A.; Vorozhtsov, G.V. Catalysis and photocatalysis by phthalocyanines for technology, ecologyand medicine. J. Porphyrins Phthalocyanines 1999, 3, 592-610.

68. Edrei, R.; Gottfried, V.; Van Lier, J.E.; Kimel, S. Sulfonated phthalocyanines: Photophysical properties in vitro cell uptake and structure-active relationships. J. Porphyrins Phthalocyanines 1998, 2, 191-199.

69. Dhami, D.; Phillips, D. Comparison of the photophysics of an aggregtion and non-aggregating aluminium phthalocyanine system incorporated into unilamellar vesicles. J. Photochem. Photobiol. A Chem. 1996, 100, 77-83.

70. Spiller, W.; Kliesch, H.; Wohrle, D.; Hackbarth, S.; Roder, B.; Schmurpfeil G. Singlet oxygen quantum yield of different photosensitizers in polar solvents and micellar solutions. J. Porphyrins Phthalocyanines 1998, 2, 145-158.

71. Tokumaru, K. Photochemical and photophysical behavior of porphyrins and phthalocyanines irradiated with violet or ultraviolet light. J. Porphyrins Phthalocyanines 2001, 5, 77-86.

72. Seotsanyana-Mokhoshi, I.; Kuznetsova, N.; Nyokong, T. Photochemical studies of tetra-2,3pyridinoporphyrazine. J. Potochem. Photobiol A Chem. 2001, 140, 215-222.

73. Wohrle, D.; Gitzel, J.; Okura, I.; Aono, S. Photoredox properties of tetra-2,3pyridinoporphyrazines $(29 \mathrm{H}, 31 \mathrm{H}$-tetrapyrido[2,3:b: 2',3'-g:2",3”-I:2',',3','-q]porphyrazines. J. Chem. Soc., Perkin Trans. II 1985, 1171-1178.

74. Yhamae, M.; Nyokong, T. Cobalt (II) porphyrazines catalyzed reduction of nitriles. J. Electroanal. Chem. 1999, 470, 126-135.

75. Hanack, M.; Meng, D.; Beek, A.; Sommerauer, M.; Subramanian, L.R. Separation of structural isomer of tetra-tert-butylphthalocyaninate nickel(III). J. Chem. Soc. Chem. Commun. 1993, 58-60.

76. Sommerauer, M.; Rager, C.; Hanack, M. Separation of 2(3), 9(10), 16(17), 23(24)-tetrasubstituted phthalocyanines with newly developed HPLC phases. J. Am. Chem. Soc. 1996, 118, 10085-10093.

77. Chan, W.-S.; Brasseur, N.; LaMadeleine, C.; Ouellet, R.; Lier, J. Efficacy and mechanism of alminium phthalocyanine and its sulphonated derivatives mediated photodynamic therapy on murine tumours. Eur. J. Cancer 1997, 33, 1855-1859.

78. Negrimouski, V.M.; Bouvet, M.; Lukyanets, E.A.; Simon, J. Towerd chiral 1,2naphthalocyanines: Syntheses of the pure geometrical isomers of the magnesium and lutetium complexes. J. Porphyrins Phthlocyanines 2000, 4, 248-255.

79. Rihter, B.D.; Bohorquez, M.D.; Rodgers, M.A.J.; Kenny, M.E. Two new sterically hindered phthalocyanines: synthetic and photodynamic aspect. Photochem. Photobiol. 1992, 55, 677-680. 
80. Geyer, M.; Plenzig, F.; Rauschanbel, J.; Hanack, M.; Rey, B.D.; Satre, A., Torres, T. Subphthalocyanines. Preparation, reactivity, and physical properties. Synthesis 1996, 1139-1151.

81. Birks, J.B. Photophysics of Aromatic Molecules; Wiley: New York, NY, USA, 1970.

(C) 2009 by the authors; licensee Molecular Diversity Preservation International, Basel, Switzerland. This article is an open-access article distributed under the terms and conditions of the Creative Commons Attribution license (http://creativecommons.org/licenses/by/3.0/). 